\title{
Observations sur Stenasellus virei dans ses Biotopes Naturels (Crustacea Isopoda Asellota des eaux souterraines)
}

\author{
par \\ Guy MAGNIEZ* \\ Observations on Stenasellus virei in its Natural Biotopes \\ (Crustacea Isopoda Asellota of Subterranean Waters)
}

\begin{abstract}
SUMMARY
Thanks to intensive exploration and to new methods for capturing aquatic underground fauna, 117 localities are now known for Stenasellus virei.

The description of some typical biotopes suggests that the species lives as well in karstic waters as in phreatic ones, inside the different environment of the hydrogeological classification of subterranean waters.

St. virei buchneri and St. v. hussoni are almost cavernicolous. St. v. angelieri is distributed in the underground waters of Catalonia. St. v. boui is located in the underflow of Salat river basin. St. v. virei is widely distributed in the alluvial water-level of Garonne and Ebro rivers basins.

The dispersion of St. virei into the alluvial environment explains the process of colonization of continental underground waters. It explains also the existence of an apparently insulated population into the sink-hole of Padirac.

The actual distribution of the five subspecies is explained by important restrictions of the area in quaternary glacial ages, followed by local (in the water-level of the tributaries of Garonne river) spreading during postglacial time.

The postglacial reconquest of the Salat river underflow by this species seems to have been responsible for the latest subspeciation (St. v. boui).

The endemic populations of fossil karstic systems seem to have an abnormal composition. They include unusually large adults, juvenile stages being rare. They differ from the phreatic populations, which exhibit a normal distribution is size groups, with a normal percentage of juveniles.

These differences between karstic and interstitial populations may result from the fact that in caves, St. virei is often insulated from its original phreatic biocoenosis: an intraspecific competition between size classes has taken the place of normal heterospecific struggle for existence.
\end{abstract}

\footnotetext{
* Laboratoire de Biologie Animale et Générale, Université de Dijon, 6, Bd. Gabriel, 21000
} DIJON, FRANCE. 
SOMMAIRE

\section{PREMIER CHAPITRE}

\section{MILIEU DE VIE NATUREL DE STENASELLUS VIREI:}

I - GENERALITES .

A. Rappel historique . . . . . . . . . . . . . 118

B. Liste des stations de Stenasellus virei connues à la fin de 1973 . . 118

C. Répartition écologique des stations . . . . . . . . . . . 120

D. Les stations dans leur contexte hydrogéologique . . . . . . 121

II - BIOTOPES KARSTIQUES DE STENASELLUS VIREI . . . . . . 122-139
A. GENERALITES .

B. Biotopes situés au niveau des grottes non actives:

1. Accumulations d'eau: flaques, gours, lacs 2. Circulations d'eau à faible débit

C. Biotopes des rivières souterraines actives

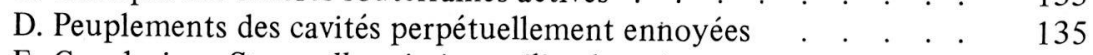

E. Conclusion: Stenasellus virei en milieu karstique: . . . .
Peuplements de la zone de percolation temporaire, de la zone amphibie et de la zone noyée. Question de la température des biotopes karstiques

III- BIOTOPES NON-KARSTIQUES DE ST. VIREI

A. Historique: Captures en plaine dans un puits maçonné, dans le lit d'une rivière de montagne, dans une source vraie

B. Stenasellus virei dans les nappes alluviales récentes

1. Garonne 2. Tarn.

C. Stenasellus virei dans le sous-écoulement des cours d'eau

1. Données générales 2. Stenasellus virei boui dans le sous-

écoulement du Nert 3. Stenasellus virei virei dans le sous-

écoulement du Tarn.

D. Stenasellus virei dans l'interstitiel non alluvial:

1. Massifs nord-pyrénéens 2. Plaine aquitaine

E. Conclusion: Stenasellus virei en milieu interstitiel

Peuplements des nappes parafluviales, de l'inféroflux des rivières épigées, des nappes perchées. Milieu de vie originel de l'espèce.

Question de la température des biotopes interstitiels

IV- CONSEQUENCES DE CES OBSERVATIONS

A. Sur le statut cavernicole de l'espèce

1. Stenasellus virei virei 2. St. virei buchneri 3. St. virei hussoni

4. St. virei angelieri 5. St. virei boui 
B. Aire de répartition de Stenasellus virei

1. Limites géographiques et contexte géologique

2. St. virei angelieri 3. St. virei buchneri 4. St. virei boui

5. St. virei hussoni 6. St. virei virei . . . . . . . . . . . . 153

a. Peuplements alluviaux du Tarn . . . . . . . . . . . . . . 159

b. Padirac: une population karstique adventice d'un peuplement phréatique . . . . . . . . . . . . . . . . . . 159

C. Signification de l'aire actuelle; les variations quaternaires.

Les glaciations. Les phases froides et sèches tardi-würmiennes.

Influence de la phase postglaciaire. La période historique

$\mathrm{V}-\mathrm{CONCLUSIONS}$ $166-167$

DEUXIEME CHAPITRE

DONNEES SUR LES POPULATIONS NATURELLES DE STENASELLUS VIREI

Conclusions . . . . . . . . . . . . . . . . . . . . . . . $168-171$

Bibliographie . . . . . . . . . . . . . . . . . . . . . 171 


\section{PREMIER CHAPITRE}

\section{MILIEU DE VIE NATUREL DE STENASELLUS VIREI}

\section{GENERALITES}

Le nombre des stations de Stenasellus virei s'est accru d'une manière considérable depuis le milieu de ce siècle. Cette multiplication des peuplements recensés est due à la fois à l'intensification des prospections dans la région pyrénéo-aquitaine et au perfectionnement des méthodes de capture. Les prospections récentes sont surtout le résultat de l'activité des membres permanents et temporaires du laboratoire souterrain du C.N.R.S. Les procédés de capture de la faune aquatique souterraine se révélant plus efficaces que la traditionnelle chasse à vue sont les suivants:

* Lavages de graviers de sources et exsurgences,

* Filtrages permanents des cours d'eau souterrains ou des exutoires,

* Sondages tubés Bou-Rouch, éventuellement appâtés.

Il était donc devenu nécessaire de réunir les données historiques et bibliographiques à l'ensemble des observations récentes pour obtenir un inventaire aussi complet que possible des stations de l'espèce. Cet inventaire pouvait alors servir de base pour une synthèse des données écologiques sur l'ensemble des biotopes représentés. Il est maintenant possible d'extraire des listes chronologiques de stations une classification de ces biotopes qui tienne compte des milieux physiques auxquels elles appartiennent.

\section{A. Rappel historique}

En 1919, on connaissait 15 stations de St. virei, après les remarquables explorations souterraines de Fage, Jeannel, Racovitza et de leurs collaborateurs. Ce nombre s'élevait à 25 en 1957 , après les découvertes de Stammer (1936), les citations de Remy (1948), de Ginet (1955) et de Husson (1957). Il se montait à 33 en 1959, après la publication de la 9ème énumération des grottes visitées de Biospeologica. Dans le courant de 1967, 77 stations étaient connues et j'en ai alors publié une première liste (Magniez 1967/1968) qui, dès la fỉn de 1970, était suivie d'une seconde énumération de 28 localités nouvelles (Magniez 1971a). Une énumération complémentaire paraitra en 1974.

Comme, dans le présent travail, il est fait mention à de multiples reprises des peuplements de Sténaselles de nombreuses stations, je donne ci-dessous une liste complète des localités connues au début de 1974. Pour chacune, nous trouverons le numéro d'ordre, la dénomination exacte et la détermination de la sous-espèce de St. virei qui y vit. Cette détermination n'est douteuse que dans les rares cas où je n'ai pu observer personnellement les individus, ou lorsque ceux qui furent capturés étaient trop jeunes pour être identifiés subspécifiquement.

\section{B. Liste des stations de Stenasellus virei connues à la fin de 1973}

\section{Département de l'Ariège}

4 - Grotte de Moulis (hussoni), 6 - Grotte de l'Estelas (hussoni), 9 - Grotte du Tuc d'Audoubert (hussoni), 12 - Grotte de Peyort (hussoni), 14 - Grotte de Ste-Hélène (hussoni), 19 - Puits de la Mate (hussoni), 24 - Ruisseau souterrain d'Aulot (hussoni), 27 - Tute de Jovis supérieure 
(hussoni), 28 - Tute de Coumaratte (hussoni), 29 - Gouffre du Plagnol de la Plagne (hussoni), 30 - Grotte Caujolle (boui ?), 31 - Gouffre de Lacoste (hussoni), 32 - Grotte inférieure de Liqué (hussoni), 33 - Grotte de Ste-Catherine du Milieu (hussoni), 36 - Gouffre du Bourdal (hussoni), 38 - Grotte Foulquier à Salège (hussoni), 39 - Aven de Ste-Catherine (hussoni), 40 - Source de Salège (hussoni), 41 - Galerie artificielle de Couflens de Betmajou (boui), 42 Grotte des Trois-Frères (hussoni), 43 - Grotte d'Audinac (hussoni), 44 - Fontaine des Oiseaux (hussoni), 45 - Source et abreuvoir de Peyort (hussoni), 46 - Source n ${ }^{\mathrm{O}} 1$ à Durban-sur-Arize (virei), 48 - Source captée d'Arbosec (hussoni), 52 - Aven du Tuc des Mandres (hussoni), 54 Gouffre du Sauvajou (hussoni), 60 - Source de Millas (hussoni), 61 - Source captée près de la Bièle (hussoni), 63 - Source de Gamas (hussoni), 64 - Grotte de Lespiougue (hussoni), 66 Gouffre de la Coume-Ferra (hussoni), - 67 Grotte inférieure de Montagagne (hussoni), 68 Rivière souterraine d'Aliou (hussoni), 69 - Tute de Jovis inférieure (hussoni), 70 - Puits à Fycheil (virei ?), 72 - Cigalère des Trinquets (hussoni), 74 - Sondage tubé dans le ruisseau de Lachein (boui), 75 - Sondage tubé dans le Nert (boui), 77 - Sondage tubé dans le Salat (boui), 86 - Exsurgence permanente du Baget (hussoni), 87 - Sources de Jouan d'Arau (virei + hussoni), 88 - Source du Bousquet (hussoni), 89 - Sous-écoulement du Nert (boui), 90 Grotte de Peyrous (hussoni), 91 - Source no 2 à Durban-sur-Arize (virei), 92 - Grotte supérieure de Montagagne (hussoni), 93 - Exsurgence temporaire de la Hillère (hussoni), 94 Exsurgence temporaire du Moulo de Jaur (hussoni), 95 - Captage d'Alas (hussoni), 96 Sous-écoulement du ruisseau de Lachein (boui), 97 - Sondage tubé dans le Volp (virei), 98 Sondage tubé $\mathrm{n}^{\mathrm{O}} 1$ dans l'Hers (virei), 99 - Sondage tubé $\mathrm{n}^{\circ} 2$ dans l'Hers (virei), 100 - Source karstique de Campet (hussoni), 101 - Exsurgence de la Bièle (hussoni), 102 - Sondage tubé dans le Sour (virei), 111 - Grotte de Poudane (hussoni), 117 - Exsurgence de Fontsainte (boui).

109 - Sous-écoulement du Dourdou (virei).

\section{Département de l'Aveyron}

104 - Nappe alluviale de la Dordogne (virei).

\section{Département de la Haute-Garonne}

3 - Grotte du Mont-de-Chac (hussoni), 7 - Gouffre du Poudac-Gran (hussoni), 11 - Grotte de Lespugne de Saleich (hussoni), 15 - Grotte de Gourgue (hussoni), 20 - Puits Pons à Toulouse (virei), 22 - Grotte de la Maouro (hussoni), 23 - Grotte de Terreblanque (hussoni), 25 Grotte du Béguet (hussoni), 26 - Gouffre du Béguet (hussoni), 47 - Source Hountalayrou (hussoni), 49 - Captage de Borde de Darré (hussoni), 50 - Source à Boulogne sur Gesse (hussoni), 51 - Ruisseau souterrain de St.Paul (hussoni), 55 - Grotte de Riusec inférieur (hussoni), 65 - Grotte du Goueil-di-Her (hussoni), 103 - Grotte de Riusec supérieur (hussoni), 105 - Exsurgences pérennes du Goueil-di-Her (hussoni).

1 - Gouffre de Padirac (virei).

\section{Département du Lot}

\section{Département des Hautes-Pyrénées}

2 - Grotte de Gargas (hussoni), 8 - Grotte de Castel-Mouly (hussoni), 10 - Grotte du Bédat (hussoni), 13 - Grotte de l'Haiouat de Pelou (hussoni), 18 - Grotte de l'Eglise de Bas-Nistos (hussoni), 37 - Grotte de la Tute du Chef (hussoni), 57 - Grotte de Batsère (hussoni), 82 Sondage tubé dans le Nistos (virei).

\section{Département des Pyrénées-Orientales}

21 - Nappe alluviale de la Têt à Thuès-les-Bains (angelieri), 53 - Nappe alluviale du Tech, station $\mathrm{n}^{\mathrm{O}} 1$ (angelieri), 56 - Nappe alluviale du Tech, station $\mathrm{n}^{\mathrm{O}} 2$ (angelieri), 58 - Nappe alluviale du Tech, station $\mathrm{n}^{\mathrm{O}} 3$ (angelieri), 110 - Rivière souterraine de l'Empereur (angelieri), 114 - Source de Durdull (angelieri). 


\section{Département du Tarn}

71 - Puits tubé à Albi (virei), 73 - Sondages tubés dans le Tarn à Ambialet (virei), 76 Sondages tubés dans le Tarn à Albi (virei), 81 - Source de la Mouline du Gô à Albi (virei), 83 Sondages tubés dans le Tarn à Marsal (virei), 84 - Puits du Lycée d'Albi (virei).

107 - Fontaine de Bruniquel (virei).

Département du Tarn-et-Garonne

108 - Avenc del Pouetons à Monserrat (angelieri).

Province de Barcelone

Province de Guadalajara

115 - Cueva del Tornero à Checa (virei).

Province de Huesca

5 - Solencio de Morrano (virei).

\section{Province de Lerida}

112 - Sous-écoulement d'un affluent du Rio, Ribagorzana à Pont-de-Suert (virei), 113 - Sousécoulement du Rio Noguera Pallaresa dans le défilé des Collegats (virei), 116 - Avenc de la Cabana d'En Garrava à Toloriu (angelieri).

\section{Province de Santander}

16 - Cuevas de Altamira (2 grottes), (buchneri), 17 - Cueva de la Estacion de Santa Isabel de Quijaz (buchneri), 34 - Cueva de la Cullalvera (buchneri), 35 - Cueva del Molino (buchneri), 59 - Cueva de la Castañera (buchneri), 62 - Cueva de la Clotilde (buchneri), 78 - Cueva de Cofresnedo (buchneri), 79 - Cueva de Codisera (buchneri), 80 - Cueva de Rascavieja (buchneri), 85 - Cueva del Pielago (buchneri).

106 - Cueva de Can Massiet à La Riba (virei).

\section{Province de Tarragone}

Remarque: Selon G. Escola y Boada (in litt.), St. virei serait présent dans de nombreuses grottes de Catalogne et il en prépare l'inventaire.

\section{Répartition écologique des stations}

La plupart correspondent à des grottes de la région nord-pyrénéenne ou à des cavités espagnoles déjà répertoriées (77 sur les 117). Les autres se réfèrent à des prospections des eaux souterraines non karstiques, liées à des milieux à porosité d'interstices (40). Les descriptions déjà publiées (Magniez 1967/68, 1971a), ou à paraitre, permettent d'en faire la classification suivante:

1. Les grottes et leurs annexes (eaux des terrains perméables en grand).

2. Les sources, puits maçonnés ou tubés, les sondages Karaman-Chappuis, les sondages tubés Bou-Rouch (eaux des formations perméables en petit).

Ainsi, la connaissance écologique de l'espèce est une acquisition progressive, ayant procédé en plusieurs étapes:

- Les données bibliographiques se rapportaient essentiellement aux concepts classiques de la grotte et du "milieu cavernicole", abritant la "faune cavernicole".

- Les explorations récentes, qui ont abouti à l'établissement des listes de stations, représentent une étape intermédiaire fastidieuse, mais nécessaire pour la 
connaissance de l'espèce. Elles ne sont pas achevées, mais montrent déjà l'extrême variété des types de biotopes souterrains colonisés par St. virei. Une classification précise de ces derniers s'impose donc.

\section{Les stations dans leur contexte hydrogéologique}

Une vision beaucoup plus synthétique de l'habitat de l'espèce peut maintenant intervenir. Elle tient compte de la classification des aquifères souterrains proposée par les hydrogéologues actuels (Gèze, Cavaillé, Schoeller, par exemple). Elle a déjà été remarquablement utilisée par Rouch (1968), qui a exposé une conception moderne et dynamique du problème des peuplements en Copépodes Harpacticides du milieu karstique. En faisant abstraction des particularités de chacune des 117 stations connues de l'espèce, les biotopes de St. virei peuvent être regroupés, selon leur appartenance à chacune des subdivisions de la classification des eaux souterraines continentales admise actuellement:

\section{Eaux des terrains perméables en grand (substratum karstique)}

Une zonation des massifs calcaires dans le sens vertical, faisant abstraction des cavités accessibles à l'Homme par elles-mêmes, est généralement adoptée:

a. Zone de percolation temporaire = zone supérieure, parfois dénommée zone dénoyée ou zone d'infiltration et de ruissellement souterrain, chacun de ces termes possèdant sa justification hydrologique particulière, je préfêre le troisième, qui rend le mieux compte de la nature des biotopes à Sténaselles correspondants.

b. Zone amphibie au niveau de laquelle se font les variations de niveau des grands plans d'eau souterraine du massif (rivières actives en continuité avec les exutoires fonctionnels actuels).

c. Zone noyée: l'éventuel système aquifère sous-jacent au précédent, perpétuellement ennoyé (cavités de dissolution, galeries, fissures, diaclases et joints de stratification plus ou moins élargis des dispositifs holokarstiques).

Cette zonation présente une valeur générale, mais le plus ou moins grand développement de chaque zone est lié à des facteurs locaux propres à chaque massif karstique. Certains de ces facteurs appartiennent au passé, comme les variations altitudinales du plan des rivières anciennes au voisinage du massif ou la structure sédimentaire elle-même de celui-ci. D'autres facteurs sont actuels, comme la situation altitudinale du massif par rapport au plan du réseau hydrographique actuel, ou comme le régime local des précipitations.

Ces systèmes ne sont connus, du point de vue biologique, que dans leur portion la plus superficielle, au voisinage immédiat de la zone amphibie correspondante (c'est-à-dire dans la partie des assises calcaires faisant saillie dans la topographie et constituant le massif proprement dit). Cependant, on doit tenir compte de l'existence, au sein des diverses auréoles calcaires du Bassin aquitain, par exemple, même dans les zones recouvertes par des terrains sédimentaires plus récents, c'est-à-dire "en plaine", de réserves et circulations aquifères considérables. Vers l'Ouest du bassin, ces couches s'infléchissent en profondeur et la température de l'eau incluse devient trop élevée, mais, dans les portions moyennes du bassin, surtout dans les zones fracturées, il existe un domaine de vie possible très développé pour la faune aquatique souterraine, non seulement dans la bordure méridionale, sous-pyrénéenne du bassin, mais également au niveau des auréoles septentrionales de celui-ci. Je citerai simplement un exemple emprunté à Vouvé, Cazal, Plaud et Pouchan (1969) et relatif à l'ensemble calcaire turonien-sénonien:

* A Montflanquin (Lot-et-Garonne), un forage de $90 \mathrm{~m}$ recoupe une galerie noyée de section $2 \mathrm{~m}$ par $2 \mathrm{~m}$, fonctionnant en conduite forcée avec un débit artésien possible de $360 \mathrm{~m} 3 / \mathrm{h}$.

* A Lormont (Gironde), un autre sondage dans ces calcaires possède un débit potentiel de $200 \mathrm{~m} 3 / \mathrm{h}$. Les auteurs ont montré en outre que des systèmes de fractures assuraient des interconnexions entre les divers aquifères jurassiques, crétacés et tertiaires et que la porosité d'inter- 
stices des calcaires relayait la "porosité de chenaux" pour assurer la circulation rapide des eaux dans ces assises. Si des faunes sont installées dans de tels conduits ou réserves aquifères profonds, leur mise en évidence sera malaisée. Le filtrage continu des exutoires remontants, en particulier lors des crues, tel qu'il est pratiqué par Rouch (1970), pourra apporter une solution à ce problème.

\section{Eaux des terrains perméables en petit (substratum non karstique)}

a. Nappes des couches sédimentaires perméables: Dans l'état actuel de nos prospections, aucune station de St. virei ne semble correspondre à ce cas. Pourtant, ces types d'aquifères sont extrêmement développés dans les séries géologiques aquitaines (Vouvé, Cazal, Plaud et Pouchan 1969). Cette situation n'est peut-être que provisoire et due à l'absence des prospections systématiques de ces nappes.

b. Nappes des formation superficielles: Les dépôts éluviaux ou colluviaux donnent lieu à l'existence de nappes phréatiques locales dont la faune peut être capturée au niveau de leur exutoire.

c. Nappes des dépôts alluviaux (terrasses alluviales et plus généralement alluvions récentes ou actuelles du réseau hydrographique).

Ainsi, en utilisant comme principe directeur la classification physique des différents types d'aquifères souterrains, définie par les hydrogéologues, nous allons pouvoir, en décrivant un nombre restreint de stations caractéristiques, donner une idée assez précise de la remarquable ubiquité écologique de $S t$. virei.

\section{BIOTOPES KARSTIQUES DE ST. VIREI}

\section{A. Généralités}

En 1949 encore, St. virei pouvait passer pour un cavernicole typique, car on le connaissait uniquement dans les eaux de 19 cavités naturelles. A la suite de l'observation des biotopes du Crustacé dans 6 grottes seulement (Padirac 1908, Gargas 1905, Mont-de-Chac 1906, Moulis 1909, Solencio de Morrano 1911 et l'Estelas 1912), mais dans des conditions écologiques très comparables, Fage et Racovitza purent le retrouver en 1913 au Gouffre de Padirac, dans le biotope qu'ils considérèrent dès lors comme "normal" pour l'espèce: le fond limoneux des mares d'eau stagnante, bien pourvues de débris ligneux, qui étaient le trait commun des cavités citées par Racovitza (1950). L'auteur ajoutait même que l'habitat correspondant à la découverte originelle de l'Isopode par Viré et aux captures de Tournier (les eaux courantes du Ruisseau de la Fontaine, dans le Gouffre de Padirac), ne devait être qu'accidentel. En effet, des Asellides oculés, comme Asellus aquaticus (L.) ou Proasellus meridianus (Racovitza) affectionnent particulièrement le fond des eaux épigées stagnantes ou peu courantes, riches en débris végétaux en décomposition. Il était donc normal, à cette époque, d'assigner à St. virei des préférences écologiques similaires dans le milieu aquatique hypogé.

Le nombre des stations cavernicoles de $S t$. virei atteignait 70 dans le courant de 1969 , et j'ai pu dès cette date visiter et étudier la plupart d'entre elles. Il y a lieu de préciser si le ou les biotopes aquatiques de chacune sont conformes aux affirmations de Racovitza ou s'il faut envisager une classification écologique plus poussée 
de ces stations. Remarquons d'abord que le fait de désigner une grotte comme station d'une espèce aquatique n'est qu'un moyen commode de signaler sa présence en un lieu donné du milieu hypogé karstique. En effet, la grotte accessible à l'Homme est généralement répertoriée et bien repérée dans la topographie par ses coordonnées cartographiques dans les trois dimensions de l'espace. Une espèce donnée pouvant être localisée en un ou plusieurs points bien déterminés d'un système complexe de galeries, on se doit de préciser davantage la nature et la position du biotope.

Prenons le cas de deux cavités à topographie très compliquée: la grotte du Bédat (no 10) où St. virei hussoni existe dans plusieurs accumulations d'eau éloignées les unes des autres; la grotte de Riusec inférieur (no 55) dans laquelle cette forme n'a été décelée en 1964 qu'un un seul point d'eau étroitement localisé, sans que nous connaissions dans le premier cas les raisons de la dissémination du Crustacé et dans le second les facteurs restrictifs de celle-ci.

Il arrive qu'une grotte à galeries subhorizontales sèches ("rivière souterraine fossile") recoupe, en des points privilégiés du massif, des circulations d'eau dont la direction générale est verticale. La faune aquatique souterraine parait liée à ces écoulements fonctionnels (qui sont multiples et dont la répartition dans le massif semble très aléatoire) et à leurs conduits. Sa liaison avec le système de galeries fossiles que l'Homme est obligé d'emprunter pour accéder à ces circulations est purement locale et accidentelle.

\section{B. Biotopes situés au niveau des grottes non actives}

\section{Accumulations d'eau: flaques, gours, lacs}

Beaucoup de cavités abritant St. virei hussoni: grottes du Mont-de-Chac (3), de Lespugne (11), de Peyort (12), de Liqué (32), de la Tute de Jovis supérieure (27), par exemple, ou les cavités abritant St. virei buchneri: Cuevas de Altamira (16) et de la Clotilde (62), se présentent comme des galeries ou des systèmes de galeries dans l'ensemble sèches. Le creusement de la plupart d'entre elles résulte manifestement de l'activité d'importants cours d'eau souterrains qui ont aujourd'hui totalement disparu ou émigré vers des niveaux inférieurs. Des dépôts argileux parfois abondants forment le sol dont certaines zones sont constituées par d'anciens concrétionnements calcitiques. Ces cavités possèdent, en un ou plusieurs points bien localisés, quelques accumulations d'eau stagnante (au moins en apparence), soit très temporaires, soit pratiquement permanentes. Les bassins de celles des grottes qui furent explorées et décrites au début du siècle par Jeannel, Racovitza et Fage ne semblent pas s'être sensiblement modifiés depuis. Certaines des accumulations permanentes peuvent s'assécher au terme d'un été exceptionnellement sec. Dans ce cas, le limon du fond reste néanmoins très humide et plastique. L'alimentation en eau de ces bassins, toujours modeste, est fournie par des suintements temporaires ou pratiquement permanents. Ces apports proviennent des niveaux formant le toit de la grotte (collecte dans la couverture pédologique et ruissellement à travers les couches calcaires fissurées). Ils peuvent aussi avoir pour origine partielle des conden- 
sations à la voûte. Cette eau parvient au sol de la cavité, soit par chute libre des gouttes, soit par migration laminaire sur des concrétions verticales. Le niveau de l'accumulation d'eau dans le bassin semble résulter d'un équilibre entre ces apports quantitativement limités, le soutirage capillaire à travers le fond de la cuvette (Rouch 1968) et peut-être les échanges avec l'atmosphère de la grotte. Le bilan étant faiblement négatif dans le courant de la belle saison, on assiste à une baisse lente du niveau jusqu'à la fin de l'été. Cette baisse est suivie d'une remontée automnale et hivernale du niveau, avec éventuellement une phase très temporaire de débordement du bassin et un écoulement vers l'aval de la cavité. Un cycle annuel relativement régulier semble donc pouvoir être observé dans les cas privilégiés.

Un tel système aquifère paraît, au premier abord, relativement isolé des circuits souterrains des eaux, surtout vers l'aval. Mais il faut préciser la nature de cet isolement: il n'est pas réel du point de vue hydrogéologique, car une accumulation d'eau, telle qu'elle est envisagée ici, se trouve bien sur le trajet d'un cheminement liquide souterrain du haut vers le bas (Rouch 1968). Pourtant, il constitue une condensation d'une certaine masse de liquide entre deux goulots d'étranglement que l'eau emprunte à l'état très divisé. Cette notion semble importante pour l'étude d'un Crustacé aquatique dont les adultes atteignent couramment $1 \mathrm{~cm}$ de longueur, car elle provoque des concentrations de cette faune souterraine qui se trouve alors plus ou moins emprisonnée dans ces bassins. Les accumulations d'eau de ce type, situées dans des cavités aujourd'hui non actives peuvent donc abriter des Sténaselles. Pourtant, l'importance numérique des peuplements et la densité des Isopodes y varient dans de larges limites. Il convient de préciser, à l'aide de trois exemples correspondant à des stations réelles, les variations possibles de l'importance de cet habitat.

\section{a. Flaques ou bassins de faible dimension (quelques $\mathrm{dm} 2$ )}

La Tute de Jovis supérieure à Alos, Ariège (no 27; Biospeologica 1407) est une grotte qui offre une unique accumulation d'eau de ce type. Sa vaste salle au plancher stalagmitique et argileux (fig. 19,A1) présente, près de la paroi Est, une petite dépression dans l'argile compacte qui est constamment alimentée en eau par des gouttes tombant d'un point privilégié de la voûte. Bouillon et Coiffait furent les premiers à constater qu'elle abritait quelques Sténaselles adultes (St. virei hussoni) en 1955. En 1961, j'ai pu constater que la station était toujours dans le même état que 6 ans plus tôt: une demi-douzaine de Sténaselles étaient visibles dans cette flaque toujours très pauvre en nourriture. Les températures extrêmes y sont de $10^{\circ} 1$ en mars et de $11^{\circ} 2$ en septembre, tandis que dans le gour à fond argileux, situé dans une niche concrétionnée de la grotte et également peuplé par St. virei hussoni et Pelodrilus leruthi, la température varie de $10^{\circ} 7$ à $11^{\circ} 5$ pour les mêmes époques. Suivie régulièrement jusqu'en 1970, la cuvette argileuse montre toujours la même permanence et le même peuplement mais je n'ai pu encore y observer la reproduction de l'Isopode.

D'autres cavités de même type possèdent des accumulations d'eau de faible volume. Lorsque la flaque est permanente, un groupe de Sténaselles adultes peut y subsister et être visible toute l'année. Mais, il s'agit d'un biotope dont l'exis- 
tence est précaire. Au cours d'une année particulièrement sèche, l'alimentation en eau peut tarir et la population être décimée. Il suffit parfois d'y prélever, au cours de plusieurs ponctions rapprochées, tous les individus visibles pour faire disparaitre purement et simplement la "station". Ainsi, la grotte de la Tute du Chef (nO 37) à Bas-Nistos, Hautes-Pyrénées, contient une série de gours stalagmités à fond argileux qui se mettent temporairement en eau (Rouch 1968), (température $8^{\circ} 7$ à 902). Quelques adultes de St. virei hussoni y vivaient et furent collectés en février 1961 par Chodorowski. Depuis cette date, il a été facile de vérifier qu'aucun nouveau terrier n'avait été creusé par les Isopodes et que l'espèce ne s'y était pas réinstallée. Or les gours de la Tute du Chef s'assèchent en été et se repeuplent régulièrement en Copépodes souterrains (Elaphoidella longifurcata et Speocyclops gallicus) lors de la remise en eau, à la saison pluvieuse, par migration du massif vers la grotte (Rouch 1968). La notion de station à St. virei, dans le cas de la Tute du Chef a une signification particulière: cette grotte est en fait l'abri temporaire de quelques individus de l'espèce qui y parviennent épisodiquement, les années humides, à la faveur de certains cheminements souterrains des eaux. Il ne s'agit pas de populations cavernicoles autonomes et il faut considérer comme une nécessité logique l'existence d'un peuplement véritable de l'espèce au niveau de la masse des eaux souterraines imbibant le massif karstique tout entier, la présence de quelques Sténaselles dans la grotte n'étant qu'un accident fortuit. Le cas des grottes de Castel-Mouly (n ${ }^{\mathrm{O}}$ 8) ou de l'Haiouat de Pelou ( $\mathrm{n}^{\mathrm{O}} 13$ ), Hautes-Pyrénées, (température de l'eau: $11^{\circ}$ ), choisies parmi toute une série d'autres cavités, est du même type et aussi démonstratif que celui de la Tute du Chef.

Dans certains cas, l'apparition temporaire des Sténaselles pourrait être observée "sur le vif". Ainsi, dans un même massif calcaire ariégeois existent deux cavités très proches l'une de l'autre et qui ont été bien étudiées par les biospéléologues. St. virei hussoni a été observé en 1966 dans la première (Grotte de Montagagne inférieure, $\mathrm{n}^{\circ}$ 67), qui possède des réserves d'eau notables en 1966. (température: $9^{\circ}$ ). Au début de 1969, j'ai pu constater la présence de quelques individus identiques aux précédents dans la seconde cavité (grotte supérieure de Montagagne, $\mathrm{n}^{\mathrm{O}}$ 92). Les Sténaselles se tenaient sur des fragments de bois immergés dans une petite vasque calcitique et parmi des graviers absorbant le suintement efférent (température de l'eau: $8^{\circ} 3$ le 31.03.1969). L'espèce n'y avait pas été signalée auparavant car les prospecteurs précédents avaient visité la cavité à la belle saison alors que la vasque n'était pas en eau. L'espèce peut donc apparaître dans une cavité à la faveur d'une succession de saisons ou d'années anormalement humides qui renforçent les circulations internes du massif, facilitent leurs communications avec les accumulations d'eau des grottes et rendent celles-ci moins temporaires. Ces observations, bien que fragmentaires et purement qualitatives, montrent l'existence, sous forme de restrictions ou d'expansions saisonnières ou pluriannuelles, d'une fluctuation des peuplements de St. virei hussoni au sein d'un même massif karstique.

\section{b. Bassins plus importants ( 1 à plusieurs $\mathrm{m} 2$ de surface)}

L'exemple typique est l'unique bassin de la grotte du Mont-de-Chac, à Saleich, Haute-Garonne ( $\mathrm{n}^{\mathrm{O}} 3$ ). Cette cavité est une des stations classiques à Stenasellus virei 
hussoni. Elle est petite et sèche dans son ensemble, mise à part la salle terminale qui possède une retenue d'eau quasi-permanente. Il s'agit d'une vasque limitée vers l'aval par une muraille calcitique épaisse dont le fond est imperméabilisé par une couche de limon de quelques centimètres. Chaque année, en hiver et au printemps, elle se remplit et le trop-plein se déverse vers l'aval où il est soutiré à travers l'argile. La vasque atteint alors $20-40 \mathrm{~cm}$ de profondeur et s'étend sur plusieurs $\mathrm{m} 2$. Dans ces conditions, les Crustacés y paraissent peu abondants, car très dispersés. Au mois de septembre, par contre, la surface se réduit régulièrement à $1 \mathrm{~m} 2$ au moins et la profondeur à quelques $\mathrm{cm}$, si bien que la population, rassemblée sur un faible espace, y paraít très dense. Certaines années à arrière-saison particulièrement sèche, le gour ne contient plus d'eau libre (décembre 1972, par exemple) et tous les Sténaselles se réfugient au fond de leurs galeries, protégés par la boue humide qui les environne.

La température de l'eau varie notablement: selon les années, on a relevé de $9{ }^{\circ} 9$ à $11^{\circ} 2$ en mars-avril, de $11^{\circ}$ à $11^{\circ} 8$ en juillet-août et de $12^{\circ}$ à $12^{\circ} 6$ en septembre. La vasque est alimentée par des suintements permanents sur la concrétion verticale qui la limite partiellement vers l'amont. L'eau est très incrustante. Cette coulée liquide apporte constamment de nombreux matériaux nutritifs visibles, notamment des excréments de Chauve-souris qui peuvent d'ailleurs tomber directement dans la vasque car une partie des Chiroptères hivernant dans la grotte s'installent à ce niveau, comme l'avait noté Husson en 1955. Au fond de l'eau existent aussi quelques branchages macérés et restes osseux de petits Mammifères. L'eau de percolation apporte aussi une microfaune de Copépodes (Nitocrella gracilis, N. subterranea, Speocyclops racovitzai), comme l'a montré Delay $(1968,1969)$, par la méthode de filtrage continu. La nourriture disponible pour les Stenasellus est donc relativement

\section{FIGURE 19}

Biotopes cavernicoles de Stenasellus virei

A. Coupe très schématique des grottes dites "Tute de Jovis supérieure", (n 27) et "Tute de Jovis inférieure", $\left(n^{\circ} 69\right)$ :

1: cavité fossile entièrement sèche, sauf un suintement permanent $(\mathrm{E})$, dont les gouttes alimentent une flaque également permanente, de quelques $\mathrm{dm}^{2}$. Le sol (S) est formé d'argile plus ou moins pulvérulente et de dépôts calcitiques $(C)$. La flaque $(F)$ est la seule condensation de la cavité, mise à part une niche concrétionnée située à l'arrière-plan, dans laquelle on trouve un petit gour permanent. La flaque abrite toujours quelques St. virei hussoni adultes. Elle a toujours montré ce même aspect durant plus de dix ans d'observations.

2: La grotte active sous-jacente est une galerie basse, abritant la rivière souterraine actuelle (R). Elle possède des plages de galets (G). St. virei hussoni y vit également, mais son observation et sa capture y sont particulièrement malaisées. $\mathrm{D}=$ infiltration souterraine diffuse.

B. Coupe très schématique d'une partie de la grotte de Peyort $\left(\mathrm{n}^{\mathrm{O}} 12\right)$. St. virei hussoni peut s'y rencontrer dans des flaques argileuses permanentes $(\mathrm{F})$, existant sur un plancher de concrétions (C), ou parfois de roche vive. Des écoulements temporaires de percolation $(\mathrm{P})$ peuvent les alimenter. A gauche, un suintement permanent $(\mathrm{S})$, à température très constante, forme une série de minuscules bassins (B), logés dans des cupules de la roche et étagés le long de la pente. Ces bassins abritent des Sténaselles formant un peuplement très constant. On trouve ici un cas typique d'infiltration et de ruissellement souterrain en milieu karstique. 

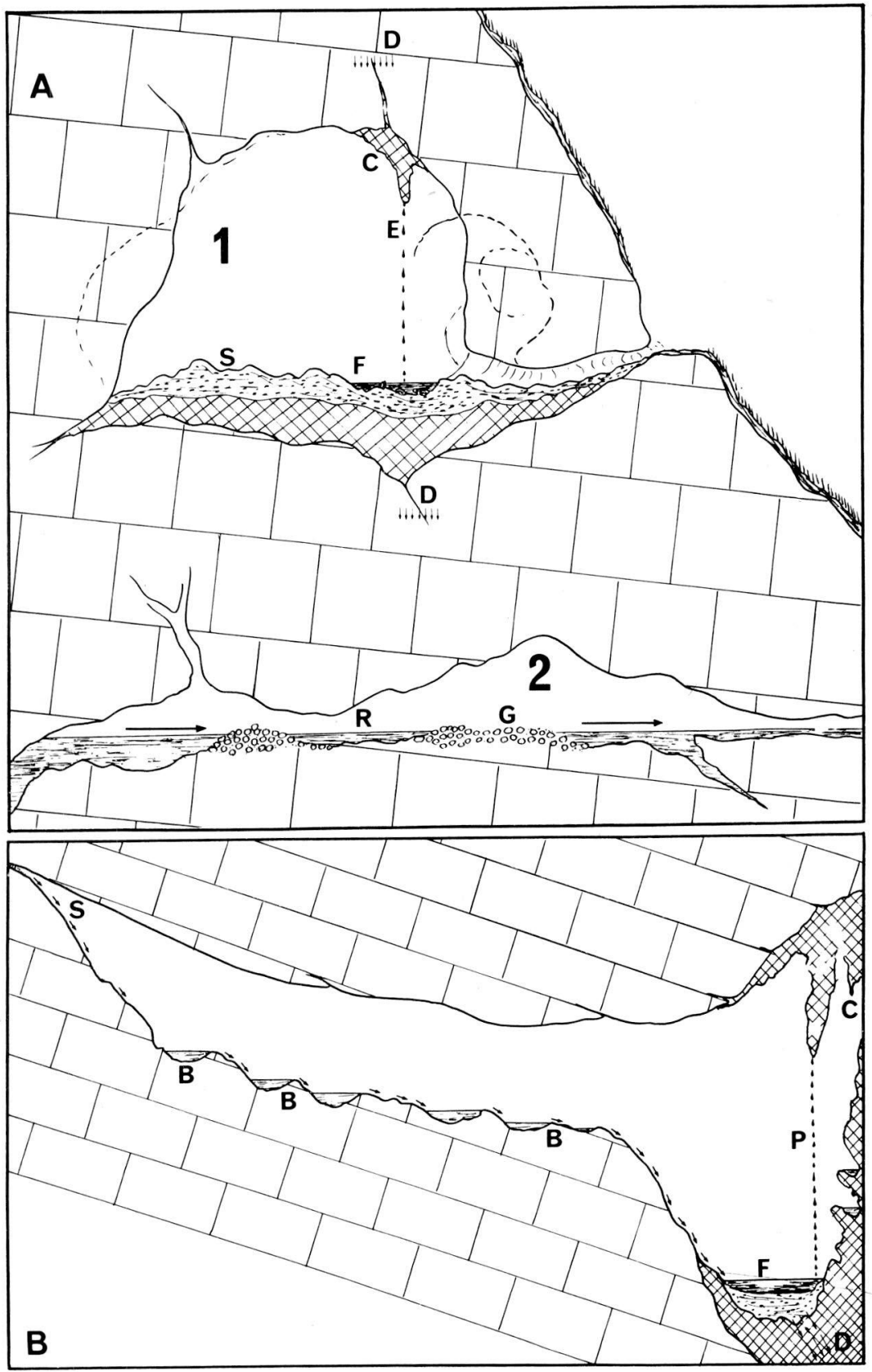
abondante et son arrivée échelonnée dans le temps. Une telle accumulation d'eau permet à un nombre important de Sténaselles de prospérer. Ainsi, dès 1906, Jeannel, puis en 1912, Jeannel et Racovitza pouvaient constater que la vasque abritait une abondante population de cet Isopode. J'ai étudié en détail (voir plus loin) cette population, entre 1960 et 1968 et rapporté les observations faites sur elle depuis plus d'un demi-siècle (Jeannel, Jeannel et Racovitza, Husson 1955). Toutes concordent pour montrer qu'il s'agit d'un peuplement permanent. Dans cette population se voit toujours une proportion appréciable de femelles gestantes (Racovitza 1950, Magniez 1968a). La reproduction de l'espèce a donc lieu normalement dans des groupements d'individus de cette importance et fournit des générations de jeunes très largement pléthoriques (voir plus loin le paragraphe relatif aux populations naturelles de St. virei) alors que je n'ai pu la mettre en évidence dans les petits groupes d'individus isolés dans les flaques de faible taille et pauvres en nourriture. Aujourd'hui encore, malgré les récents et importants prélèvements d'individus, la vasque est bien peuplée et il est toujours possible d'y observer plusieurs dizaines d'individus sur le limon du fond, la plupart des autres étant cachés dans les multiples terriers creusés par ces Isopodes. Les collections d'eau analogues à la vasque du Mont-de-Chac sont donc susceptibles d'abriter des populations autonomes de St. virei hussoni, capables de s'y perpétuer par reproduction in situ pratiquement sans apport d'individus du massif.

c. Lacs souterrains (leur surface se mesure par dizaines ou centaines de $\mathrm{m} 2$ ): Exemple, la grotte de l'Estelas, Ariège $\left(\mathrm{n}^{\mathrm{O}} 6\right)$.

La partie terminale de cette large galerie concrétionnée, déprimée par rapport à la région moyenne sur laquelle s'est déposé un épais talus calcitique, est occupée par un vaste lac, au fond garni d'une épaisse couche de limon très meuble. Les ressources alimentaires, tant animales que végétales y sont toujours abondantes. La faune y est représentée en particulier par de nombreux Oligochètes Phreoryctidae Pelodrilus leruthi et Copépodes souterrains: Speocyclops anomalus. Le lac est permanent bien que la profondeur soit très variable (près de $1 \mathrm{~m}$ à la saison pluvieuse, mais seulement quelques $\mathrm{cm}$ en fin d'été). Sa température varie entre $7^{\circ} 9$ et $8^{\circ} 4$. La grotte, perchée à quelques $900 \mathrm{~m}$ sur le flanc Est du Pic de l'Estelas est certainement la galerie d'une très ancienne rivière souterraine, galerie tronquée vers l'aval par l'érosion et obturée vers l'amont par le concrétionnement. L'accumulation d'eau qui se produit provient des suintements locaux à travers le sol et les couches calcaires du toit; elle doit être évacuée vers le bas par soutirage lent, à l'état très divisé, à travers les dépôts formant le plancher de la galerie. C'est la station classique le plus populeuse de St. virei hussoni. En 1912, Jeannel et Racovitza notaient déjà que "le grand lac et les flaques limoneuses voisines en hébergeaient des milliers ...". En septembre 1955, Husson a retrouvé cette colonie aussi prospère et de 1960 à 1970, il m'a été possible d'y prélever environ un millier d'adultes, sans déclin visible. Ici, comme au Mont-de-Chac, les conditions écologiques sont telles qu'elles rendent possible la reproduction régulière de l'espèce et le maintien de la population au cours des années, sans qu'un apport d'individus provenant de l'environnement karstique paraisse nécessaire. Ce type d'accumulation d'eau représenté par le 
lac de l'Estelas peut abriter, lui aussi, une population stable relativement isolée, comprenant de nombreux individus (vraisemblablement des milliers). Il ne semble pas que cette population participe à des échanges massifs d'individus adultes avec les portions de la circulation souterraine situées, soit en amont, soit en aval du bassin. Sur d'autres exemples (grottes de Liqué, du Mont-de-Chac), Delay (1968-1969) a montré qu'il existe un apport de quelques jeunes Stenasellus par saison, en nombre infime par rapport à la population de la collection d'eau. (Les techniques utilisées permettaient de noter l'arrivée des individus avec l'eau de percolation, vers le gour, mais non les départs d'individus en sens inverse).

d. Remarques: En aval de son lac terminal, toute la moitié profonde de la grotte de l'Estelas possède un plancher stalagmitique avec de nombreux bassins concrétionnés ou à fond limoneux. Ces bassins se mettent en eau durant la saison pluvieuse, mais on les trouve, à quelques exceptions près, totalement à sec à partir de juillet. C'est ce que j'ai pu observer au cours des années 1960 à 1965, 1967 et 1970. Dans ces conditions on n'y rencontre que de très rares individus au cours des prospections d'hiver ou de printemps. Au cours des années 1966 et surtout 1968-1969, j‘ai pu constater que certains de ces bassins, normalement temporaires, avaient été alimentés bien plus régulièrement et se trouvaient en eau en juillet-août. D'assez nombreux Stenasellus y étaient visibles, surtout dans ceux à fond limoneux qui leur offrent la possibilité de creuser leurs terriers. L'espèce était largement disséminée dans la grotte. Il semble donc possible d'observer, dans une cavité abritant l'Isopode, des variations de l'extension des peuplements, si une succession d'années à pluviosité très différente amène de sérieuses fluctuations dans le régime hydraulique de la grotte. Envisageons un autre exemple qui tend à montrer que, au moins sous certains climats aux saisons bien tranchées, du point de vue des précipitations, l'occupation par les Sténaselles des collections d'eau de la grotte pourrait n'être que saisonnière. Le Professeur P. Remy avait visité la Grotte de Sabara (Corse centrale), le 22-08-1948, (Remy 1950, p. 26-28). A cette époque la grotte était totalement exondée et aucune faune aquatique ne pouvait y être capturée. En novembre 1967 par contre, lors des prospections de P. Beron, la grotte était en eau, vraisemblablement par suite de la montée du niveau de la nappe karstique sous-jacente en équilibre avec celle de la rivière voisine, et une faune aquatique représentée par des Asellidae anophtalmes (Proasellus beroni Henry et Magniez), et des Stenasellidae (Stenasellus racovitzai Razzauti) put y être récoltée. Dans des conditions topographiques favorables, les Isopodes aquatiques seraient donc parfaitement capables de suivre les variations d'extension du milieu liquide au sein du massif.

2. Circulations d'eau à faible débit: (suintements, ruissellements, ruisseaux souterrains).

Parmi les stations étudiées, certaines se présentent comme des regards sur des circulations actives d'eau souterraine: rivière ou fort ruisseau à cours rapide et à débit abondant, coulant sur un fond de galets formant des alluvions plus ou moins épaisses, sur la roche nue ou concrétionnée ou garnie de banquettes et de placages d'argile compacte. Plus nombreuses dans le domaine des grottes aériennes sont les 
circulations liquides au débit très modeste, faibles ruisselets, se présentant parfois sous l'aspect de lents écoulements, laminaires par place. Ce sont les innombrables circuits de l'infiltration et du ruissellement souterrains, par où l'eau transite en permanence depuis la surface du massif jusqu'au réseau actif qu'elles alimentent.

a. Chenaux de suintement permanent: Un exemple précis, celui de la grotte de Peyort $\left(\mathrm{n}^{\mathrm{O}} 12\right)$ permet de définir ce type de biotope. Jeannel explora en 1914 cette galerie fossile de rivière souterraine et signala des Sténaselles dans des cuvettes tapissées d'argile (températures: $9^{\circ} 4 \mathfrak{a}^{1} 11^{\circ} 6$ ), qui jalonnent la partie moyenne de la grotte et dans deux petits lacs limoneux de la portion profonde, biotopes répondant aux types déjà étudiés (en 1a et 1b). Dans la région moyenne de la cavité, la paroi Est de la galerie est formée par une dalle calcaire oblique qui se rapproche du banc calcaire sous-jacent formant le toit de la cavité. Le contact entre les deux bancs correspond sans doute à un joint de stratification épais. Sur cette dalle oblique de roche nue ou à peine garnie de limon existe une série de suintements qui sont issus du joint entre dalle et toit de la galerie et vont se perdre par infiltration dans l'argile plus ou moins pulvérulente du plancher de celle-ci ou dans les cuvettes argileuses. Ces très faibles ruissellements divaguent sur la dalle en empruntant les lignes de plus grande pente. La surface de la roche n'étant pas lisse, mais parsemée de cupules, les écoulements forment des séries de chapelets de petites poches liquides étagées dans les concavités du calcaire. Le volume de chacune ne dépasse pas quelques $\mathrm{cm} 3$ et le fond est garni d'un minime dépôt limoneux. Elles sont réunies par une simple pellicule aqueuse par laquelle le liquide migre lentement sur la pente, à l'état laminaire, de chaque poche à celle qui est immédiatement en contre-bas. Le débit de chaque suintement parait extrêmement faible: quelques $\mathrm{cm} 3$ à quelques dizaines de $\mathrm{cm} 3$ à l'heure selon la saison. St virei hussoni semble affectionner particulièrement ce genre de milieu. On l'y observe généralement disséminé, individu par individu, dans chacune des petites retenues liquides étagées. Chaque Crustacé y reste immobile pendant de longues heures, parfois recouvert par moins d'un $\mathrm{mm}$ d'eau, mais excité, il est capable de se déplacer rapidement d'une flaque à l'autre, soit vers l'amont, soit vers l'aval, bien que l'épaisseur de la lame liquide intermédiaire soit inférieure à celle de l'Isopode qui émigre en compagnie d'un ménisque liquide. Cette particularité était déjà connue pour les Amphipodes cavernicoles du genre Niphargus. L'observation répétée (avec marquage par section du fouet d'une antenne) permet de noter que le même individu demeure parfois dans la même cuvette plusieurs mois de suite. La confection de petits barrages transversaux en argile compacte, séparant les cupules successives (fig. 19b), barrages que l'on retrouve perforés par les Crustacés d'une année à la suivante, montre que des migrations naturelles d'individus le long de la coulée liquide se produisent également. Si l'on introduit, dans une cuvette déjà habitée, un Sténaselle surnuméraire, les deux individus ne tardent pas à se rencontrer et l'un d'eux la quitte rapidement pour s'installer dans une poche liquide libre. Dans ces biotopes, j'ai pu observer des femelles gestantes: l'espèce s'y reproduit normalement.

La caractéristique de ces types d'écoulements souterrains, qui permet leur colonisation par des Asellotes dont la vie dure plusieurs années est leur permanence et 
leur régularité. La grotte de Peyort peut encore servir d'exemple pour montrer le rapport qui existe entre ces qualités et la possibilité de peuplement par St. virei: dans la partie antérieure de cette cavité et sur quelques dizaines de mètres seulement, on trouve trois venues d'eau de type différent:

a 1. Des écoulements très temporaires, directement liés aux précipitations, au niveau du vestibule (températures: $7^{\mathrm{O}} 3$ à $11^{\circ} 1$ ).

a 2. des écoulements également temporaires, mais plus durables, qui alimentent des gours stalagmités, (températures: $9^{\circ} 1$ à $11^{\circ} 2$ ).

a 3. les écoulements réguliers et permanents étudiés plus haut et qui sont les seuls peuplés par Stenasellus (températures: $9^{\circ} 7$ à 1206).

Un même jour de mars 1967 , l'eau du premier écoulement était à $7^{\circ} 3$, directement influencée par la température externe, celle des seconds à $9^{\circ} 1$ et enfin celles des écoulements peuplés à $11^{\circ} 3$, en accord avec la température moyenne de la grotte. Il est probable que les écoulements temporaires, non colonisés par les Sténaselles, représentent un cas de percolation temporaire typique, telle que Rouch (1968) l'a étudiée à l'Aven de Ste-Catherine (Ariège), tandis que l'eau des suintements permanents à Sténaselles a subi un séjour souterrain plus long, peut-être en partie en milieu interstitiel dans des formations d'altération des terrains surplombant localement la grotte. Le type de biotope souterrain constitué par les chenaux de suintement permanent au sein de la zone dénoyée des massifs karstiques semble donc convenir parfaitement à St. virei hussoni (de même qu'à la forme karstique cantabre St. v. buchneri). Le type de ruissellement souterrain visible à Peyort n'est évidemment observable que lorsqu'il recoupe une grotte accessible à l'Homme. On est pourtant obligé de supposer que ces écoulements à faible débit existent en nombre immense dans l'intimité des massifs calcaires, puisque chacun est infime et que ce sont eux qui assurent le transfert de l'eau infiltrée en surface vers les niveaux inférieurs du massif karstique où ils se réunissent pour alimenter les rivières souterraines actives. Cet ensemble de constatations et de déductions logiques nous amène à souscrire à l'affirmation de Rouch (1969) selon laquelle la grotte ne représente qu'une portion infime des biotopes occupés par les cavernicoles aquatiques à l'intérieur du massif karstique. Pour bien préciser ces problèmes, donnons un autre exemple qui se rapporte non à Stenasellus, mais à un Asellide anolphtalme. Ariagno et Ginet (1963), lors de leur étude de la topographie et de la faune de la grotte de Corveissiat (Ain) y ont fait des observations très intéressantes. Les Aselles (Proasellus cavaticus selon la détermination de J-P Henry) sont rares dans la rivière souterraine active qui parcourt la cavité. Pourtant, celle-ci reçoit un affluent latéral au débit modeste, mais régulier, dont le cours débute au fond d'un vaste puits vertical. Les eaux y parviennent, soit par chute libre des gouttes, soit par écoulement laminaire sur les parois verticales. Les auteurs avaient signalé que les Aselles vivaient sur le plancher de la galerie (gours et ruisseau), mais que ce biotope était surtout le domaine des Amphipodes (Niphargus virei). Les Aselles étaient beaucoup plus nombreux sur la paroi verticale mouillée où "ils forment de véritables placages de centaines d'individus". Ariagno et Ginet nous ayant aimablement communiqué les renseignements nécessaires, Henry et moi-même avons pu observer ce remarquable 
biotope et constater l'extraordinaire abondance des Asellides plaqués au rocher dans ce flux liquide pelliculaire migrant du haut vers le bas. Les très jeunes Niphargus se complaisent également dans ce milieu et, comme les Aselles, sont capables de s'y déplacer, tant en descendant le courant qu'en le remontant. Les suintements apportent en permanence de fins débris nutritifs et un volume très faible d'eau abrite une dense population de Crustacés, conséquence de son état pelliculaire sur la roche. Le biotope se maintient par suite de la régularité de débit du ruisellement, sans doute en relation avec l'épaisseur du toit rocheux et l'importance de la couverture pédologique et végétale. La connaissance de ces types de biotopes aquatiques souterrains permet de faire deux remarques. D'abord, on doit se garder de réduire le problème des circulations d'animaux aquatiques dans la zone dénoyée des massifs karstiques à un simple entraînement par le courant de l'amont vers l'aval. Cela n'est vrai qu'au niveau des grands vides dans le massif, c'est-à-dire lorsque la descente de l'eau a lieu en chute libre, depuis une voûte de grotte par exemple, mais c'est un cas particulier. La percolation doit surtout mettre en jeu une migration de l'eau à l'état très divisé sur les parois des fissures du calcaire. Les migrations actives vers l'amont dans ces écoulements pelliculaires sont parfaitement possibles, surtout pour des Crustacés marcheurs robustes. Pour Stenasellus virei, on peut même penser que les déplacements actifs sont la règle alors que l'entraînement passif par l'eau vers l'aval n'est qu'accidentel. Ensuite, il semble qu'au niveau de la zone de percolation temporaire des massifs karstiques les conditions de vie pour des Crustacés aquatiques de taille importante, comme Stenasellus, ne sont les meilleures que lorsque, pour des raisons géologiques ou climatologiques, la percolation temporaire devient localement une percolation permanente. Il est certain que la zone dénoyée des massifs karstiques couverts d'un lapiaz, sous un climat à longues périodes de sécheresse, n’offre qu'un abri médiocre ou nul à des Asellotes souterrains (cas du karst méditerranéen). Par contre, la même zone d'un massif garni d'un épais manteau forestier en climat régulièrement pluvieux leur sera beaucoup plus propice. C'est le cas des massifs nord-pyrénéens colonisés par St. virei hussoni, ce qui pourrait expliquer que, contrairement aux autres Stenasellidae, cette forme maintient de nombreuses populations dans les systèmes aquifères des "grottes fossiles".

\section{b. Ruissellements permanents et faibles ruisseaux}

Lorsque les écoulements cessent d'être laminaires et lents et présentent un lit propre avec un débit plus important (de l'ordre du litre par seconde, par exemple, ce qui correspond à des débits environ un millier de fois plus important que ceux des suintements évoqués plus haut), nous pouvons parler de ruisselets ou de ruisseaux souterrains et citer en exemple la grotte du Plagnol de la Plagne, dans le massif de Sourroque dominant St-Girons, Ariège (no 29) où St. virei hussoni est commun. Cette cavité très étroite et sinueuse correspond au lit même de ce faible ruisseau souterrain creusé dans les calcaires. Elle débute par un puits vertical circulaire d'une dizaine de mètres qui s'ouvre au fond d'une doline. Le puits absorbe les eaux épigées lors des précipitations ou de la fonte des neiges et sur ses parois suintent également les eaux interstitielles des formations d'altération surmontant le calcaire crétacé. L'alimentation en eau est donc permanente quoiqu'irrégulière. A la base de 
la verticale commence le lit du ruisseau dont le tracé utilise un décollement entre les masses calcaires. Ce lit est une succession de bassins étagés contenant chacun quelques litres ou dizaines de litres d'une eau très limpide. Le fond est garni de limon sableux noirâtre riche en matière organique provenant de l'humus et de la végétation superficielle. Entre les replats, l'eau forme des rapides qui cascadent sur la roche plus ou moins concrétionnée. La déclivité est forte et la galerie devient vite, vers l'aval, inaccessible. Vers l'amont, elle reçoit un affluent de même type. Les températures de l'eau relevées à la belle saison variaient de $9^{\circ}$ à $9^{\circ} 6$. A chaque visite, nous avons pu constater la présence de quelques Sténaselles adultes dans chacun des bassins. Les Isopodes vivent en compagnie de Niphargus sp., du Triclade Plagnolia vandeli et de l'Oligochète Pelodrilus leruthi, accompagnés de formes épigées venues avec les eaux. La faune de Sténaselles se renouvelle sans difficultés puisque les visites et collectes annuelles y ont été faites depuis 1960 sans qu'un appauvrissement du ruisseau ne se soit manifesté. Il est vrai que nous ne pouvons visiter qu'une partie infime du cours d'eau souterrain alors qu'il est probablement colonisé par les Sténaselles sur toute sa longueur. Il se pourrait que certains des Isopodes vivant au niveau du puits proviennent de populations installées dans le "milieu hypotelminorhéique" sus-jacent: écoulements hypodermiques dans les formations d'altération superficielles, donc du milieu interstitiel, comme le pense Meštrov (1962). Nous n'avons pu encore capturer de Sténaselles interstitiels à ce niveau pour vérifier s'ils appartiennent bien à la même forme que ceux de la grotte. De toute façon, si un tel entraînement existe, il ne s'agit que d'un phénomène local, car St. virei hussoni vit dans la quasi-totalité des cavités du massif de Sourroque contenant de l'eau, colonisant entièrement le massif karstique. Si de nombreuses stations de St. virei hussoni appartiennent à ce type (no 4, 18, 22, 23, 25, 26, 29, $31,36,40$, etc..., par exemple), le biotope constitué par les ruisseaux souterrains n'a fourni que peu d'indivichus au total et je n'ai pas utilisé ceux-ci pour la réalisation d'élevages. En effet, à ces écoulements souterrains correspondent en général des conduits extrêmement étroits et irréguliers et il est rare que l'on puisse observer et prospecter le lit de tels ruisseaux sur plus de quelques metres ou dizaines de mètres: le biotope est important pour l'espèce, mais impropre à la collecte des individus.

\section{Biotopes des rivières souterraines actives}

"Les rivières souterraines qui forment des sources à la sortie des cavernes (Baumeles-Messieurs, par exemple, dans le Jura), charrient évidemment des animaux souterrains". (Viré 1899)

Les premières explorations qui ont mis St. virei en évidence dans le milieu cavernicole furent effectuées dans des cavités dans lesquelles l'eau était présente en petites quantités, soit sous forme de faibles écoulements, soit condensée en accumulations calmes. Les grottes décrites à ce titre sont en général situées à des niveaux très supérieurs au plan des vallées actuelles et sur le trajet d'infiltrations aqueuses internes au massif, de direction générale verticale. Ces cavités correspondent souvent à des restes de conduits souterrains autrefois occupés par un réseau de 
cours d'eau actifs. Or ce dernier type de cours d'eau existe encore et Viré pouvait déjà évoquer la présence de formes troglobies aquatiques dans ce milieu dont le torrent de Baume-les-Messieurs est un bon exemple.

Dans les massifs karstiques où vit St. virei, les eaux infiltrées sortent à l'air libre par une série d'exutoires à fort débit qui se raccordent directement au réseau hydrographique de surface en donnant de gros ruisseaux ou de véritables rivières: Grottes de Ste-Hélène ( $\left.\mathrm{n}^{\mathrm{O}} 14\right)$, de la Maouro ( $\left.\mathrm{n}^{\mathrm{O}} 22\right)$, de St-Paul ( $\left.\mathrm{n}^{\mathrm{O}} 51\right)$, du Sauvajou ( $\left.\mathrm{n}^{\mathrm{O}} 54\right)$, du Goueil-di-Her ( $\mathrm{n}^{\mathrm{O}}$ 65) et d'Aliou ( $\left.\mathrm{n}^{\mathrm{O}} 68\right)$, par exemple. Elles sont peu nombreuses à la périphérie d'un massif karstique mais chacune collecte les eaux infiltrées d'une superficie considérable du massif. C'est-à-dire qu'elles sont alimentées par des systèmes extrêmement développés et ramifiés de conduits afférents. Le cas de la station originelle de l'espèce, le Gouffre de Padirac, nous offre un aperçu des difficultés pratiques de l'observation et de la capture d'un Isopode marcheur dans un tel milieu. En effet, St. virei virei y fut d'abord pêché dans un faible ruisseau annexe de la Rivière Plane, à quelques exemplaires seulement. En 1913, Fage et Racovitza le retrouvèrent, toujours par observation directe, dans une zone d'eau calme de la rivière (température 1202). Par contre, en 1963, je n'ai pu noter la présence et capturer de nombreux Sténaselles qu'en eau profonde ( 2 à $3 \mathrm{~m}$ ) (température: $13^{\mathrm{O}}$ ). Il n'est plus question de pouvoir observer directement le Crustacé dans de telles conditions, mais le piégeage, au moyen de balances appâtées, paraît indispensable. Le problème se pose de la même manière pour les rivières souterraines nord-pyrénéennes. En 1919, Chappuis, Fagniez et Jeannel eurent la chance de capturer quelques St. virei hussoni dans les laisses d'eau de la grotte de Ste-Hélène, près de Foix. Or, cette présence, comme j'ai pu le constater en 1967, semble purement accidentelle. La cavité abrite un torrent souterrain au débit si important et au cours si turbulent que toute observation et toute pêche y semblent impossibles. Les rivières souterraines permanentes offrent donc un milieu hostile aux activités des biospéléologues, c'est peut-être pourquoi elles ont, pendant longtemps, été considérées comme pauvres en faune aquatique. Ainsi, la rivière souterraine d'Aliou citée plus haut, l'un des drains principaux du massif de l'Estelas, au centre de l'aire de St. virei hussoni, a été prospectée à de multiples reprises depuis 1966. Un seul Crustacé y a été pêché à vue par C. Bou, car la prospection ne peut se faire qu'en canot pneumatique! A la Tute de Jovis inférieure $\left(\mathrm{n}^{\mathrm{O}} 60\right)$, je n'ai capturé que $2 S$. virei hussoni adultes dans le cours souterrain, ayant pu atteindre un point où la profondeur ne dépassait pas $1 \mathrm{~m}$, avec une eau suffisamment claire et calme, sur fond sableux.

La grotte du Goueil-di-Her montre un cas plus favorable (Rouch 1968). L'important ruisseau pérenne qui draine le massif d'Arbas présente des variations de niveau considérables (Lescher-Moutoué et Gourbault 1970) et, en 1966, j'ai pu trouver quelques St. virei hussoni adultes dans des laisses de crue de la portion aval de la cavité. Le cours d'eau souterrain possède une annexe d'eau calme, vaste plan liquide avec une voûte mouillante fermant normalement la galerie vers l'amont (températures notées: $7^{0} 9$ à $8^{\circ} 5$ ). En août 1967 , à la suite de travaux effectués par des groupes spéléologiques, ce grand siphon s'est trouvé désamorcé, ce qui, dans les conditions naturelles, était un phénomène rarissime (Jeannel 1943) et le lac réduit à 
une minuscule nappe de quelques $\mathrm{dm} 2$. Nous avons pu constater que la population de Sténaselles vivant normalement disséminée sur une vaste surface immergée s'était concentrée dans cette mare résiduelle à fond limoneux. Recueillie, elle sera étudiée plus loin comme exemple de peuplement karstique non confiné. Le fond de la nappe siphonante est constitué par des dépôts de graviers limoneux imbibés d'eau et abritant une riche faune interstitielle (Rouch 1968), parmi laquelle les Sténaselles sont abondants, tandis que les alluvions grossières du ruisseau, qui communiquent avec le milieu précédent, abritent également dans leurs interstices de nombreuses espèces (Lescher-Moutoué et Gourbault 1970). St. virei hussoni est donc bien représenté dans le système de la rivière souterraine active, tant en eau libre que dans les alluvions. Cette constatation peut être répétée pour les autres stations de même type et on peut conclure que St. virei colonise normalement la zone des massifs karstiques dans le plan des rivières souterraines actives de nos jours. Elle y forme d'importants peuplements permanents. Toutefois, les Crustacés ne se trouvent que rarement dans les portions à cours rapide, en pleine eau.

Quant au rejet d'animaux hypogés aquatiques par les exsurgences évoqué par Viré, il m'a été possible de l'observer pour St. virei hussoni. A l'époque des hautes eaux, des sources karstiques pérennes expulsent des individus dont on retrouve parfois les adultes, soit au niveau de l'exutoire, cramponnés à des galets, soit à plusieurs mètres en aval. C'est le cas des sorties d'eau permanentes du Goueil-di-Her où quelques St. virei hussoni ont été observés (Lescher-Moutoué et Gourbault 1970) en compagnie d'un Asellide souterrain qui vit dans le même réseau: Proasellus racovitzai. C'est également le cas à la source du Bousquet, près de St-Girons, où j'ai pu capturer une $\$$ adulte de St. virei hussoni en pleine lumière, sur un amas de Spirogyres, avec l'Asellide pigmenté et oculé Proasellus meridianus. A la saison humide les orifices fossiles des systèmes karstiques actifs peuvent également se mettre en eau et les Sténaselles peuvent migrer jusqu'à ce niveau: c'est le cas de la "source" de Campet, dans le massif de Sourroque ( $\left.\mathrm{n}^{\mathrm{O}} 100\right)$ où des individus isolés sont parfois visibles dans la partie éclairée. Toutes ces données restent fragmentaires et seules des méthodes plus perfectionnées de capture, telles que le filtrage continu des eaux à l'exutoire, méthode qui fut innovée par R. Leruth, permettront de réaliser une étude quantitative du rejet d'organismes aquatiques souterrains, et plus particulièrement de Crustacés (Lescher-Moutoué 1973, Rouch 1972).

\section{Peuplements des cavités perpétuellement ennoyées}

Lorsque dans une série calcaire horizontale ou monoclinale est intercalé un horizon imperméable situé à une altitude supérieure aux vallées actuelles, la karstification s'y trouve arrêtée par un écran et les eaux souterraines infiltrées se réunissent au contact de la couche imperméable et donnent des séries d'exsurgences qui s'alignent dans la topographie: c'est le cas des fausses sources jaillissant au pied des corniches bajociennes en pays jurassique bourguignon (Ciry 1962). Si, au contraire, les formations calcaires se développent en dessous du niveau des vallées actuelles, par suite de leur grande épaisseur, la karstification a pu s'étendre loin en dessous de ce niveau, soit par suite des variations du niveau de base, soit par le jeu des cassures naturelles 

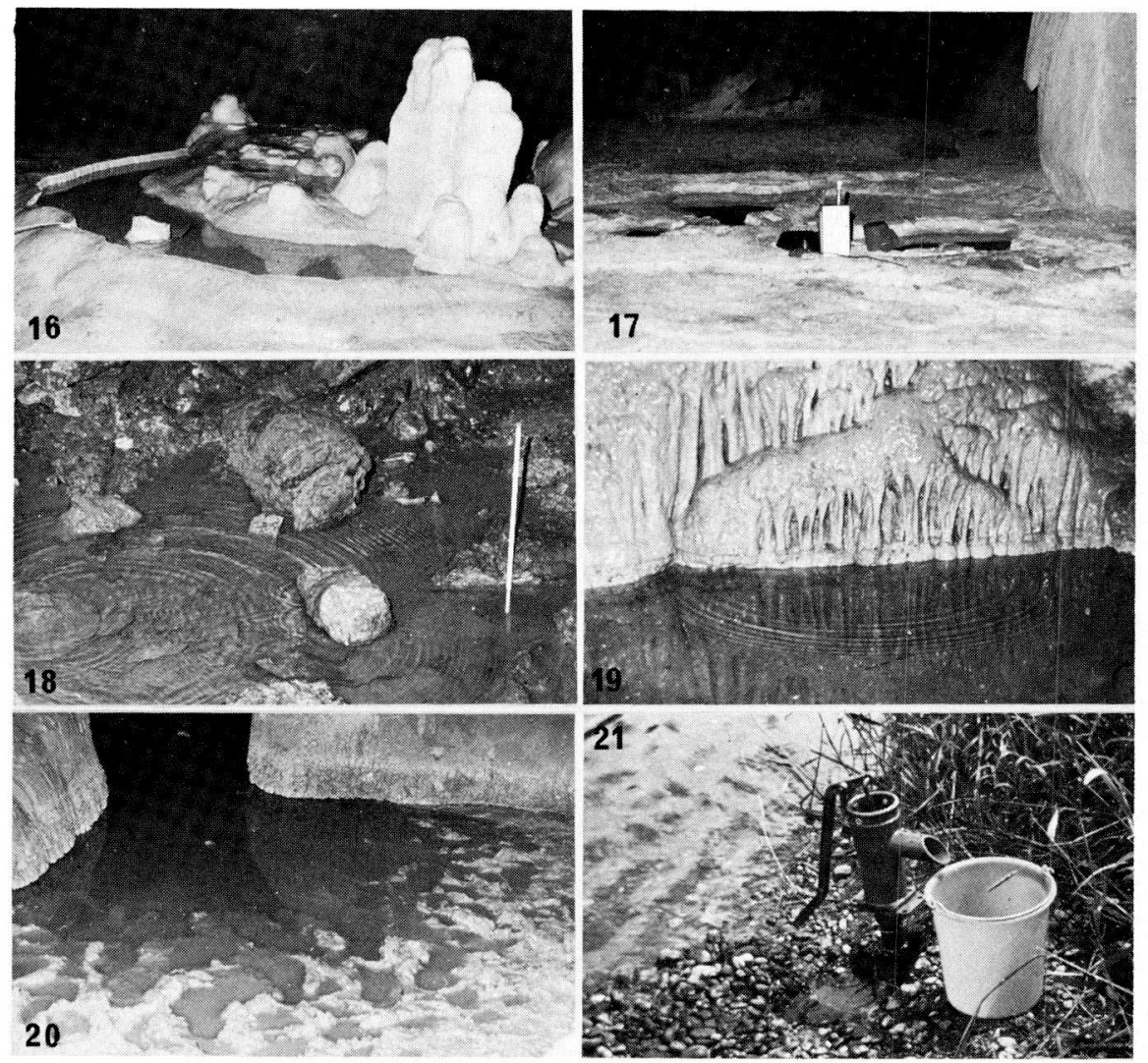

PLANCHE VI

16. Un gour de la grotte de la Tute du Chef ( $\mathrm{n}^{\mathrm{O}} 37$, cf. Magniez 1967/68, p.56). La mise en eau est trop épisodique pour permettre à St. virei hussoni d'y subsister.

17. Flaques à fond stalagmité à la grotte de l'Estelas ( ${ }^{\circ}$ 6, cf. Magniez 1967/68, p.42): habitat précaire de quelques St. virei hussoni.

18. Petite flaque pérenne à fond argileux de la grotte de la Tute de Jovis supérieure $\left(\mathrm{n}^{\mathrm{O}} 27, \mathrm{cf}\right.$. Magniez 1967/68, p.53): habitat permanent de quelques St. virei hussoni.

19. Vasque de la grotte du Mont-de-Chac ( ${ }^{\circ}$ 3, cf. Magniez 1967/68, p.40), en période de hautes eaux (alimentation par suintements sur la coulée calcitique, cf. texte).

20. Partie aval du lac souterrain de l'Estelas à l'étiage (cf. texte). On y trouve la plus belle population cavernicole accessible de St. virei hussoni.

21. Sondage tubé Bou-Rouch $(1,10-1,20 \mathrm{~m})$ dans la nappe alluviale de la Dordogne à Beaulieu, Corréze (station $n^{0}$ 104, St. virei virei, cf. texte, fig. 26 et Magniez 1971a, p.21). 
dans le calcaire (Gèze 1958, Ciry 1962, Rouch, Juberthie C. et Juberthie L. 1968). Il en résulte l'existence de systèmes de cavités perpétuellement ennoyées, conduits ou fissures, dont les eaux doivent suivre un cheminement remontant pour faire retour au réseau hydrographique, soit par des exutoires libres, soit par diffusion sous-alluviale (Trombe 1952). Dans certains cas favorables, des cavités noyées peuvent être visitées par des spéléologues munis d'appareil respiratoire (De Lavaur 1950). En général, on doit se contenter de noter dans certaines grottes, l'existence de conduits qui se prolongent en contre-bas du niveau permanent du cours d'eau souterrain. Ce sont donc de simples regards sur les systèmes karstiques noyés. Parmi les stations cavernicoles de St. virei connues, peu d'exemples typiques peuvent être cités. Toutefois, les cavités du Bédat à Bagnères de Bigorre, Hautes-Pyrénées ( no 10) ou de Ste-Catherine à Balaguères, Ariège ( $\mathrm{n}^{\mathrm{O}}$ 33) permettent d'observer des systèmes de conduits ennoyés en permanence et dont la zone superficielle abrite des populations de St. virei hussoni. Comme le montre Rouch (1968), le filtrage continu à leur exutoire des eaux ayant transité dans ces karts noyés permet de se faire une idée précise sur leur peuplement, pour St. virei hussoni dans les massifs nordpyrénéens (Rouch 1970), comme pour St. buili dans le karst des Corbières et de l'Hérault (Rouch, Juberthie C. et Juberthie L. 1968).

\section{E. Conclusion: Stenasellus virei en milieu karstique}

Au terme de cette description sommaire des différents biotopes observés pour les sous-especes karstiques de Stenasellus virei, il apparait que chacun peut être situé dans l'une des trois zones superposées que les hydrogéologues reconnaissent dans un massif karstique typique:

- La zone supérieure ou zone de percolation, appelée parfois zone d'infiltration et de ruissellement souterrain ou zone dénoyée.

- La zone moyenne ou zone amphibie (Rouch 1968), ou zone de circulation permanente (Gèze 1968) = galeries amphibies de Cavaillé (1964). Elle est moins facilement accessible et l'étude de sa faune est plus récente (Lescher-Moutoué et Gourbault 1970, Rouch 1970).

- La zone inférieure ou zone noyée ou zone d'imbibition générale (Gèze 1958). Son développement est tributaire de conditions géologiques ou paléohydrographiques favorables (systèmes holokarstiques). Les peuplements de St. virei dans chaque zone pourront donc se définir de la manière suivante:

\section{Peuplements de la zone de percolation temporaire}

Dans la zone supérieure des massifs karstiques, le peuplement (St. virei hussoni pour les Pyrénées centrales, St. virei buchneri pour les massifs urgoniens cantabres) n'est que très partiellement observable au niveau des grottes. Il est essentiellement aléatoire et tributaire de conditions hydrologiques locales favorables.

a. Souvent, les accumulations d'eau dans les grottes de cette zone sont temporaires. Elles s'assèchent chaque année. Les cas d'alimentation par une véritable percolation temporaire ont été étudiés par Rouch (1968) en particulier. Flles ne permettent pas l'installation des Sténaselles, mais tout au plus la présence périodique des Copépodes souterrains dans les gours, par migration à partir de l'aval. 
b. Lorsque des accumulations d'eau de ces cavités sont permanentes, bien alimentées par l'infiltration et le ruissellement souterrains, même si le débit est faible et d'origine exclusivement karstique: cas du Mont-de-Chac, de Liqué (Delay 1968), elles peuvent éventuellement donner asile à des populations permanentes de Sténaselles. Les apports d'individus provenant de l'amont sont exceptionnels et négligeables par rapport au groupe concentré dans le bassin.

c. Lorsque les collections d'eau sont permanentes et alimentées abondamment et régulièrement par un ruissellement souterrain pérenne, éventuellement soutenu par des infiltrations de nappes éluviales contigües ou superposées, les possibilités de vie de l'espèce se multiplient et on peut observer des apports d'individus provenant de l'amont. Les circulations liquides à faible débit (suintements, ruisseaux, ruissellements permanents) sont très largement peuplées par l'espèce, les individus se répartissant tout au long de la veine liquide.

d. Dans tous les cas, la présence de Sténaselles, parfois d'un seul individu, dans une cavité, est l'indice du peuplement de la zone supérieure du massif par l'espèce. Les individus de la grotte ne représentent qu'un accident local de répartition et la masse des peuplements se trouve dans des systèmes aquifères inaccessibles à l'Homme. Réciproquement, l'absence de Sténaselles dans une grotte "aérienne" d'un massif n'est pas une preuve de l'absence de l'espèce dans le massif: elle peut y vivre dans des systèmes de percolation non recoupés par la grotte et surtout dans les niveaux inférieurs ennoyés du massif. Il est vraisemblable que des fluctuations saisonnières et surtout pluriannuelles des peuplements de Sténaselles se produisent dans le massif karstique. Elles seraient tributaires des fluctuations hydrologiques. Au niveau de la grotte, elles se traduisent par la plus ou moins grande extension des peuplements dans les collections d'eau dont le régime hydraulique se modifie. Au niveau $\mathrm{du}$ massif, les fluctuations se traduiraient par l'apparition épisodique d'individus dans une grotte normalement non peuplée, lors d'un regain d'humidité, ou par la disparition temporaire de la population d'une grotte habituellement colonisée par l'espèce.

\section{Peuplements de la zone amphibie}

Dans le plan des cours d'eau actifs qui drainent les massifs karstiques, St. virei hussoni a pu être mis en évidence en eau libre. La densité des individus parait faible, par suite du grand volume des eaux et de leur mouvement. En fait l'observation et la capture offrent des difficultés considérables, mais il s'agit d'un biotope normal pour l'espèce.

Lorsque les rivières souterraines déposent dans leur lit des alluvions grossières (galets, graviers, sables), elles possèdent un véritable milieu interstitiel sous-jacent. Dans ce sous-écoulement, de grands peuplements permanents de St. virei hussoni existent, au même titre que dans l'eau karstique libre. Du point de vue écologique, on peut rapprocher ce fait de l'installation de $S t$. virei dans les nappes phréatiques des formations perméables en petit (voir plus loin). 


\section{Peuplements de la zone noyée}

En raison de l'environnement géologique et de la topographie locale, il est difficile de donner une idée précise du développement des réseaux holokarstiques dans les massifs calcaires des Pyrénées centrales. Dans un cas géologiquement plus favorable, les chercheurs du laboratoire souterrain de Moulis ont montré que la zone noyée d'un massif languedocien abrite une faune aquatique d'une grande richesse, beaucoup plus diversifiée que celle de la zone de percolation sus-jacente, avec en particulier la présence de Stenasellus buili. Dans le domaine pyrénéen, la situation de certaines cavités, qui fonctionnent comme des regards sur des systèmes occupés en permanence par l'eau et qui rejettent St. virei hussoni lors des crues (Rouch 1970,1972 ) indique que la zone inférieure des réseaux holokarstiques abrite des peuplements permanents de l'espèce. Pour des raisons climatiques, on peut penser que les autres Stenasellidae karstiques (Stenasellus du Portugal méridional, des Balkans, de Corse et Sardaigne, de Somalie, Metastenasellus du Congo) sont essentiellement inféodés à la zone d'imbibition générale des karsts qui les abritent.

Dans les limites de l'aire de l'espèce, les sous-espèces karstiques St. virei hussoni et $S t$. virei buchneri peuvent coloniser le massif calcaire à tous les niveaux. Leur présence dans les horizons où l'eau existe en permanence est un fait très général. Leur maintien dans la zone d'infiltration et de ruissellement est un phénomène aléatoire, tributaire de circonstances locales favorables (existence d'un climat atlantique régulièrement humide dans l'aire des formes pyrénéennes et cantabres).

\section{Question de la température des biotopes karstiques}

Pour les stations de St. virei hussoni, les températures extrêmes sont de $5^{0} 7$ et de $14^{\circ}$, correspondant respectivement à des grottes situées à plus de 1000 mètres, d'une part, et à moins de 400 mètres d'autre part. Toutefois, les biotopes dont la température est inférieure ou égale à $7^{\circ}$ semblent ne jamais correspondre à des stations populeuses. Le lac de l'Estelas $\left(8^{\circ}\right)$ mis à part, cette dernière catégorie correspond en général à des températures comprises entre 9 et $12^{\circ}$. Retenons également que pour une même station, il est toujours relevé une variation annuelle de température. Rarement, celle-ci ne dépasse pas quelques dixièmes de degré. Le plus souvent, elle atteint $1-2^{\mathrm{O}}$. De plus, il semble exister une certaine fluctuation pluriannuelle de la température, mais sa démonstration demanderait des relevés soigneux sur de longues périodes.

\section{BIOTOPES NON-KARSTIQUES DE ST. VIREI}

\section{A. Historique}

1. Capture en plaine dans un puits maçonné: En 1950, lorsque fut publiée la monographie posthume de Racovitza sur Stenasellus, l'espèce virei n'était connue que de 19 stations: Le gouffre de Padirac et le Solencio de Morrano pour St. virei virei, 2 grottes de la province de Santander pour St. virei buchneri et 15 cavités des Pyrénées centrales pour St. virei hussoni (Magniez 1968a). Chappuis, dans la préface du travail de Racovitza signale simplement, sans y accorder une importance parti- 
culière, que l'espèce vient d'être récoltée dans un puits à Toulouse. Cette découverte due à G. Taberly, au cours de ses recherches sur la faune phréatique des puits de la ville, est pourtant à l'origine des données actuelles sur ce nouveau type de biotope de l'Isopode et aurait dû attirer l'attention.

La station ( $\mathrm{n}^{\mathrm{O}} 20$ ) est un puits maçonné, situé dans une propriété du quartier St-Cyprien, au S-W de Toulouse. D'une profondeur d'environ $7 \mathrm{~m}$, il est creusé dans des graviers grossiers constituant les alluvions récentes de la Garonne, à quelques centaines de m seulement du lit du fleuve. Le 2 -06- 1949 fut capturée une $\$$ adulte de $9 \mathrm{~mm}$ et dans les mois suivants plusieurs autres adultes. J'ai pu vérifier ultérieurement qu'il s'agissait de la forme type, St. virei virei, comme à Padirac. En 1966, je n'ai pu capturer de Sténaselles dans le puits, mais vérifier que l'eau, violemment aspirée par une pompe électrique contenait une intéressante faune hypogée: petits Niphargus sp., Salentinella major Barbé, Microcharon sp., Cyclopides et Harpacticides. Cette découverte de Taberly présentait un intérêt considérable:

a. Cette station est située à quelques $70 \mathrm{~km}$ au Nord des grottes des Pyrénées centrales abritant l'espèce, mais à $140 \mathrm{~km}$ au Sud du Gouffre de Padirac. Elle fournit donc le premier indice de peuplement en Sténaselles de la zone intermédiaire.

b. Elle se trouve très éloignée de tout massif karstique (la région toulousaine est le domaine des molasses tertiaires), ce qui exclut tout apport de faune par migration latérale. Le puits, creusé dans les graviers quaternaires, est à une bonne distance du lit mineur du fleuve, ce qui élimine toute possibilité d'apport par les eaux épigées. Comme je l'avais signalé plus haut, il n'est pas impossible de trouver des Sténaselles dans les eaux épigées, mais c'est toujours à faible distance d'un exutoire: une source voisine de St-Girons ( $n^{\mathrm{O}} 88$ ) m'a permis de capturer une $q$ adulte en pleine lumière, dans une végétation d'algues vertes, à environ $5 \mathrm{~m}$ en aval de l'exsurgence.

$\mathrm{Au}$ niveau du puits de Toulouse, les eaux phréatiques circulent aisément dans les graviers, comme le montrent les essais de pompage du puits, effectués avec l'aimable collaboration du propriétaire et l'observation de la remontée rapide du niveau. Les interstices entre les éléments permettent donc l'existence et les libres déplacements de populations de Crustacés dont les adultes ( $($ ) peuvent dépasser de peu $9 \mathrm{~mm}$ dans cette station. Il va de soi que le puits ne représente qu'un point singulier d'un milieu liquide hypogé qui fait partie de la nappe phréatique latérale au fleuve et dont le cas sera envisagé d'une manière plus générale.

2. Capture dans le lit d'une rivière de montagne: Au cours de ses recherches écologiques et biogéographiques sur la faune des sables submergés, Angelier (1953b) effectua à partir de septembre 1949 de nombreuses prospections le long des rivières pyrénéennes et particulièrement de la Têt. Au niveau de Thuès-les-Bains (Pyrénées Orientales), ce fleuve côtier est encore un torrent rapide dont la vallée s'encaisse profondément dans le massif granitique du Carlitte. Le lit mineur du cours d'eau est encombré d'amoncellements de blocs, galets et graviers. Au niveau de l'établissement thermal existaient des bancs de sables grossiers découverts à l'étiage. Une 
trentaine de sondages selon le procédé Karaman-Chappuis lui permirent de récolter 3 jeunes Sténaselles à côté d'une riche faune psammique (station no 21). Cette découverte resta un fait isolé et exceptionnel et l'auteur se contenta de noter que St. virei était surtout une espèce troglobie, rare dans les sables submergés. Son intérêt était pourtant égal à celui de la découverte de Taberly à Toulouse. St. virei était à nouveau trouvé loin de son aire supposée de répartition (à $70 \mathrm{~km}$ à l'Est des stations ariégeoises les plus orientales), dans une région dépourvue de massifs karstiques et dans un milieu aquatique lié à une rivière, très superficiel, bien qu'hypogé. A la suite de captures ultérieures dues à N. Coineau, j'ai pu reconnaitre que les Sténaselles des rivières catalanes devaient constituer une sous-espèce particulière (St. virei angelieri). Dès cette époque et compte tenu du site des captures, on était en droit de penser que ces quelques individus ne pouvaient représenter une curiosité écologique isolée et que de véritables populations extrakarstiques colonisaient les eaux phréatiques de cette région.

3. Capture dans une source vraie: Juste au Sud du village de Moulis s'élève le massif de calcaires et dolomies jurassiques dans lequel se développe le système karstique complexe, à plusieurs étages superposés, de la grotte de Moulis, dans laquelle est installé le laboratoire souterrain du CNRS. Ce relief représente un flanc de pli anticlinal faillé et immédiatement à l'Est de la masse calcaire vient, en contact anormal, une série synclinale crétacée avec des schistes aptiens et albiens très redressés (Meštrov 1962, Bouillon 1964). Sur ces terrains imperméables en forte pente se trouvent des formations d'altération de la roche-mère (limons avec plaques de schistes) mêlés sur les hauteurs avec des éboulis jurassiques. Localement la roche nue affleure (fig. 20d). Cette structure donne lieu à l'existence d'une série de sources étagées, alimentées par l'eau infiltrée dans les formations superficielles poreuses. La principale est dénommée Fontaine des Oiseaux $\left(\mathrm{n}^{\mathrm{O}} 44\right)$. En période de hautes eaux et par basse température (janvier 1962), Bouillon et Meštrov y découvrirent quelques Sténaselles, en compagnie de Niphargus sp., Pelodrilus leruthi et Triclades obscuricoles. Les eaux de ces sources s'écoulent vers le réseau hydrographique situé en contre-bas (lit du Lez). Les deux auteurs ont donc montré par leurs captures, la présence de Stenasellus virei (subsp. hussoni identiques à ceux de la grotte de Moulis toute proche) dans le bassin d'alimentation d'une source vraie, de terrains non karstiques, sur un versant montagneux, au sein de l'aire connue de l'espèce. C'est le troisième type des milieux phréatiques abritant l'Isopode.

\section{B. Stenasellus virei dans les nappes alluviales récentes}

1. Garonne: La découverte de l'espèce dans un puits à Toulouse nous invite à examiner en détail la nature du milieu correspondant. D'après la dernière édition de la carte géologique au $1 / 80$ 000 ème de Toulouse, la zone où se trouve la station correspond à la basse plaine de la Garonne, qui ne s'élève que de 8 à $15 \mathrm{~m}$ au dessus du niveau d'étiage du fleuve. Elle était partiellement submergée lors des crues catastrophiques avant que les travaux humains ne la préservent. Au niveau du quartier St-Cyprien de Toulouse, cette basse plaine atteint $4500 \mathrm{~m}$ de largeur. Elle est donc beaucoup plus large que le lit moyen proprement dit du fleuve qui ne mesure que 500 à $800 \mathrm{~m}$. Cette basse plaine est formée au sommet par 1-2 $\mathrm{m}$ de limons d'inondations déposés par les crues, parfois surmontés de sol historique constitué depuis l'époque gallo-romaine. Sous les 
limons se trouvent des dépôts grossiers: sables et surtout cailloutis souvent volumineux. Ces nappes de graviers et galets comprennent des éléments roulés de quartz, quartzites, lydiennes, schistes plus ou moins métamorphiques, gneiss et granites, parfois de grès et calcaires, provenant tous de la chaîne axiale pyrénéenne ou des massifs sous-pyrénéens. Ces alluvions grossières ont été datées, car leur base a fourni à Toulouse même des restes d'une forme évoluée d'Elephas primigenius. Il s'agit donc d'alluvions déposées par la Garonne à partir des derniers temps de la glaciation würmienne et jusqu'à l'époque historique. Les alluvions plus anciennes du cours d'eau forment latéralement aux précédentes des terrasses plus ou moins surélevées selon leur âge (Chaput 1924, 1927). Ces graviers de la basse plaine n'existent naturellement pas seulement au niveau de Toulouse. Il est important de montrer que la vallée actuelle de la Garonne forme un véritable chenal d'alluvions postglaciaires où les éléments grossiers dominent (fig. 20A). Dès la région sous-pyrénéenne, ce chenal atteint environ $1000 \mathrm{~m}$ de largeur. Au niveau de Muret, il se développe transversalement sur quelques $2500 \mathrm{~m}$ et il se poursuit en aval de Toulouse, atteignant ou même dépassant fréquemment $5000 \mathrm{~m}$. On retrouve ces alluvions récentes jusque dans le cours inférieur du fleuve, avec un grain qui demeure grossier. Le chenal de la Garonne finit par se confondre avec celui de la Dordogne dont les alluvions de même structure sont formées par des fragments rocheux arrachés au Massif Central. On peut donc considérer que le fleuve coule au sein de ces dépôts récents. Du point de vue hydrologique ce sont même deux entités inséparables: les alluvions sont très perméables et imbibées par une nappe permanente qui est en équilibre constant avec le niveau épigé. Il ne s'agit pas d'une nappe captive ou immobile, mais d'un véritable flux souterrain qui double latéralement le cours superficiel, les eaux interstitielles migrant de l'amont vers l'aval. Toutes les données géologiques sur ces alluvions de basse plaine de la Garonne montrent que la station à St. virei virei de Toulouse n'est qu'un point banal d'un immense chenal aquifère qui accompagne le fleuve sur des centaines de $\mathrm{km}$ et qui est susceptible d'abriter les Crustacés en tout point où la granulométrie le permet.

Si la vallée de la Garonne est le chenal alluvial directeur du bassin aquitain, elle n'est pas seule à présenter cette structure. En effet, tous ses grands affluents, qu'ils viennent du Massif Central (Lot, Tarn, etc...) ou des Pyrénées (Ariège, Salat, Neste etc...), surtout dans la partie de

\section{FIGURE 20}

Stenasellus virei en milieu interstitiel

A. Capture de Stenasellus virei virei dans un puits maçonné $(\mathrm{P})$ en ville de Toulouse (station $n^{\mathrm{O}}$ 20). Le biotope est constitué par la nappe des graviers de la basse plaine de la Garonne (a2a) qui sont surmontés de limons d'inondation et de sol historique. L'espèce peut coloniser aussi les graviers et galets du lit (a2b) (L). La vallée est creusée dans des terrains molassiques oligomiocènes imperméables $(\mathrm{T})$.

B. Coupe transversale très schématique d'une grande vallée alluviale en plaine (Garonne). Largeur totale $=5 \mathrm{~km}$ environ. $\mathrm{T}=$ terrains tertiaires imperméables; $\mathrm{a} 1 \mathrm{a}=$ haute terrasse; $\mathrm{a} \mathbf{b}$ $=$ moyenne terrasse $; \mathrm{a} 1 \mathrm{c}=$ basse terrasse $; \mathrm{a} 2 \mathrm{a}=$ alluvions de basse plaine $(\mathrm{P}=$ puits maçonné $)$; $\mathrm{a} 2 \mathrm{~b}=$ alluvions les plus récentes $\mathrm{du}$ lit du fleuve $(\mathrm{G}=$ Garonne $) ; \mathrm{S}=$ sources d'alluvions. Seules les nappes fonctionnelles de basses plaines et de basses terrasses ont montré jusqu'à présent des peuplements de Sténaselles (Garonne, Tarn, Dordogne).

C. Recherche de Stenasellus virei dans le sous-écoulement d'un cours d'eau A = graviers et galets du lit de la rivière $(\mathrm{R}) ; \mathrm{D}=$ terrains encadrants (alluvions colmatées par exemple); les Sténaselles ont d'abord été découverts dans ce biotope par sondage Karaman-Chappuis (KC) (Angelier 1949). La méthode des sondages tubés Bou-Rouch (BR) se montre beaucoup plus efficace pour la mise en évidence de cette faune interstitielle (St. virei virei; St. virei angelieri; St. virei boui)

D. Sur un versant formé de terrains schisteux (T) imperméables, les formations superficielles (E = éluvions et colluvions) donnent lieu à l'existence de nappes phréatiques locales (N) dont les exutoires sont des sources de déversement (S). Le schéma est complété par un massif calcaire karstifié (C) avec ses cavités et une vallée alluviale (V). Il peut correspondre à la station $n^{0} 44$, mise en évidence par Bouillon et Meštrov en 1962. 


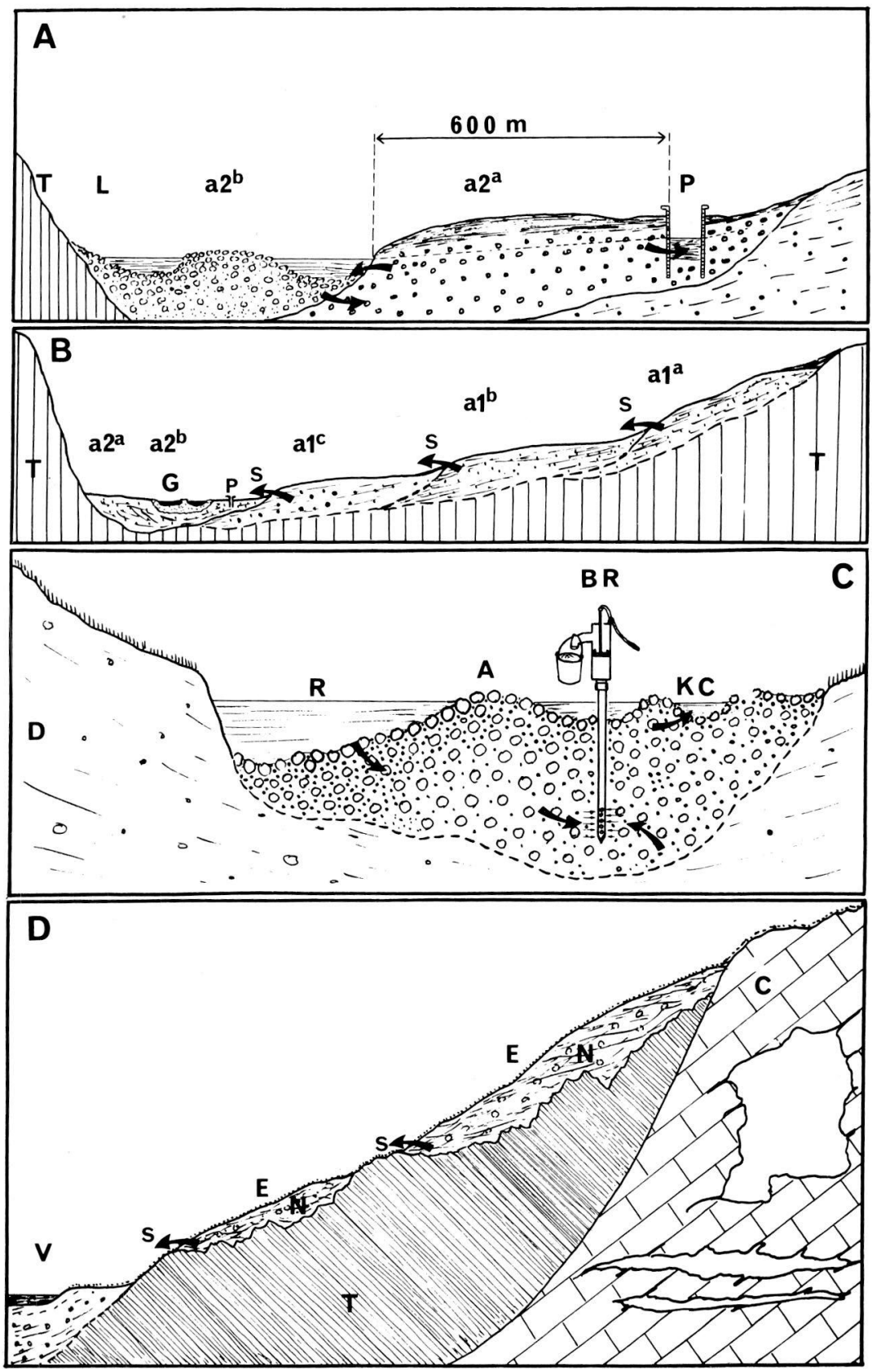


leurs cours installée dans le substratum molassique tertiaire peu induré, ont construit de larges chenaux d'alluvions récentes et possèdent leur propre flux souterrain en équilibre avec la rivière épigée, tandis que leurs terrasses d'alluvions anciennes se développent en gradins surélevés. Comme le disait fort justement Chappuis (1946 p. 1): "Toute vallée, pour ainsi dire, a un fleuve apparent épigé et un fleuve souterrain qui est composé par les eaux qui s'infiltrent à travers les alluvions qui remplissent forcément la vallée...". L'existence de ces nappes fluviales est donc une réalité physique constante. Elles sont propres non seulement au fleuve et à ses affluents principaux, mais on peut les retrouver jusque dans les vallées des rivières secondaires, partout où celles-ci ont alluvioné récemment. Elles ne sont interrompues que lorsque la rivière s'est enfoncée récemment dans un substratum de roches dures encore en voie d'érosion (cas du Salat au niveau de St-Lizier, Ariège). Il y a donc là un vaste domaine d'eaux souterraines qui s'offre à la faune phréatique. Il semble que Leruth (1938) ait été l'un des premiers, en étudiant le cas des graviers de la Meuse, à soupçonner l'importance de son développement géographique et peut-être sa continuité longitudinale et à comprendre que pour l'étude systématique de la faune peuplant ce milieu la mise à contribution de tous les puits maçonnés ou tubés s'approvisionnant dans la nappe était nécessaire.

2. Tarn: De sa jonction avec la Garonne, près de Moissac, jusqu'à son encaissement dans le socle paléozoïque à St-Juéry, le Tarn coule dans une large vallée alluviale déblayée dans les molasses tertiaires. Au niveau d'Albi, on note un grand développement transversal des basses terrasses (les plus récentes). La rivière coule dans ses alluvions subactuelles à plusieurs mêtres en contre-bas, par suite d'une reprise d'érosion. Etudiant la faune des eaux souterraines de l'Albigeois, Bou (1968) fut amené à prospecter les puits maçonnés et tubés dans un quartier d'Albi installé sur cette basse terrasse proche du cours d'eau. Dans le puits Norton d'une propriété (station $n^{0} 71$ ) une riche faune de Crustacés hypogés fut capturée après appâtage: Niphargus sp. Salentinella sp., Microcharon sp., Bathynella sp., et Cyclopides, accompagnés de 7 Stenasellus adultes que j'ai identifiés ensuite à la forme de Padirac et de la nappe alluviale de la Garonne (St. virei virei). Grâce à ces prospections, l'Isopode est mis en évidence en un point très éloigné des autres stations interstitielles, mais encore dans les nappes d'alluvions quaternaires récentes, quoiqu'isolé dans la basse terrasse un peu au dessus de la rivière actuelle. Par contre, il ne semble pas exister dans les nappes sédimentaires des molasses de même qu'il n'a jamais été observé dans les eaux provenant des calcaires tertiaires. Dans l'Albigeois, il se cantonne donc étroitement dans le domaine phréatique des alluvions du Tarn.

\section{Stenasellus virei dans le sous-écoulement des cours d'eau}

1. Données générales: La faune interstitielle des nappes parafluviales ne peut être mise en évidence, nous venons de le voir, qu'à la faveur de la présence de puits maçonnés ou tubés. Elle n'est donc accessible en général qu'à condition de disposer de forages de plusieurs mètres à travers les alluvions modernes ( 4 à $8 \mathrm{~m}$ pour la Garonne). Dans les vallées étroites du haut cours des rivières, les alluvions récentes sont moins abondantes et leurs nappes réduites ou absentes, souvent non exploitées par des puits. Par contre, dans un cas comme dans l'autre, la rivière coule sur des graviers ou galets dont elle déplace les plus superficiels en période de crue. Ce sont les alluvions les plus récentes du cours d'eau, subactuelles ou actuelles, dont les bancs découvrent partiellement à l'étiage. Ces dépôts alluvionnaires très récents sont transportés très loin des sources par le fleuve. Ainsi, au niveau de Toulouse, on les trouve dans le lit moyen de la Garonne, sous forme de bancs de galets, graviers, sables de roches cristallines ou métamorphiques pyrénéennes. Leur nature et leur origine sont donc les mêmes que pour les éléments des alluvions de basse plaine. Ils forment la partie la plus récente de ces dernières. En dessous du niveau de la surface du cours d'eau, ces dépôts sont totalement imbibés d'eau. Pour les hydrogéologues, il s'agit d'un milieu interstitiel intermédiaire, au niveau duquel se font les échanges entre l'eau épigée du fleuve et la nappe phréatique latérale. Le sens de ces échanges serait conditionné par l'abondance ou le déficit de l'alimentation. Les conditions physiques régnant dans ce sous-écoulement ou inféroflux sont beaucoup moins stables que celles de la nappe phréatique proprement dite et très largement influencées par celles du cours d'eau épigé: le renouvellement de l'eau peut y être rapide et surtout la température est loin d'y être constante. 


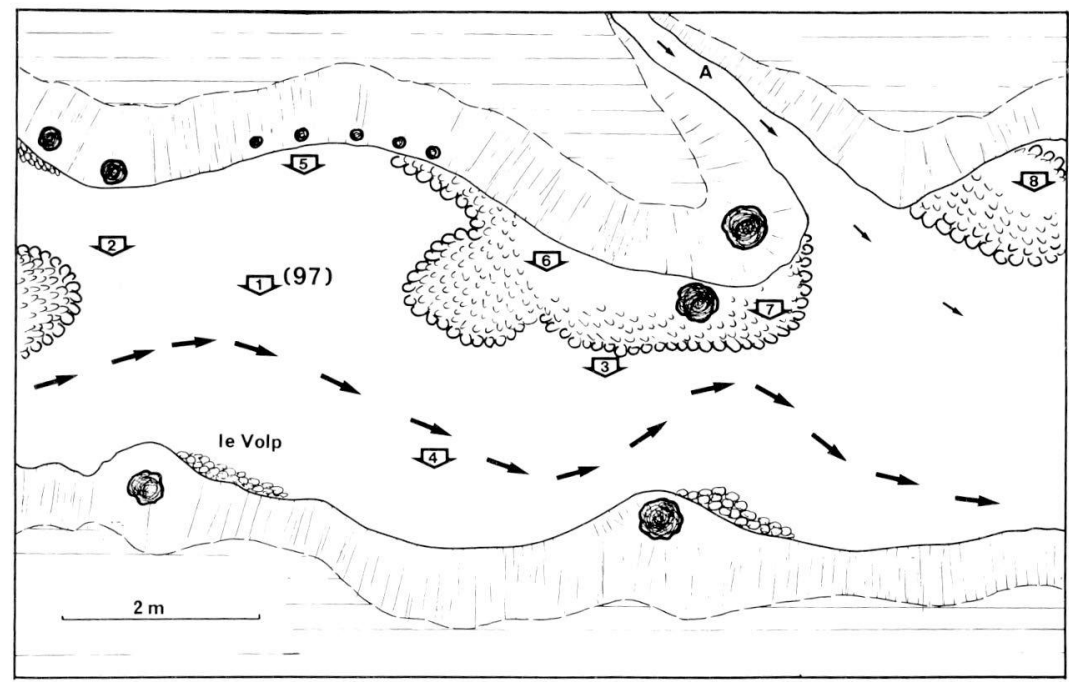

FIGURE 21

Recherche de Stenasellus virei virei par sondage tubé Bou-Rouch. Station $n^{0} 97$, dans le Volp à Montesquieu-Avantès (Ariège). Les sondages 5, 6 et 7, à 70-80 centimètres, tombent dans de l'argile très compacte et sont stériles. Les sondages 2,3 et 4 tombent à $70-80 \mathrm{~cm}$ dans une alluvion à grain assez fin (la pompe remonte de grandes quantités de sable). Ils n'ont fourni aucun Sténaselle, malgré des appâtages répétés. Le sondage 8 arrive, à $70 \mathrm{~cm}$ de profondeur, dans un milieu sableux très réducteur et azoïque. Seul le sondage $n^{0} 1$ a permis de capturer les Crustacés. Quelques individus ont été remontés de $70 \mathrm{~cm}$ de profondeur. La plupart proviennent de $80 \mathrm{~cm}$, tandis qu'aucune capture n'a pu être réalisée en dessous de $90 \mathrm{~cm}$. Le flux souterrain des petites rivières, telles que le Volp, circule donc dans un milieu interstitiel très hétérogène. Il se peut que les Sténaselles adultes, qui atteignent 7-9 millimètres, ne puissent vivre au sein de ces alluvions à phase sableuse que dans les coulées de graviers à granulométrie suffisamment grossière, tandis que les jeunes migrent avec facilité dans les interstices des passées plus sableuses. La découverte de l'espèce est donc aléatoire dans le sous-écoulement de tels cours d'eau. Coordonnées de la station n ${ }^{0}$ 97: Carte 1/20 000ème Mas d'Azil n ${ }^{0} 6$

$$
\begin{aligned}
& x=507,24 \\
& y=81,96 \\
& z=442 \mathrm{~m}
\end{aligned}
$$

$\mathrm{A}=$ petit affluent du Volp; les plages de galets exondées à l'étiage, les pentes limoneuses garnies d'arbres, situées de part et d'autre du lit mineur de la rivière, ont été figurées.

Les mesures qui ont pu être effectuées montrent que l'amplitude de la variation annuelle de température est importante et reproduit avec une légère atténuation celle du cours épigé (respectivement $10^{\circ}$ et $18^{\circ}$ pour le Tarn à la station no ${ }^{\circ} 73$ ) (Bou 1968). Selon le même auteur, les variations journalières de la température de la rivière en ce même point $\left(4^{\circ}\right)$ se répercutent encore à $50 \mathrm{~cm}$ de profondeur $\left(0^{\circ} 5\right)$. A titre de comparaison, la température de l'eau de la nappe alluviale profonde du Tarn (station $\mathrm{n}^{\mathrm{O}} 71$ ) oscille annuellement entre $13^{\circ}$ et $14^{\circ}$ (Bou 1968). C'est dire qu'en profondeur dans la nappe alluviale, la stabilité de la température rappelle celle qui règne dans les eaux des biotopes karstiques, mais que cette stabilité se dégrade au voisinage immédiat du cours épigé. 
Dans cette zone de transition peuvent s'installer des espècés animales les unes originaires de la rivière épigée, les autres des eaux souterraines. La mixité de la faune peuplant cette zone alluviale a permis à certains auteurs d'y voir un milieu de vie particulier, désigné par Orghidan (1959) sous le nom de biotope hyporhéique. Dans la nomenclature mise au point par Husmann (1970), il pourra s'agir du domaine rhithro-stygal ou potamo-stygal.

C'est Chappuis (1942) qui le premier aurait compris que, au voisinage immédiat des rivières et en période d'étiage, les dépôts alluviaux peuvent nous offrir un regard commode sur la nappe phréatique alluviale. La technique des sondages Karaman-Chappuis consiste à creuser une fosse dans les sables et graviers fluviaux, dans laquelle se rassemblent les eaux insterstitielles de la nappe, entraînant les animaux qu'elles abritent. Chappuis put ainsi mettre en évidence de riches faunes de Crustacés hypogés dans les alluvions des rivières roumaines. C'est par cette technique qu'Angelier découvrit le premier St. virei dans un tel milieu (alluvions de la Têt).

Les prospections de l'eau insterstitielle du sous-écoulement des rivières et de la nappe alluviale au voisinage immédiat du cours ont été ultérieurement beaucoup facilitées par la mise au point d'un appareil de prélèvement par Bou et Rouch (1967). Le système comprend un tube d'acier à parois épaisses $(6 \mathrm{~mm})$ de $1 \mathrm{~m}$ à $1,50 \mathrm{~m}$ de long, terminé par un cône de pénétration massif. La portion distale porte des rangées de trous latéraux de $5 \mathrm{~mm}$ de diamètre. La partie supérieure filetée reçoit un bloc d'acier que l'on frappe au moyen d'une masse pour enfoncer le tube dans les alluvions jusqu'à une profondeur maximale de $1 \mathrm{~m}$ à $1,20 \mathrm{~m}$ en pratique. Un manchon et une pompe aspirante de type courant permettent d'aspirer l'eau phréatique. Après décantation rapide du sable, un filtrage sur une soie à bluter de maille convenable permet de recueillir les animaux qui sont alors, soit fixés, soit conservés vivants et triés. L'appareil de Bou et Rouch, dont la technique dérive d'un système mis au point par Delamare-Deboutteville (1954) pour la capture de la faune des sables marins submergés a permis des progrès considérables dans la prospection des eaux souterraines continentales:

a. La prospection n'est plus limitée aux périodes d'étiage des cours d'eau et aux endroits où émergent des bancs de graviers. Elle peut se faire en tout point du lit mineur, même dans les alluvions toujours recouvertes par l'eau épigée.

b. La méthode permet de prélever l'eau phréatique à des profondeurs importantes dans la nappe (jusqu'à 1,20 m), alors que les sondages Karaman-Chappuis ne pouvaient atteindre que la région superficielle de celle-ci.

c. Elle est applicable à tous les types de cours d'eau: torrent montagnard comme le Salat (station $\mathrm{n}^{\mathrm{O}} 77$ ), ruisseau ou rivière de moyenne montagne $\left(\mathrm{n}^{\mathrm{O}} 7\right.$ et 75$)$ comme le Nert ou le Lachein, grande rivière de plaine comme le Tarn ou la Dordogne (n ${ }^{0} 76$ et 104) (Magniez 1968a, 1971a).

d. Elle a fait ses preuves en permettant de capturer dans le flux souterrain des cours d'eau, à des profondeurs de $0,40 \mathrm{~m}$ à $1,30 \mathrm{~m}$, des faunes hypogées très denses et variées (Bou et Rouch 1967, Gourbault et Lescher-Moutoué 1967, Bou 1968, Henry et Magniez 1970).

A l'aide des renseignements aimablement fournis par les auteurs, J-P. Henry et moi-même avons pu réaliser un matériel de prospection similaire qui a d'abord été expérimenté dans les rivières bourguignonnes et jurassiennes du bassin de la Saône. Les premiers essais ont montré l'importance du flux souterrain sous le lit mineur, au sein des galets calcaires de l'alluvion subactuelle. En certains points, des faunes très denses d'Amphipodes (Niphargus sp.) et d'Asellides (Proasellus cavaticus, $P$. strouhali puteanus, $P$. walteri) colonisent ce milieu où viennent parfois les rejoindre des épigés: Gammarus pulex, Carinogammarus roeselii, Asellus aquaticus, Proasellus meridianus, (Henry et Magniez 1970). Les premières mesures de température effectuées confirment les constatations de Bou (1968) et montrent que les variations de température du sous-écoulement reproduisent de manière à peine atténuée celles du cours épigé, bien qu'il y règne l'obscurité du milieu souterrain.

Dans la région aquitaine, ces prospections ont amené la découverte de Stenasellus virei virei et $S t$. virei boui dans le flux souterrain de plusieurs affluents ou sous-affluents de la Garonne, 
soit pyrénéens (Hers, Salat, Volp, Nert, Lachein), soit du Massif Central (Dordogne Tarn). Ces stations sont suffisamment éloignées les unes des autres pour qu'on puisse dès maintenant admettre que ce type de peuplement, lié aux rivières actuelles et à leur vallée alluviale, est normal pour l'espèce. Bien entendu, de nombreuses lacunes subsistent quant aux limites et à la continuité géographique de ces peuplements. Mais, la solution de ces problèmes exigerait des prospections le long de tous les cours d'eau aquitains, des plus importants aux plus faibles. Rappelons pour mémoire que la Garonne mesure $575 \mathrm{~km}$, la Dordogne $490 \mathrm{~km}$, le Lot $481 \mathrm{~km}$ et le Tarn $375 \mathrm{~km}$, pour ne citer que quelques uns des principaux. Ce travail ne peut être réalisé, ni en un laps de temps très court, ni par un seul chercheur, ni en vue de la capture d'une seule espèce souterraine. Il suffira donc pour le moment pour préciser l'importance de ce type de peuplement, de faire appel à deux études réalisées, l'une sur une petite rivière pyrénéenne (Nert) du Couserans, l'autre sur un grand affluent du fleuve en plaine (Tarn).

2. Stenasellus virei boui dans le sous-écoulement du Nert: Le Nert est un court affluent de rive droite du Salat (grand affluent de rive droite de la Garonne dont le bassin, qui s'étend sur la partie occidentale du département de l'Ariège jusqu'à la chaîne axiale, correspond à une petite région naturelle: le Couserans). Le Nert débouche dans la vallée du Salat à $4 \mathrm{~km}$ en amont de St-Girons. Sa vallée orientée Ouest-Est est subrectiligne et profondément encaissée dans les terrains paléozoïques du massif de l'Arize. Le fond de cette vallée structurale en V est subhorizontal en profil transversal par suite de la présence de dépôts alluviaux (fluvio-glaciaires ?) limoneux et le lit mineur de la rivière, qui ne dépasse pas quelques mètres de large en aval, se creuse dans ces formations. Ce lit est encombré de blocs, galets et graviers de roches dures qui en constituent l'alluvion subactuelle. Les eaux sont rapides par suite d'une dénivellation de 700 $\mathrm{m}$ sur les $13 \mathrm{~km}$ du cours. Le régime des eaux est relativement régulier, pluvio-nival, car le bassin versant est très boisé et le climat pluvieux. Les alluvions du lit mineur ne découvrent normalement pas et aucune plage n'est visible à l'étiage, si bien que le procédé KaramanChappuis n'est pas utilisable pour prospecter les eaux sous-jacentes (Gourbault et LescherMoutoué 1967). Les alluvions adjacentes qui sont plus anciennes ne semblent pas permettre le développement de nappes latérales importantes par suite de la faible largeur de la vallée et du colmatage par les éléments argileux et limoneux (Gourbault et Lescher-Moutoué 1968). Les deux auteurs ont donc prospecté la circulation sous-jacente par le procédé des sondages tubés Bou-Rouch. Les tubes ont été enfoncés dans le dépôt du lit mineur avec un espacement convenable (17 sondages sur les $8 \mathrm{~km}$ inférieurs du cours). Les profondeurs atteintes sont de 0,70 à $1,20 \mathrm{~m}$ dans l'alluvion. Ces sondages ont permis d'affirmer que, dans toute la zone prospectée, les formations d'alluvions grossières sont bien développées selon la verticale et très perméables. L'eau y circule facilement à travers un réseau d'interstices non colmatés (au moment des crues, cette circulation s'accélère encore et de nombreux débris végétaux sont entraînés dans le sous-écoulement). La pompe permet dans chaque cas d'aspirer un fort débit aqueux et le liquide phréatique entraîne avec lui une faune interstitielle extrêmement riche tant en espèces qu'en individus: Triclades ( 3 espèces), Harpacticides ( 9 espèces), Cyclopides ( 9 espèces), Amphipodes ( 3 espèces), Asellotes (Microcharon rouchi et Stenasellus virei), ainsi que des représentants d'autres groupes (Oligochètes, Ostracodes, Coléoptères et larves diverses). Ayant étudié plus particulièrement les Triclades et les Cyclopides hypogés, N. Gourbault et F. Lescher-Moutoué ont pu admettre que, sur les $8 \mathrm{~km}$ de cours prospectés, on était en présence d'un peuplement continu pour un bon nombre d'espèces (les inévitables irrégularités granulométriques locales de l'alluvion pouvant expliquer l'absence de certaines espèces au niveau de certains sondages). Les auteurs m'ont aimablement confié les Sténaselles récoltés en 8 stations. Tous sont morphologiquement identiques et appartiennent à la forme St. virei boui que j'ai considérée (Magniez 1968a) comme caractéristique du sous-écoulement du Salat et de ses divers affluents du Couserans. L'un des sondages étudiés a été choisi par les auteurs pour y effectuer des prélèvements hebdomadaires, avec appâtage, pendant une année. Cette station $\left(n^{\circ} 75\right)$ a permis la capture durant ce laps de temps, de plusieurs milliers de Sténaselles (appartenant tous à cette même sous-espèces), sans qu'aucun signe d'épuisement ne se manifeste. Les auteurs ont toutefois noté que la faune s'appauvrissait temporairement lors des crues, comme si les espèces hypogées se réflugiaient alors plus profondément, hors de portée des remaniements qui se produisent dans les alluvions en cette circonstance. 


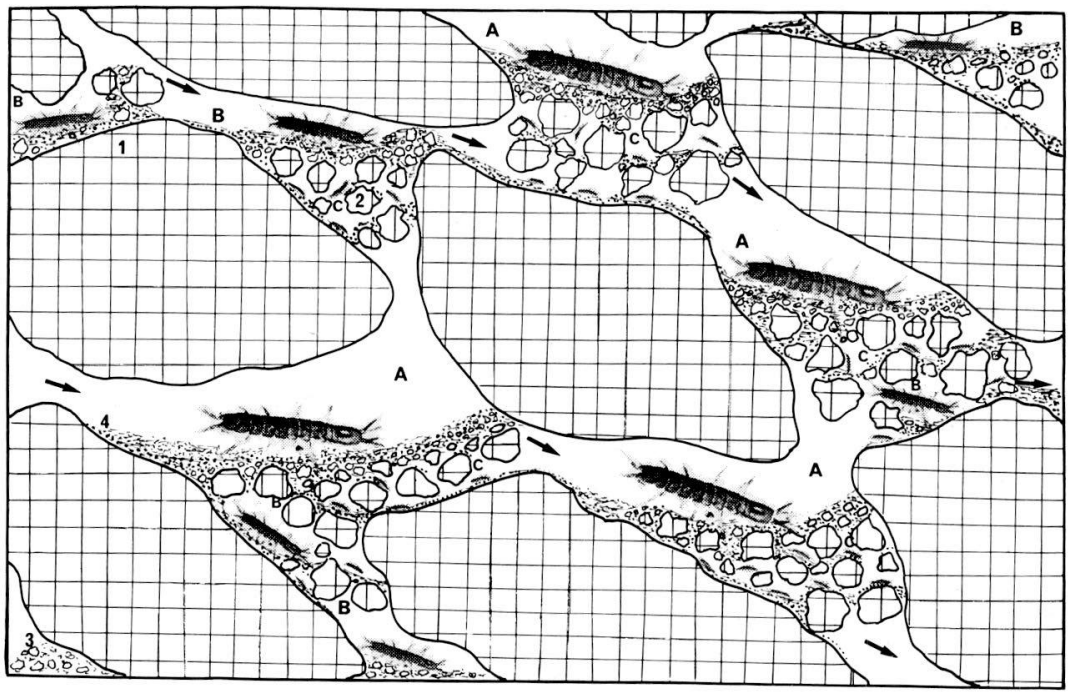

FIGURE 22

Schéma interprétatif montrant l'installation des Sténaselles dans le sous-écoulement d'une rivière à alluvions grossières. La trame des alluvions est constituée par des galets (1), plus ou moins aplatis et orientés.

Les interstices sont libres ou très partiellement occupés par des éléments sableux (2), sablonneux (3) ou limoneux (4).

Des silhouettes de Sténaselles de taille différente ont été disposées dans la figure, montrant que les individus des différentes classes de taille peuvent trouver dans ce milieu interstitiel des abris à leur mesure: $\mathrm{A}=$ adultes; $\mathrm{B}=$ immatures âgés; $\mathrm{C}=$ jeunes de 1,5 à 2 millimètres. Schéma inspiré par un travail d'Orghidan (1959, p.394) et par des observations directes.

On peut donc conclure que cette modeste rivière de moyenne montagne abrite dans son flux souterrain et les annexes souterraines de celui-ci, un peuplement continu de Sténaselles. Ce peuplement est morphologiquement très homogène et identique à ceux des rivières voisines (subsp. boui). La densité et le nombre global des individus capturés sont de plus très supérieurs à ce que montrent toutes les stations cavernicoles de l'espèce.

3. Stenasellus virei virei dans le sous-écoulement du Tarn: L'espèce ayant été mise en évidence dans la nappe de basse terrasse de la vallée à Albi (stations n ${ }^{0} 71$ et 84 ), une série de sondages tubés furent effectués par Bou (1968), afin d'étudier la faune de la nappe fluviale active, au niveau de la rivière et plus spécialement le sous-écoulement de celle-ci. Plusieurs sondages implantés dans le lit mineur du cours d'eau $\left(\mathrm{n}^{0} 73,76,83\right)$ ont fourni chacun quelques St. virei virei (Magniez 1968a, 1971c). Les sondages sont répartis entre la ville d'Albi et une trentaine de kilomètres à l'amont. A ce niveau le Tarn est déjà une large et abondante rivière au cours rapide, ayant alors parcouru plus de $150 \mathrm{~km}$ depuis sa source. Les Sténaselles semblent vivre dans des zones profondes des alluvions (galets et graviers de roches cristallines ou métamorphiques, avec un peu de limon rouge), puisque seuls les sondages atteignant une profondeur de 0,80 à $1,30 \mathrm{~m}$ en dessous du lit ont permis leur capture. Les sondages plus superficiels ramènent par contre de riches populations de Niphargus gineti (Bou 1968). Au niveau de la station la plus orientale, la vallée du Tarn est déjà profondément encaissée dans les terrains métamorphiques du socle 
hercynien (Ambialet). Nous avons donc la certitude que le flux souterrain du Tarn est peuplé par St. virei virei sur une trentaine de kilomètres en amont d'Albi. Les mêmes biotopes doivent se retrouver dans la portion aval de la rivière, jusqu'à la Garonne, mais les prospections n'ont pas encore permis de savoir si la portion amont du Tarn, au niveau des Grands Causses, abrite également le Crustacé.

Dans tous les cas, les peuplements de ce biotope semblent extrêmement peu denses, puisque les stations $n^{0} 76$ et 83 n'ont fourni chacune qu'un seul individu, la station $n^{0} 73$ en ayant procuré 6 , au cours de 3 prélèvements successifs. L'un d'entre eux était une $\$$ ovigère. Cette très faible densité des peuplements de sous-écoulement du Tarn n'est pas un fait isolé. Les découvertes de St. virei virei dans le flux souterrain d'autres rivières aquitaines (Dordogne, Hers, Volp, par exemple) ne portent que sur un seul ou quelques individus par sondage tubé productif; encore est-il toujours nécessaire d'appâter le tubage plusieurs heures à l'avance, au moyen de fragments de viande. Les peuplements de $S t$. virei virei de ces rivières de plaines sont donc beaucoup plus diffus que les peuplements de St. virei boui dans l'interstitiel du Nert.

\section{Stenasellus virei dans l'interstitiel non alluvial}

1. Massifs nord-pyrénéens: Dans les régions telles que les plateaux jurassiques bourguignons ou les Causses, dont le sous-sol est formé d'importantes assises calcaires restées monoclinales ou subhorizontales, la fraction des eaux de précipitation et de condensation destinée à s'infiltrer peut le faire en tous points en empruntant d'emblée des voies karstiques, après avoir traversé la mince couverture pédologique. Dans la région nord-pyrénéenne centrale habitée par $S t$. virei, au contraire, les variations de la sédimentation paléozoïque, puis jurassique et crétacée et les mouvements tectoniques ultérieurs amènent l'existence fréquente de contacts non horizontaux entre les terrains imperméables ou à perméabilité diffuse et les couches calcaires perméables en grand (c'est le cas au niveau du massif de Moulis). De plus cette mosaïque de terrains aux propriétés aquifères différentes a été profondément disséquée par l'érosion et les pentes sont souvent accentuées. Ainsi, sur des couches schisteuses ou gréseuses, par exemple, la collecte des eaux d'infiltration se produit à travers le manteau d'altération superficielle et le ruissellement hypodermique (cf. Meštrov 1962) se développe selon les lignes de pente en des zones privilégiées de la surface de la roche-mère. Les eaux peuvent apparaître au jour à la faveur d'un horizon plus dur et imperméable ou d'une rupture de pente, dans l'axe des fonds de talweg. On a alors des sources vraies qui peuvent répondre aux différents types définis par les hydrogéologues (déversement en particulier). Elles sont nombreuses sur les versants nord-pyrénéens et servent d'exutoires à des nappes éluviales ou colluviales perchées, parfois rudimentaires ou très localisées à des vallons déterminés (Bouillon 1964). C'est seulement dans de rares cas (8 stations au total) que St. virei a pu être mis en évidence à l'exutoire de ces nappes, soit par observation et capture directe (Meštrov 1962, Bouillon 1964), soit par la méthode de filtrage continu des sources (Lescher-Moutoué 1968), qui fournit parfois des échantillons de Sténaselles suffisamment représentatifs pour donner une idée de la population interstitielle existante (voir plus loin).

Comme les contacts entre les terrains imperméables et les assises calcaires sont fréquents dans cette région, ils peuvent amener la disposition en série, sur un même système hydrographique local, de parcours souterrains de type phréatique et de cheminements karstiques des eaux. Selon les cas, ce seront des eaux phréatiques hypodermiques qui alimenteront partiellement des écoulements en grottes (stations $\mathrm{n}^{\mathrm{O}} 45,48,64$ par exemple), ou inversement des ruissellements karstiques qui seront plus ou moins transfusés dans le milieu perméable en petit (stations $n^{\circ} 41,61,87$, par exemple). Cela expliquerait que, dans l'aire nord-pyrénéenne, c'est en général la forme St. virei hussoni, typiquement inféodée aux massifs karstiques de cette région, qui se retrouve dans les nappes éluviales géographiquement adjacentes.

2. Plaine aquitaine: Dans le domaine des molasses tertiaires aquitaines, les terrains sont plutôt imperméables, le coefficient de ruissellement considérable et les réserves d'eau souterraine minimes. Elles se localisent souvent dans des lentilles où le sédiment est plus sableux et donnent lieu à des nappes phréatiques faibles, que des puits vont parfois chercher à plusieurs dizaines de 
mètres de profondeur et qui tarissent quelquefois en été. Lorsque les formations superficielles d'altération sont développées sur ce substratum, elles peuvent atteindre 4-5 m dans certains vallons, donnant lieu à l'existence de nappes éluviales locales. La découverte de quelques individus de St. virei dans une source de Boulogne-sur-Gesse (Haute Garonne), (station $n^{0} 50$ ) reste le seul indice de l'existence de ces peuplements interstitiels. Toutefois, il n'a pas été possible jusqu'à aujourd'hui de réaliser des prospections détaillées à la saison humide au niveau des régions molassiques de l'Aquitaine. De même, au niveau des grandes vallées plio-quaternaires (Garonne et principaux affluents), les restes des moyennes et hautes terrasses, suspendues à plusieurs dizaines de mètres au dessus de la basse plaine actuelle, recèlent également des nappes phréatiques perchées dont les eaux voient le jour par des sources de déversement. Les nappes supérieures sont très inconstantes par suite de phénomènes d'imperméabilisation des alluvions anciennes et St. virei n'a pu encore y être mis en évidence. Comme pour les biotopes précédents, cette absence n'est peut-être que la conséquence du manque de prospections aux époques favorables de l'année et de l'étendue du domaine à prospecter, le seul bassin hydrographique de la Garonne (Dordogne exclue), représentant 1/10 ème du territoire français!

\section{E. Conclusion: Stenasellus virei en milieu interstitiel}

La découverte de St. virei en milieu interstitiel est un événement récent (1949). Jusqu'en 1967, on pouvait penser que ces types de biotopes étaient exceptionnels pour l'espèce. La mise au point de dispositifs de capture de la faune phréatique (méthodes de filtrage continu au niveau des sources et des sondages tubés BouRouch) a permis de déceler l'Isopode en de nombreux points dans les eaux souterraines des formations perméables en petit. Mais l'application de ces méthodes est trop récente pour avoir permis une prospection systématique des eaux phréatiques dans l'aire entière que l'on peut assigner à St. virei et les recherches sur le terrain devront être poursuivies pendant de longues années. Dès maintenant, plusieurs observations peuvent être faites:

1. Peuplements des nappes parafluviales: Stenasellus virei colonise largement le domaine des eaux phréatiques alluviales, surtout celles qui sont liées au réseau hydrographique post-glaciaire et actuel: basses terrasses et alluvions modernes du bassin aquitain.

2. Peuplements de l'inféroflux des rivières épigées: Cette colonisation est particulièrement remarquable et continue dans une annexe privilégiée de la nappe fluviale: l'eau souterraine qui circule dans les alluvions les plus récentes, sous le lit mineur du cours d'eau ou sous-écoulement. Ce biotope hyporhéique abrite l'espèce, tant dans le cas des rivières de montagne qu'en plaine, mais selon des modalités différentes dans les deux cas. A l'occasion de cette constatation, j'ai pu montrer que ces types de peuplements, morphologiquement différents et écologiquement dissociés des populations karstiques de l'espèce méritaient de former des sous-espèces distinctes: St. virei angelieri pour les nappes alluviales du Roussillon, St. virei virei pour le bassin hydrographique Garonne-Dordogne, surtout à basse altitude, St. virei boui pour le flux souterrain des vallées du Couserans (Salat et des affluents, à des altitudes de 400 à $800 \mathrm{~m}$ ou plus). On doit donc prendre conscience du rôle capital des dépôts quaternaires comme biotopes du Crustacé, donc du récent dynamisme colonisateur de celui-ci. 
3. Peuplements des nappes perchées: St. virei semble également installé dans les nappes phréatiques des formations superficielles éluviales ou colluviales, mais d'une manière très irrégulière, sauf peut-être au niveau des massifs karstiques nord-pyrénéens, pour lesquels il faudrait considérer ces peuplements interstitiels locaux comme des dépendances du peuplement karstique principal. Elles correspondent en général à la sous-espèce St. virei hussoni caractéristique des eaux des massifs karstiques de cette région, ce qui tend à montrer qu'il existe ou qu'il a existé récemment des circulations aquiferes communes, dans un même massif, aux réseaux karstiques et aux formations d'altération sur les terrains imperméables adjacents aux calcaires. D'importantes prospections seront encore nécessaires pour préciser la répartition de l'espèce dans le domaine interstitiel non alluvial, principalement en plaine.

4. Milieu de vie originel de l'espèce: L'existence de St. virei dans les différents types de biotopes phréatiques cités ici ne doit pas nous surprendre. J'ai déjà indiqué précédemment que la vie interstitielle doit être le cas normal et originel pour les Stenasellidae, tant pour le genre Stenasellus que pour les genres tropicaux.

5. Question de la température des biotopes interstitiels: Les diverses données montrent qu'au niveau des nappes phréatiques profondes, les variations annuelles deviennent minimes ( $1^{\circ}$ environ) et comparables à celles que l'on enregistre dans un biotope karstique. Les stations de St. virei virei correspondantes étant, pour la plupart, situées à basse altitude, leur température moyenne est souvent de l'ordre de 12 à $14^{\circ}$, parfois plus.

Au niveau du sous-écoulement des rivières, ou des nappes superficielles, il semble que Stenasellus virei puisse être soumis sans dommage à des variations annuelles de température beaucoup plus intenses: $6^{\mathrm{O}}$ à $15^{\circ}$ environ pour le sous-écoulement d'un ruisseau de montagne, $8^{\circ} 5$ à $18^{\circ} 5$, et même $23^{\circ} 5$, au niveau d'un flux souterrain de rivière de plaine. En ce qui concerne le premier exemple, on peut penser à établir un rapprochement entre les températures extrêmes des biotopes cavernicoles connus ( $6^{\circ}$ pour des cavités à $1200 \mathrm{~m}$ et $13-14^{\circ}$ pour des cavités à $\left.300-400 \mathrm{~m}\right)$, et les températures extrêmes qui ont été constatées dans un même biotope alluvial ( $6^{\circ}$ et $15^{\circ}$, par exemple). La question de la "sténothermie" de Stenasellus virei paraít alors différente. L'espèce est-elle un véritable sténotherme ou tout simplement un animal supportant facilement la relative sténothermie (écart annuel de l'ordre de $1^{\circ}$ ) de la plupart de ses stations connues?

\section{CONSEQUENCES DE CES OBSERVATIONS}

\section{A. Sur le statut cavernicole de l'espèce}

$\mathrm{Au}$ terme de cet inventaire des biotopes de l'espèce, il convient de revenir sur le statut qui lui avait été attribué. Jusqu'à 1949, St. virei pouvait en effet être considéré comme inféodé aux eaux des grottes. Le fait se conçoit parfaitement puisque les 18 stations pyrénéennes connues étaient des cavités naturelles abritant précisément la forme St. virei hussoni que nous avons reconnue comme propre à ce type de biotope. 
$\mathrm{Au}$ cours de ses recherches sur les Oligochètes souterrains, Mestrov (1962) découvrit à plusieurs reprises l'Isopode dans le "milieu hypotelminorhéique" qu'il avait précédemment défini. Il en avait conclu que $S t$. virei est un élément caractéristique de ce biotope et qu'à son avis, le peuplement des grottes résulterait d'un entraînement ou d'une migration des Crustacés à partir des eaux interstitielles des formations superficielles. St. virei ne peut donc plus être considéré comme un véritable cavernicole, bien que son installation dans le domaine karstique soit probablement très ancienne (Vandel 1964). Dans cette hypothèse, les eaux libres des grottes ne seraient qu'un habitat secondaire alors que le domaine des nappes éluviales des versants montagneux serait le principal lieu de vie de l'Isopode. L'ensemble des prospections réalisées depuis ne semble pas confirmer d'une manière générale cette opinion.

En ce qui concerne la présence de $S t$. virei dans les nappes alluviales des vallées, elle a été longtemps tenue pour exceptionnelle et Angelier pouvait encore écrire en 1953: "Stenasellus virei est une forme de grottes et de puits rare dans les sables submergés...". Les méthodes de prospections mises récemment au point ont beaucoup renouvelé les données de ce problème.

Le statut de l'espèce est en réalité complexe. J'ai pu montrer (Magniez 1968a) que $S t$. virei se compose de plusieurs groupes de peuplements auxquels il a été attribué valeur de sous-espèces par suite des différences morphologiques qu'elles manifestent. Ces différences ont pour corollaire une distribution dans des biotopes et dans une aire différents pour chaque sous-espèce; le cas de chacune est à examiner isolément.

1. Stenasellus virei virei: La forme-type a été découverte d'abord en milieu karstique (Padirac). Or il s'agissait d'une exception écologique. Toutes les prospections récentes montrent qu'elle est inféodée aux nappes alluviales, plus particulièrement en plaine (altitudes de 0 à $450 \mathrm{~m}$ ). Ce serait donc une sous-espèce typiquement interstitielle avec quelques populations installées dans le karst, par suite de l'existence de dispositifs hydrogéologiques particuliers (le cas du système Padirac-Dordogne est décrit plus loin).

2. St. virei buchneri n'a été mis en évidence, pour le moment, que dans une dizaine de grottes des calcaires urgoniens cantabres. Nous n'en connaissons aucune station phréatique. Sous réserve de découvertes ultérieures, nous pouvons donc la considérer comme une forme cavernicole.

3. St. virei hussoni, connu de plus de 60 stations, est caractéristique des massifs calcaires nordpyrénéens dont il peuple les différentes zones: zone noyée, zone amphibie (eau libre et interstitiel des rivières souterraines) et plus irrégulièrement la zone de percolation. Des peuplements annexes et secondaires peuvent se trouver dans les nappes éluviales ou d'éboulis adjacentes aux massifs, mais cette forme est typiquement cavernicole.

4. St. virei angelieri n'était connu que du milieu interstitiel alluvial du Roussillon. Il pouvait passer pour un phréatobie typique, mais il vient d'être observé dans une rivière souterraine du Vallespir, ce qui obligera peut-être à réexaminer cette opinion.

5. St. virei boui paraît localisé dans un milieu interstitiel très particulier: le sous-écoulement à grands interstices des rivières du Couserans (Salat et affluents). On peut donc le qualifier d'hyporhéique.

Des 5 formes de St. virei, 2 paraissent donc étroitement confinées dans les eaux 
interstitielles, 2 autres sont liées au milieu karstique, tandis que St. virei virei, la forme-type, bien que normalement inféodée aux nappes alluviales de plaine, montre de larges capacités d'installation dans les divers biotopes des eaux souterraines continentales. Il existe une bonne concordance entre les dissociations écologiques constatées et la diversification morphologique au sein de l'espèce.

\section{B. Aire de répartition de Stenasellus virei}

On trouvera ici des données et des réflexions sur l'aire actuelle de l'espèce et ses limites, sur les aires des sous-espèces, les fluctuations de celles-ci et leurs causes probables. Une explication du prétendu isolement de la station de Padirac, conforme aux données écologiques exposées plus haut est également proposée.

1. Limites géographiques et contexte géologique: St. virei est installé sur un vaste territoire qui s'étend en direction méridienne sur plus de $500 \mathrm{~km}$ et en latitude sur quelques $400 \mathrm{~km}$. L'Isopode est présent à la fois sur les versants Nord et Sud des Pyrénées bien que les stations connues soient plus nombreuses et écologiquement plus diversifiées au N de la chaine. Les données sur les milieux de vie des Sténaselles développées plus haut nous incitent à ne plus délimiter l'aire de vie de ces formes en fonction de leur présence dans un massif karstique donné, comme on peut le faire pour un cavernicole strict, mais plutôt à raisonner au niveau du bassin hydrographique. Pour le moment, St. virei a été observé dans les eaux souterraines du bassin aquitain au sens large (Garonne-Dordogne+Adour), du bassin de l'Ebre et dans ceux des fleuves côtiers des Pyrénées-Orientales et de la province de Santander. Il n'est pas possible d'affirmer que ces limites sont définitives. L'espèce du Portugal septentrional St. nobrei est très proche systématiquement de St. virei et entre les aires des deux formes s'étend toute la portion N-W de l'Espagne où des Sténaselles n'ont pas encore été capturés.

L'aire de l'espèce apparait fragmentée pour deux raisons essentielles:

a. l'axe pyrénéen forme une barrière E-W de haute altitude et l'espèce n'a pas été décelée à plus de $1300 \mathrm{~m}$ (température des eaux souterraines 5-6 ${ }^{\circ}$ ).

b. elle appartient à la fois aux versants atlantique (bassin de la Garonne et des Rios cantabres) et méditerranéen (Ebre, Têt, Tech), ce qui pourrait suggérer que les peuplements initiaux sont antérieurs à l'organisation de l'hydrographie actuelle. Toutefois, l'espèce reste inconnue, à l'intérieur de l'aire, dans certaines régions, comme le Pays basque, soit qu'elle y manque, soit que les prospections des habitats extrakarstiques aient été insuffisantes dans cette zone intermédiaire entre les stations pyrénéennes et cantabriques. La recherche sur le terrain ne peut donc être considérée comme terminée et des lacunes importantes restent à combler.

Si la présence des Sténaselles est liée, en un lieu donné, à la présence des eaux souterraines, sous quelque forme que ce soit, elle ne semble pas en liaison avec des horizons géologiques particuliers. Pour l'habitat karstique, les grottes qui abritent le Crustacé sont creusées dans les calcaires des divers étages crétacés qui forment des reliefs importants au Sud de la vallée de la Garonne. Les stations cantabres se trouvent elles aussi dans les formations urgoniennes. Pourtant, les dépôts calcaires 
ou dolomitiques du lias ou du jurassique moyen abritent aussi l'espèce dans leurs cavités, dans les Pyrénées (grottes de Moulis, de Gourgue), comme en Quercy (Padi$\mathrm{rac}$ ), bien que leurs faciès soient différents. Plus rarement, les terrains primaires ou tertiaires sont mis à contribution: galerie de mine de Couflens-de-Betmajou (Ariège) forée dans des calcaires griottes rouges et verts du dévonien terminal, grotte du Solencio de Morrano (Huesca, Espagne) dans les calcaires lutétiens. La terminaison Ouest du Plantaurel, isolée au N-W de la Garonne, forme un chaînon à ossature de calcaires daniens qui s'ennoient progressivement sous le cône détritique miocène du Lannemezan. Cette structure abrite St. virei hussoni dans ses eaux souterraines,

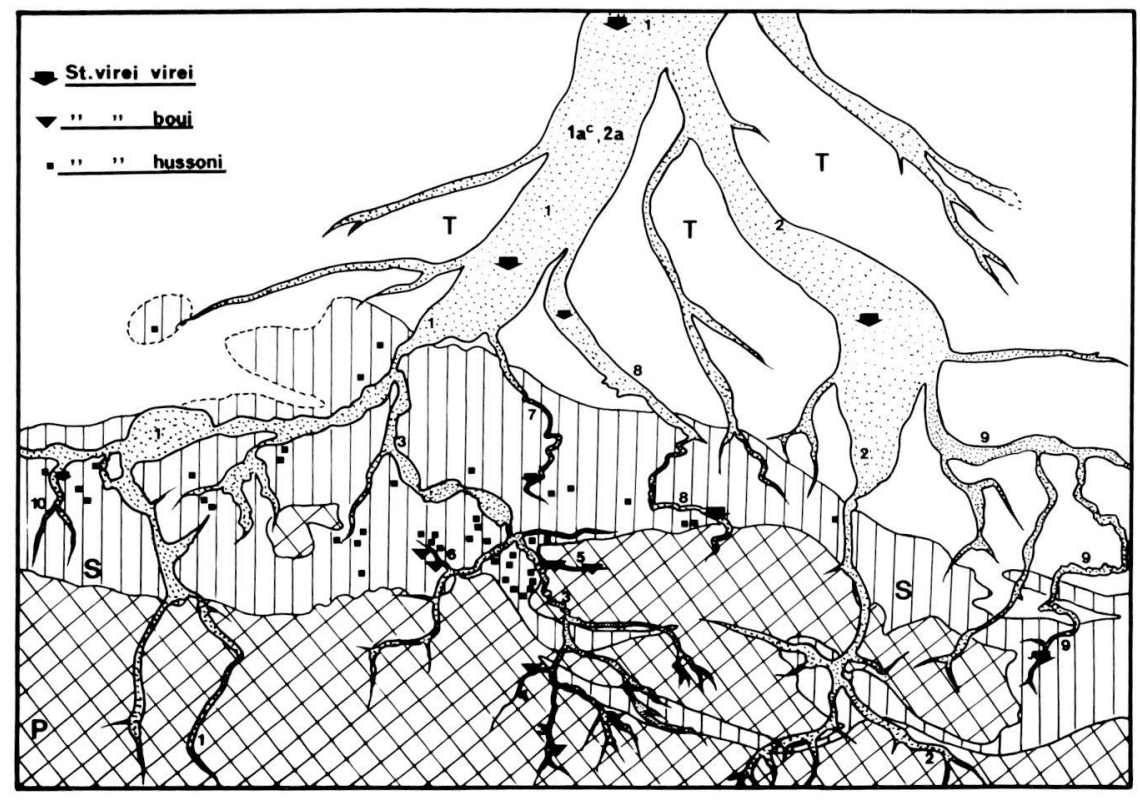

\section{FIGURE 23}

Carte très schématique, d'après la feuille géologique au 1/320 000ème de Toulouse.

Les terrains paléozoïques et cristallins (P) des Pyrénées centrales, les terrains secondaires (S), comprenant des formations calcaires karstifiées, ainsi que les terrains tertiaires $(\mathrm{T})$, souvent imperméables, sont figurés.

Les chenaux alluviaux de la haute Garonne et de ses principaux affluents des Pyrénées centrales sont indiqués en surimposition.

Les stations interstitielles de Stenasellus virei virei et de St. virei boui sont pointées, montrant leur appartenance au biotope alluvial du réseau hydrographique actuel. On voit que St. virei boui est inféodé aux nappes alluviales du Couserans (bassin du Salat), tandis que St. virei virei serait installé dans les nappes alluviales du bassin aquitain, au sens large (Garonne et affluents pyrénéens + affluents du Massif Central + Dordogne).

Les carrés noirs indiquent les stations ou groupes de stations de St. virei hussoni (grottes ou rivières souterraines en général). $1=$ Garonne; 2 =Ariège; $3=$ Salat; $4=$ Estours; $5=$ Nert; $6=$ Lachein; $7=$ Volp; $8=$ Arize $; 9=$ Hers; $10=$ Nistos. 
l'Isopode étant rejeté par plusieurs sources locales (Bouillon 1964), sans qu'on puisse préciser la nature de l'habitat. Dans le cas des biotopes interstitiels, le rôle joué par les formations quaternaires perméables est considérable. S'il s'agit de nappes éluviales ou colluviales de versants montagneux, la genèse d'un milieu à interstices suffisamment grands pour abriter des Sténaselles adultes, par altération de la roche du sous-sol, est plus dépendante de la nature pétrologique de celle-ci que de son âge. Dans le cas des formations alluviales, nous avons affaire à ces dépôts quaternaires plus ou moins anciens et discontinus (nappes supérieures des terrasses) ou plus récents et continus (basse plaine et nappe fluviale), parfois subactuels (alluvions du lit mineur et sous-écoulement). La présence des Sténaselles et la densité des peuplements semblent y dépendre plus de la granulométrie et des possibilités de circulation de l'eau souterraine que de la nature du substrat. Remarquons, et nous aurons l'occasion d'y revenir par la suite, que si les Sténaselles peuvent former des peuplements denses dans les alluvions quaternaires récentes des vallées, cela n'implique en aucune façon que ce type de biotope est récent, disons plus récent que le biotope karstique. Ce sont les stations, dans leur site actuel, qui sont récentes, mais le type de biotope a pu exister antérieurement dans un contexte paléogéographique différent. Quant aux biotopes actuels, $S t$. virei est donc installé dans des terrains de tous âges, du primaire de la chaîne axiale pyrénéenne aux alluvions actuelles. Il ne semble pas exister de relation entre cet âge et la présence des peuplements de l'espèce. Seule intervient la plus ou moins grande aptitude des formations à se karstifier ou à emmagasiner de l'eau phréatique. L'espèce étant aujourd'hui scindée en plusieurs entités, chacune avec des caractéristiques écologiques et biogéographiques propres, il faut examiner les problèmes, différents dans chaque cas, qu'elles posent.

2. St. virei angelieri: Cette forme est encore mal connue, par suite du faible nombre des stations et de la rareté des individus. L'aire actuelle correspond au domaine phréatique de la Têt et du Tech (sous-écoulement et nappes alluviales). Ces dernières sont très développées vers l'aval (Gadel et Got 1968). Les rivières, leurs alluvions récentes et leurs nappes, s'étalent largement pour former la plaine du Roussillon. Les biotopes sont donc comparables à ceux que rencontre St. virei virei dans ses stations alluviales aquitaines. Mais dans leur haut cours, Têt et Tech sont des torrents montagnards à vallées étroites dont le flux souterrain se cantonne au lit du cours d'eau. Les biotopes sont alors comparables à ceux de St. virei boui dans les Pyrénées centrales. L'aire est délimitée au Nord par le massif des Corbières dont les eaux karstiques abritent St. buili (aucune cohabitation entre les deux formes n'a été constatée) et à l'Est par la Méditerranée. Vers le Sud, cette aire franchit l'axe pyrénéen, puisque St. virei angelieri a été découvert dans une cavité de la vallée du Rio Segre et près de Montserrat. On peut penser qu'elle s'étend sur les bassins des fleuves côtiers de Catalogne (Fluvia, Ter, Llobregat), mais les prospections sont encore insuffisantes pour le démontrer et le domaine de la Catalogne intérieure (Ebre et affluents) semble colonisé par St. virei virei. Vers l'Ouest, enfin, un hiatus entre l'aire de St.v.angelieri et celle de St.v.hussoni semble exister au niveau du massif cristallin du Carlitte et de l'Ariège orientale (fig. 25).

3. St. virei buchneri: La dizaine de stations karstiques connues se répartissent sur $60 \mathrm{~km} \mathrm{d'E} \mathrm{en}$ $\mathrm{W}$ et sur $30 \mathrm{~km}$ de N au S, dans les massifs calcaires encadrant Santander, entre Ramales-de-laVictoria et Altamira. Du point de vue hydrographique, l'aire correspond aux bassins d'une série de courts fleuves côtiers issus de la cordillère cantabrique et se dirigeant vers l'Atlantique (Rios 
Ason, Miera, Pas et Besaya de l'E à l'W). La sous-espèce cantabre paraít isolée à quelques 300 $\mathrm{km}$ à l'Ouest de l'aire de St. virei hussoni. Or, des prospections récentes des chercheurs espagnols viennent de mettre en l'évidence l'espèce en plusieurs points du bassin de l'Ebre (Escola y Boada, in litt). Rappelons que cet immense bassin sédimentaire s'étend fort loin vers l'Ouest, car le fleuve prend sa source à $50 \mathrm{~km}$ seulement de Santander, sur le versant Sud de la chaîne, donc au voisinage immédiat de l'aire reconnue pour St. virei buchneri. La lacune de peuplement serait beaucoup moins étendue dans cette direction qu'il ne le semblait. Il n'est pas sans intérêt de noter aussi qu'à proximité immédiate de l'aire de St.v.buchneri (moins de 30 $\mathrm{km}$ ), des affluents du Douro prennent leur source. Or les nappes alluviales de ce fleuve sont le domaine de St. nobrei. Si le lien physique entre les aires de ces différentes formes est maintenant rompu, l'hydrographie actuelle en laisse subsister des traces évidentes.

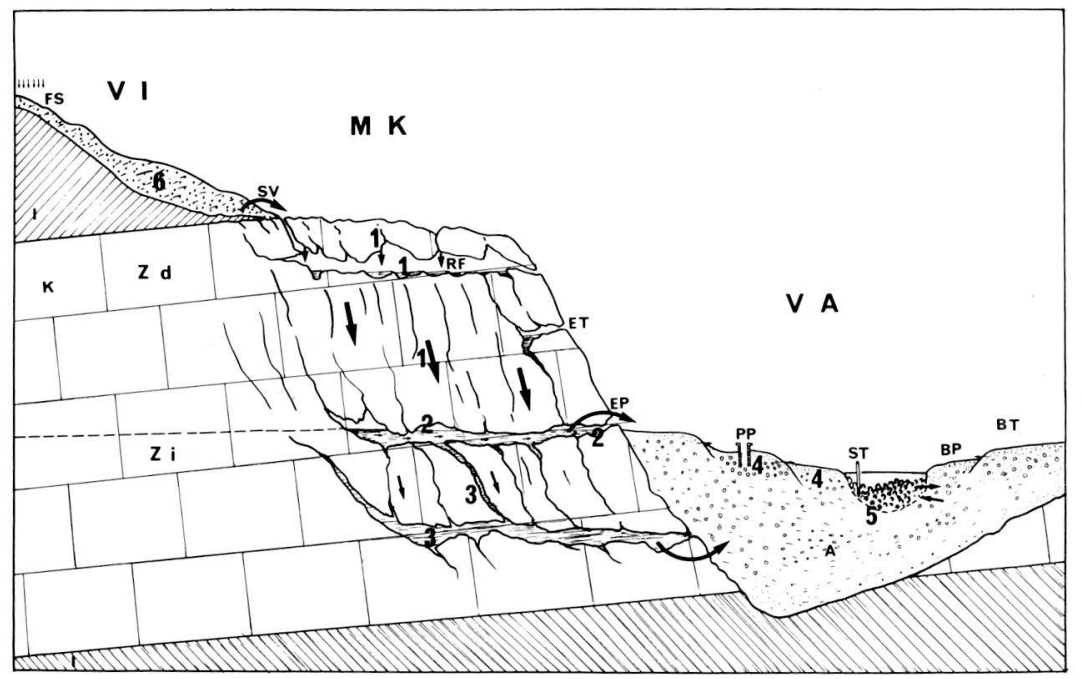

\section{FIGURE 24}

Schéma synthétique mettant en évidence les différents biotopes connus pour les diverses sousespèces de Stenasellus virei. La juxtaposition d'un massif karstique et d'une grande vallée alluviale avec ses terrasses vues en coupe transversale est purement artificielle.

$\mathrm{A}=$ alluvions perméables; $\mathrm{BP}=$ basse plaine; $\mathrm{BT}=$ basse terrasse $; \mathrm{EP}=$ exsurgence permanente; $\mathrm{ET}=$ exsurgence temporaire; $\mathrm{FS}=$ formations d'altération superficielle perméables; $\mathrm{I}=$ terrains stratifiés imperméables; $\mathrm{K}=$ terrains karstifiables (perméables en grand); $\mathrm{MK}=$ massif karstique (inclus ici dans une série monoclinale régulière pour simplifier la représentation); $\mathrm{PP}=$ puits permanents; $\mathrm{RF}=$ réseau fossile; $\mathrm{ST}=$ sondage tubé; $\mathrm{SV}=$ source vraie; $\mathrm{VA}=$ vallée alluviale; $\mathrm{VI}=$ versant sur terrain imperméable; $\mathrm{Zd}=$ zone dénoyée du karst; $\mathrm{Zi}=$ zone d'imbibition générale (perméabilité en grand dans la zone karstifiée des assises calcaires, perméabilité diffuse ailleurs). 1 = biotopes de la zone d'infiltration et de ruissellement souterrain (propre à St. virei hussoni ou à St. virei buchneri); 2 = biotopes de la zone amphibie (rivières souterraines actives), (hussoni, buchneri ou virei); 3 = biotopes de la zone noyée du massif (St. virei hussoni, buchneri, virei ou St. buili); 4 = biotopes interstitiels des nappes alluviales de basse terrasse ou de basse plaine (St. virei virei ou angelieri); $5=$ biotopes du flux souterrain des cours d'eau (St. virei virei en plaine, St. virei angelieri ou boui pour certaines rivières de montagne); $6=$ biotopes interstitiels des nappes éluviales (St. virei virei ou St. virei hussoni selon la localisation géographique). Les flèches verticales indiquent que nappes phréatiques et systèmes karstiques sont alimentés par les précipitations atmosphériques. 
4. St. virei boui: Cette forme montre à la fois une aire géographique restreinte et une localisation écologique précise. Elle peuple, d'une manière continue dans les cas favorables, le flux souterrain des rivières de moyenne montagne, à cours rapide, du Couserans. Elle paraît localisée dans le haut bassin d'un seul affluent de la Garonne (le Salat et ses annexes). Ce milieu interstitiel particulier, caractérisé par la facilité du renouvellement de l'eau abrite une faune très variée, dense et mobile (Gourbault et Lescher-Moutoué 1968). Le flux souterrain du Salat étant en continuité avec celui de la Garonne, qui abrite St. virei virei plus en aval, la question de l'existence d'une limite entre les aires respectives se pose. Or, le long du chenal d'alluvions, nous ne connaissons aucun point où les deux sous-espèces viennent en contact. Il faut donc supposer l'existence d'une barrière, soit géographique, soit écologique qui les sépare. Remarquons simplement que St. virei boui, qui vit dans un milieu interstitiel aux eaux renouvelées riches en oxygène, est précisément la sous-espèce la plus pauvre en pigments sanguins, tandis que St. virei virei qui semble beaucoup moins exigeant quant à cette teneur (station $\mathrm{n}^{\circ}$ 97) est la plus vivement colorée des sous-espèces.

Les vallées de certains affluents du Salat, dont le sous-écoulement est peuplé par St. virei boui, sont profondément encaissées dans des massifs karstiques ariégeois. Dans ces massifs, on trouve uniquement la forme cavernicole St. virei hussoni. Le dispositif est particulièrement net au niveau du ruisseau de Lachein (affluent du Lez situé à Balaguères, Ariège). Ce ruisseau est alimenté en eau karstique par des exsurgences dont le fonctionnement et la faune sont étudiés par Rouch (1970-1972). Le cours aérien possède un sous-écoulement actif dans les graviers et galets du lit mineur. Le massif calcaire voisin est occupé par St. virei hussoni à tous ses niveaux: zone dénoyée (stations $\mathrm{n}^{\mathrm{O}} 33$ et 39 ), zone active, comme le montre le rejet d'individus par les exsurgences (stations $n^{0} 86,93,94,95$ ), (Rouch 1970). Or, les prélèvements par sondages tubés dans le ruisseau épigé ( $\mathrm{n}^{\mathrm{O}}$ 74-96) montrent la présence d'un peuplement continu bien qu'irrégulièrement dense de St. v. boui en compagnie d'une riche faune interstitielle (Bou et Rouch 1967). Aucune confusion n'est possible entre les sous-espèces boui et hussoni qui diffèrent par des caractères externes bien nets (Magniez 1968a) et ne dérivent pas l'une de l'autre. Tout se passe donc, dans un tel site, comme s'il existait un hiatus entre les milieux aquatiques souterrains voisins: la forme karstique et celle de la nappe alluviale vivent au voisinage immédiat l'une de l'autre, mais n'ont point de contact. Une barrière écologique les sépare actuellement. Les individus de St. virei hussoni rejetés par les exsurgences sont destinés à périr ou sont dévorés par les épigés, mais ne peuvent, dans les conditions actuelles, coloniser le flux souterrain du cours d'eau aérien.

5. St. virei hussoni: La grande majorité des 60 stations connues sont des grottes. L'aire se limite strictement aux massifs karstiques nord-pyrénéens. Elle est limitée au Sud par la chaîne axiale paléozoïque non colonisée par cette forme. A l'Ouest, elle ne dépasse pas les massifs entourant Bagnères-de-Bigorre (Hautes-Pyrénées). Vers l'Est la limite est constituée par la vallée de l'Ariège et au Nord par l'ennoyage de la chaîne du Plantaurel sous les dépôts molassiques. Toutes les stations nord-pyrénéennes citées en 1950 par Racovitza lui appartiennent. Dans ce travail apparaissait encore l'idée de l'isolement des diverses populations au niveau des grottes ou réseaux karstiques décrits. Nous avons vu que la notion de "colonie" cavernicole est à reviser totalement. Elle doit être remplacée par celle de peuplement d'ensemble du massif karstique considéré, dans ses diverses zones, les quelques populations directement visibles dans l'eau des grottes n'en représentant qu'une part infime, groupe d'individus parfois nombreux mais plus ou moins coupés du peuplement général du massif. Dans certaines grottes de la zone dénoyée peuvent n'exister que des populations temporaires, en fonction du régime des eaux.

Les massifs nord-pyrénéens à ossature calcaire peuplés par cette forme sont profondément entamés d'Est en Ouest par le creusement récent des vallées quaternaires de la Garonne, de ses principaux affluents, et de l'Adour. Ils constituent donc actuellement une série de blocs, relativement isolés les uns des autres. Ainsi, les vallées du Salat, de la Garonne, de la Neste d'Aure, de l'Adour isolent-elles les massifs karstiques du Plantaurel, d'Arbas, de Nistos, du Montaigut et du Bédat. Les vallées méridiennes ont contribué de plus à cloisonner les massifs dans la direction Est-Ouest: ainsi la vallée du Lez sépare-t-elle les massifs d'Arbas et de Sourroque, celle de la Garonne le massif d'Arbas de l'ensellement occidental du Plantaurel, etc.... 
Les géologues nous enseignent que le creusement des vallées actuelles, principalement en montagne est un phénomène récent, plio-quaternaire. Cette ère, malgré sa courte durée a donc permis de considérables évolutions de la topographie, surtout dans les régions d'orogenèse récente (Gignoux 1950, p. 710). A la traversée des chaînons calcaires nord-pyrénéens, les rivières ont coulé autrefois à un niveau bien supérieur. Des cavités comme la grotte de l'Estelas, perchée à près de $900 \mathrm{~m}$, représentent une portion de cours d'une ancienne rivière souterraine. Le réseau actif du massif se trouve actuellement à plusieurs centaines de mètres en contre-bas (Alliou) et la grotte supérieure n'abrite plus qu'un lac immobile désormais perché dans la zone dénoyée. L'enfoncement du réseau hydrographique externe a donc cloisonné le massif en blocs séparés et il a eu comme corollaire la migration vers le bas du plan des rivières souterraines actives et le grand développement vertical de la zone d'infiltration et de ruissellement. On peut donc considérer que l'érosion fluviale a peu à peu rompu l'unité structurale des assises calcaires et ainsi dissocié leurs peuplements. C'est alors qu'il est possible d'interpréter les variations anatomiques mineures qui différencient les peuplements de St. virei hussoni originaires des différents massifs karstiques qui abritent cette forme (Magniez 1968a).

Cette même évolution des massifs karstifiés fait qu'il est difficile d'envisager des rapports actuels entre populations karstiques (forme hussoni) et populations alluviales (formes boui ou virei). Le massif calcaire possède son propre drainage interne qui se raccorde au réseau épigé par un nombre restreint d'exutoires à fort débit. Ces exutoires sont des zones d'érosion à seuil rocheux et le transfert direct de l'eau karstique à la nappe alluviale ne semble généralement pas réalisé (Trombe 1952). Ainsi, le cas de St. virei boui nous a appris qu'un cours d'eau coulant dans un massif calcaire pouvait abriter dans son flux souterrain une sous-espèce de St. virei différente de celle qui vit dans le massif, à proximité immédiate. Ces peuplements ne sont pas contemporains: la forme karstique est installée depuis longtemps dans le massif, ayant supporté

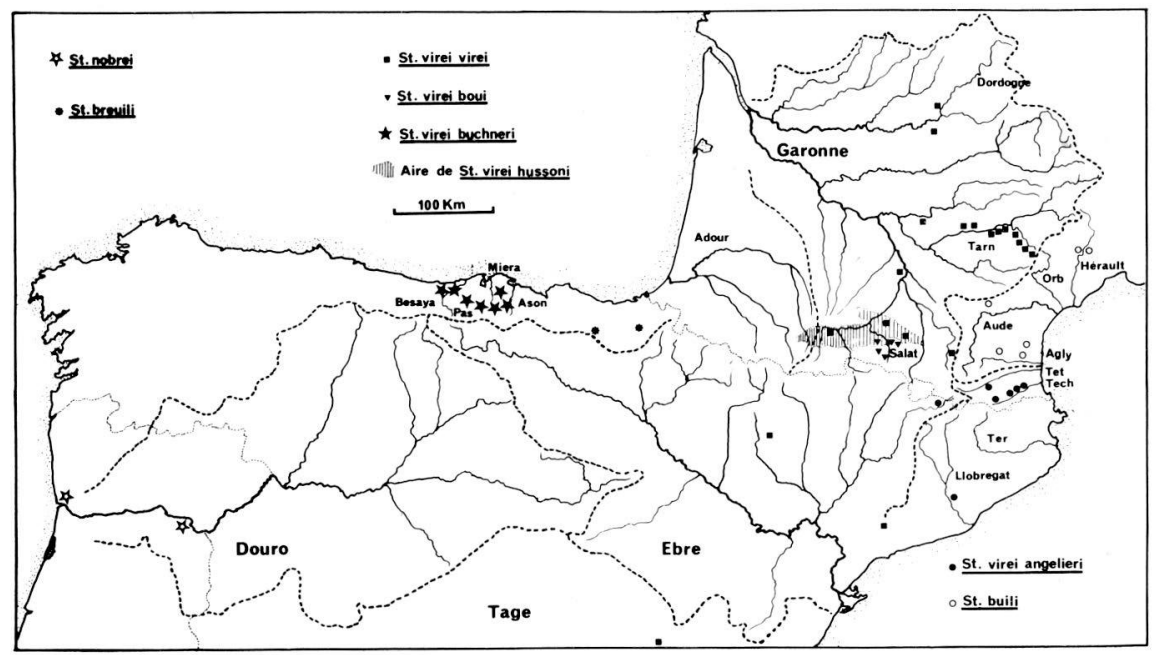

FIGURE 25

Aire de répartition de l'espèce polytypique Stenasellus virei. On peut noter la vaste diffusion de la forme-type de l'espèce: St. virei virei, par suite de sa présence dans l'interstitiel alluvial. Les autres sous-espèces sont nettement plus localisées.

On remarque que l'espèce St. nobrei, morphologiquement très voisine de St. virei, occupe un bassin hydrographique contigu (Douro). Les limites des grands systèmes fluviaux sont indiqués en pointillés gras. 
les vicissitudes de son morcellement par l'érosion, tandis que la forme interstitielle montagnarde est venue coloniser le flux souterrain par migration depuis l'aval à une époque récente (postglaciaire) et les conditions hydrogéologiques actuelles ne permettent pas leur rencontre.

6. St. virei virei: Si l'on s'était contenté de rechercher St. virei dans les eaux karstiques, la répartition de cette forme serait restée inexplicable, par suite de l'isolement apparent de certaines stations (Padirac, Solencio de Morrano par exemple). La forme-type est beaucoup plus répandue en réalité et les prospections récentes montrent qu'elle est liée au milieu interstitiel et plus particulièrement aux systèmes alluviaux Garonne-Dordogne et peut-être de l'Ebre. Pour le moment, seule une partie du cours de la Garonne et de certains affluents a été prospectée, mais la dissémination des sondages indique que le peuplement est largement répandu dans l'ensemble de ce réseau hydrographique. Le biotope, graviers quaternaires de basse terrasse et de basse plaine, présente une extension géographique considérable dans le bassin aquitain, jusqu'au niveau du cours inférieur du fleuve. Les sondages tubés dans la nappe fluviale montrent que $S t$. virei virei semble vivre dans les parties profondes, à partir de $0,80 \mathrm{~m}$ et que la présence de limons intercalés dans les graviers et la baisse de la teneur en oxygène dissous ne paraîssent pas constituer des obstacles à sa présence. Par contre, la densité des peuplements semble faible dans ce milieu interstitiel de plaine, mais la nature des captures (jeunes individus, adultes, $\supsetneq$ ovigères) montre que cette forme se perpétue normalement dans la nappe alluviale.

a. Peuplements alluviaux du Tarn: J'ai précisé que le seul lien physique qui unit ces biotopes de l'Albigeois au reste de l'aire de la sous-espèce est constitué par l'épandage d'alluvions récentes et les basses terrasses de la rivière qui rejoignent le chenal alluvial de la Garonne en aval de Montauban. Dans le bassin du Tarn, les Sténaselles ne colonisent jamais les systèmes karstiques (calcaires tertiaires, Causses de Limogne et grands Causses jurassiques, calcaires primaires de la Montagne Noire) (Bou 1966), par contre, suivant le cours souterrain de la rivière vers l'amont, ils se sont installés dans la nappe fluviale jusque dans l'Albigeois cristallin. Tout se passe comme si, dans cette région, St. virei virei avait colonisé la nappe alluviale à une époque très récente, en remontant le chenal d'alluvions de la rivière.

b. Padirac, une population karstique adventice d'un peuplement phréatique: Quant à la station de Padirac, elle reste très éloignée de l'aire principale pyrénéenne et même des peuplements alluviaux du Tarn. Ce fait n'avait pas manqué d'intriguer les auteurs anciens, lorsque $S t$. virei était considéré comme strictement cavernicole. Les importantes masses calcaires du jurassique moyen, formant le causse du Quercy, recèlent de nombreuses cavités naturelles avec d'abondantes et multiples circulations souterraines. L'ensemble a été prospecté avec soin, avant les Pyrénées, et jamais des Sténaselles n'y ont été trouvés ailleurs qu'à Padirac. Ce n'est pas faute d'avoir recherché les Asellotes dans ces grottes, puisque Proasellus meridianus a été découvert à Saint Géry (Biosp. 482) ou à la grotte du Souci (Biosp. 655), par exemple. L'explication classique de cette absence généralisée des Sténaselles en Quercy apparait dans les divers travaux de Dollfus, Viré, Jeannel et Racovitza: St. virei virei de Padirac serait un cas résiduel unique du peuplement souterrain antéquaternaire du Causse, peuplement qui aurait été détruit partout ailleurs par les rigueurs du climat périglaciaire. Il est possible que l'ancêtre de notre St. virei virei ait pu coloniser les eaux souterraines du Quercy aux temps antéquaternaires, puisque les calcaires y ont subi un premier cycle de karstification paléogène, avec formation des gouffres à phosphates, mais personne ne peut apporter la preuve d'un tel fait. D'ailleurs, dans ce cas, pourquoi l'espèce aurait-elle persisté à Padirac et non dans des cavités plus occidentales situées à des altitudes plus faibles donc ayant supporté des températures moins basses lors des phases glaciaires? 
Compte tenu des données écologiques accumulées sur St. virei virei, je préfêre formuler une seconde hypothèse, plus plausible, pour justifier la présence de ce peuplement de Padirac: cette forme pourrait exister, dans les eaux du gouffre, comme une population annexe de la faune de la nappe phréatique de la Dordogne. En effet, la grande rivière coule en contre-bas du Causse, au voisinage immédiat de Padirac, dans un vaste chenal d'alluvions récentes et les eaux de la cavité se dirigent vers la vallée par des cheminements souterrains, en conduite forcée, encore incomplètement explorés (De Lavaur 1950). Cette thèse est renforcée par l'étude de la topographie du principal exutoire du réseau souterrain de Padirac: la Fontaine de St-Georges à Montvalent (Lot) (fig. 26). Cette exsurgence remontante, qui débouche presque au niveau de la rivière actuelle, permet, par sa structure, la transfusion directe des eaux apportées par le conduit karstique dans la nappe alluviale fonctionnelle de la rivière (De Lavaur 1950, Trombe 1952). Un tel dispositif hydrogéologique, qui semble peu commun dans l'aire pyrénéenne de St. virei hussoni (son absence expliquerait alors l'isolement karstique actuel de cette forme), serait capable d'assurer le transfert des espèces hypogées de la nappe alluviale vers la rivière souterraine et vice-versa.

Pour étayer cette hypothèse, la meilleure solution était d'effectuer des prospections sur le terrain et d'essayer de mettre en évidence les Sténaselles dans la nappe phréatique de la vallée alluviale de la Dordogne. Malgré les obstacles naturels et artificiels (taille excessive des galets, retenues hydroélectriques, exploitations de gravières, zones construites et polluées, etc...) une petite portion de la berge Nord de la rivière, à environ $2 \mathrm{~km}$ en aval de Beaulieu (Corrèze) (station $\mathrm{n}^{\mathrm{O}} 104$ ), s'est

\section{FIGURE 26}

1. Carte très schématique, d'après la feuille géologique au $1 / 80000$ de Brive $\left(n^{\circ} 183\right)$, montrant le site des deux stations les plus septentrionales de Stenasellus virei virei.

La station $n^{0} 1$ (Gouffre de Padirac $=$ GP) se trouve dans les calcaires du jurassique moyen (Jm). Les flèches jalonnent le cours souterrain de la rivière de Padirac dont l'exutoire se trouve à la Fontaine de St-Georges $(\mathrm{F})$ à Montvalent $(\mathrm{M})$. Au voisinage de cette localité, les calcaires, par suite de leur plongement, se trouvent au niveau de la vallée alluviale actuelle de la Dordogne (D), ce qui permet les échanges d'eau souterraine entre milieu karstique et nappe alluviale. Plus à l'Est, les calcaires sont au contraire largement suspendus au dessus de la vallée alluviale qui se creuse au milieu des terrains triasiques et liasiques (TL) plutôt imperméables. La station $n^{0} 104$ se trouve en milieu interstitiel, sondage tubé dans la nappe des alluvions récentes (A2) de la Dordogne, un peu en aval de Beaulieu-sur-Dordogne (B) en un point où la vallée est encore encaissée dans le socle cristallin (C) du Massif central. La nappe alluviale de la rivière constitue donc le principal milieu de vie de St. virei virei .

2. Coupe verticale très schématique de la vallée de la Dordogne au niveau de la Fontaine de St-Georges à Montvalent (Lot) (d'après G. de Lavaur, 1950, modifié). La vallée active de la Dordogne (D) est creusée dans les calcaires du jurassique moyen $(\mathrm{Jm})$. Les eaux du système hydrographique souterrain (R) parviennent à la fontaine (F) par un conduit noyé en permanence et peuvent être transfusées au moins en partie vers la nappe alluviale active des alluvions A2 de la rivière (flèches grêles). Les flèches grasses indiquent la possibilité du peuplement des eaux karstiques par des espèces vivant normalement dans les eaux phréatiques de la vallée (Stenasellus virei virei en particulier). 
OBSERVATIONS SUR STENASELLUS VIREI DANS BIOTOPES NATURELS 161

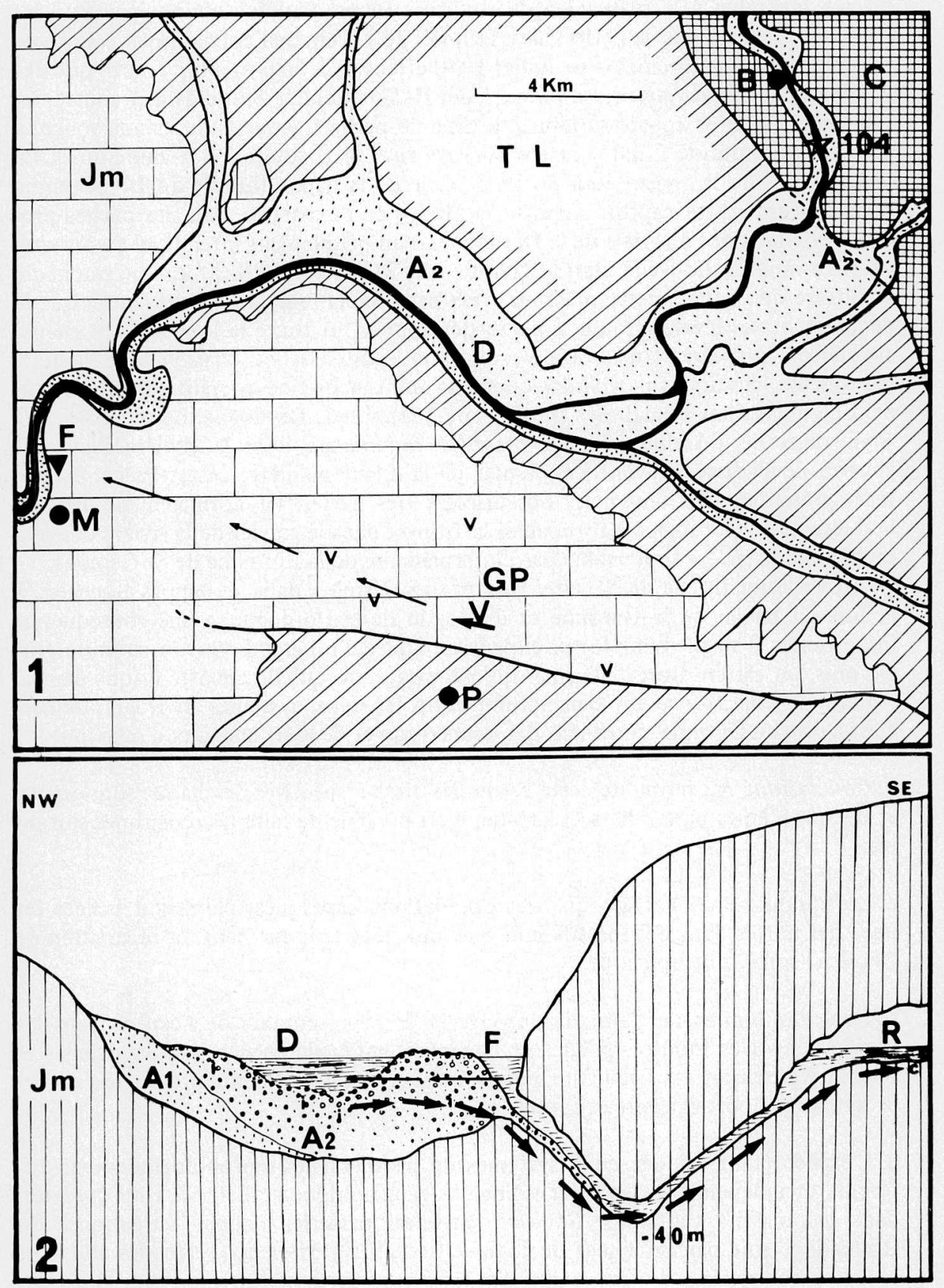


révélée favorable à la réalisation de sondages tubés. Sur une bonne épaisseur, les alluvions y sont faites de petits galets éruptifs de $1.5 \mathrm{~cm}$ peu colmatés par les phases plus fines. Les prélèvements de juillet 1970 effectués à 0,80 m n'ont fourni que des Amphipodes (Niphargus cf. ladmiraulti; dét.R. Ginet et Ch. Morand). Par contre, un sondage à $1,10 \mathrm{~m}$ appâté durant $2 \mathrm{~h}$ avec de petits fragments de viande rouge, a permis la capture de 2 individus de $S t$. virei virei ( $10^{t}$ adulte $+1 \%$ immature). La température de la rivière était de $14^{\circ} 5$, celle de la nappe fluviale de $14^{\circ}$. Comme pour le Tarn, cette capture apporte la preuve de l'existence, dans les parties profondes de la nappe alluviale de la Dordogne, d'un peuplement interstitiel de St. virei virei. Comme la nouvelle station (photo. VI, 21) se trouve à $30 \mathrm{~km}$ en amont de l'exutoire de Padirac, cette présence n'est pas accidentelle et on peut penser que le peuplement se développe, ou a pu se développer sur toute la longueur du chenal alluvial de la rivière. Tout porte à croire que les Sténaselles karstiques de Padirac, par ailleurs identiques morphologiquement, ont une origine interstitielle et proviennent de migrations à partir des alluvions modernes de la Dordogne. Les peuplements souterrains de l'Asellide oculé Proasellus meridianus dans la Rivière Plane du gouffre de Padirac peuvent s'expliquer de la même manière: cette espèce, épigée, mais présentant des tendances obscuricoles très nettes, vit normalement dans les herbiers de la Dordogne, j'ai pu aussi la trouver dans le gravier de la rivière et elle a pu peupler la rivière souterraine par l'intermédiaire de la Fontaine de St-Georges.

La vie interstitielle de St. virei virei et son existence dans les nappes alluviales, à la fois du bassin de la Garonne et du bassin de la Dordogne, a une conséquence importante: il s'agit d'une forme expansive, douée d'un grand pouvoir colonisateur. De plus, on est en droit d'affirmer qu'elle existe, ou qu'elle a existé jusque dans la région où l'on trouve un lien naturel entre les deux systèmes hydrographiques, c'est-à-dire en Gironde, confluent des cours d'eau et de leurs chenaux d'alluvions.

7. Conclusion: Au terme de cette revue des aires respectives de chaque sous-espèce et des problèmes particuliers à chacune, il est possible de faire les remarques suivantes:

a. Lorsqu'on ne connaissait que des populations karstiques, paraissant isolées les unes des autres dans des massifs indépendants géographiquement, la répartition de l'espèce semblait inexplicable.

b. Dans les limites de l'aire, la découverte de représentants de l'espèce dans les nappes alluviales montre qu'elle est largement inféodée aux eaux interstitielles et que sa répartition est beaucoup plus continue, largement tributaire du réseau hydrographique post-glaciaire et actuel.

c. L'espèce étant scindée en 5 systèmes de peuplements morphologiquement différents et indépendants, soit par isolement géographique actuel: St. virei buchneri dans les massifs cantabres, St. virei angelieri dans les nappes phréatiques du Roussillon, soit par isolement écologique actuel: St. virei boui dans les alluvions récentes des rivières de Couserans, $S t$. virei hussoni dans les eaux karstiques des 
massifs compris entre Ariège et Adour; la forme considérée comme type de l'espèce, $S t$. virei virei, semble fondamentalement interstitielle. Son aire de dispersion est très vaste et elle possède un dynamisme colonisateur considérable dans les divers biotopes souterrains. Cette complexité du problème biogéographique posé par l'espèce est l'indice d'une histoire compliquée. Il faut essayer d'en dégager les traits principaux.

\section{Signification de l'aire actuelle; les variations quaternaires}

Il est unanimement reconnu aujourd'hui que les phases glaciaires quaternaires, plus spécialement les deux derniers paroxysmes du Riss et du Würm, ont eu un profond retentissement sur l'extension et la richesse qualitative des faunes cavernicoles, en particulier celles de l'Europe tempérée (Vandel 1960). Pour le genre Stenasellus, hormis les especces tropicales, il en a certainement été de même. On peut ainsi imaginer que des espèces entières ont disparu à cette occasion. En effet, en Europe occidentale et centrale, aucun Stenasellus ne dépasse le 46ème parallèle vers le Nord. Aucune forme n'est connue dans les régions comprises entre la Bulgarie centrale (où vit St. rumelicus) et le Turkménistan (St. asiaticus vit dans une venue d'eau thermale des environs de Samarcande, à peu près sous le 38ème parallèle). De même que tous les Stenasellus européens, $S t$. virei constitue un relicte thermophile antéquaternaire dans la faune d'Asellotes de l'Europe occidentale (Vandel 1964).

Pourtant, comme les Sténaselles ne peuvent plus être tenus pour des cavernicoles parfaits, strictement inféodés au domaine aquatique des grottes et incapables de tout dynamisme colonisateur, il convient de tenir compte des divers facteurs historiques qui se sont succédés, ayant pu agir d'une manière positive ou négative sur l'aire de l'espèce pour lui donner ses contours actuels.

1. Les glaciations: Elles ont d'abord été caractérisées par des phases à la fois froides et humides, avec une rétention considérable des précipitations sur les hauteurs et un grand développement des glaciers dans toutes les vallées des Pyrénées centrales, y compris dans la partie méridionale des massifs karstiques situés au Nord de la chaîne paléozoïque (ceux de la haute vallée de l'Ariège en particulier), amenant la destruction de la faune souterraine dans toute cette région (Vandel 1960). Dans de telles conditions, on peut penser que les Sténaselles ont pu néanmoins subsister au niveau des parties Nord de ces massifs karstiques, les glaciations n'ayant provoqué à leurs paroxysmes qu'un abaissement de $1000 \mathrm{~m}$ des limites des neiges persistantes. En effet, $S t$. virei hussoni dans ses stations d'altitude $(1200-1300 \mathrm{~m})$ parvient à vivre dans les eaux à $5-6^{\circ}$, tandis que ses stations les plus basses, sont à 13-14 (Jeannel 1926, Trombe 1952, Magniez $1967 / 68$, 1971c). Au niveau des massifs karstiques nord-pyrénéens, il pouvait donc supporter une baisse de $8^{\mathrm{O}}$ de la température moyenne annuelle. Il en est de même pour St. virei virei qui a pu, dans l'hypothèse la plus favorable, se maintenir dans les nappes alluviales de basse vallée de la Garonne et de la Dordogne.

2. Les phases froides et sèches tardi-würmiennes: Elles ont certainement constitué une agression climatique beaucoup plus marquée et influé sur la répartition des Sténaselles dans tous leurs milieux de vie:

a. Les rigueurs du climat et le déficit des précipitations ont dû être responsables de la dégradation et du blocage des nappes aquifères hypodermiques (nappes éluviales, colluviales, milieu hypotelminorhéique) jusqu'à une altitude assez basse sur les versants nord-pyrénéens, restreignant ces types de biotopes. 
b. Ces restrictions ont atteint, selon l'opinion classique, le domaine des cavernes, par la suppression temporaire de leur alimentation et même parfois de leurs réserves en eau libre (sols gelés, zone de percolation bloquée superficiellement) (Ciry 1959, 1962). On peut toutefois envisager la survie des formes karstiques au niveau des massifs de basse altitude (région de Santillana del Mar pour St. virei buchneri, massifs du Bas-Comminges et du Plantaurel pour St. v. hussoni).

c. Enfin, la diminution provisoire des circulations hydrographiques, par suite de la rétention, a dû entraîner des baisses considérables du niveau des nappes phréatiques de vallées, d'autant que la baisse du niveau de base devait occasionner une plus forte ablation des alluvions en place et un transport très actif vers l'aval à la belle saison. Les rigueurs du climat devaient être atténuées par la basse altitude en Aquitaine et dans le Roussillon, si bien que St. virei virei et St. virei angelieri ont pu survivre en plaine. Naturellement, pendant toute la durée de ces phases, le domaine de vie actuel de St. virei boui est totalement inexistant et interdit à l'espèce.

3. Influence de la phase postglaciaire: En schématisant beaucoup les événements, les derniers épisodes froids et secs du Würm furent suivis d'un réchauffement rapide, avec une transgression marine (flandrienne) corrélative. On y a relevé, selon les géologues et les paléobotanistes, des phases au cours desquelles la température moyenne a surpassé de $2-3^{\circ}$ les moyennes actuelles avec de nettes recrudescences de la pluviosité et de l'humidité générale par rapport au climat actuel (Vandel 1960). L'ensemble de ces nouvelles conditions, réalisées il y a environ 7000 ans, a dû produire un développement considérable des couverts végétaux et, corrélativement:

a. Une reprise du fonctionnement et une extension considérable des nappes souterraines dans les formations d'altération superficielle,

b. Une réapparition et un grand développement des circulations et collectes d'eau par les massifs karstiques, avec creusement des réseaux actifs et concrétionnement dans les niveaux supérieurs,

c. Des reprises locales de l'alluvionnement dans le réseau épigé, des remontées du niveau des nappes alluviales en conformité avec la remontée du niveau de base.

La répartition actuelle des différentes sous-espèces de St. virei semble indiquer que l'espèce a profité de ces conditions post-glaciaires très favorables à la faune aquatique souterraine pour s'étendre largement sur des territoires qui lui étaient interdits lors des phases glaciaires:

d. St. virei buchneri et St. virei hussoni ont pu regagner du terrain vers le Sud, recolonisant les hauts massifs cantabres pour le premier, certains des hauts massifs calcaires situés entre rivières Ariège et Adour pour le second,

e. St. virei angelieri a pu recoloniser la haute vallée alluviale de la Têt et du Tech par migration progressive de l'aval vers l'amont dans l'interstitiel de la vallée. Il en est de même pour St. virei virei, ce qui permet d'expliquer l'existence des peuplements actuels dans le sous-écoulement et la nappe fluviale du Tarn en amont d'Albi et dans la vallée de la moyenne Dordogne, par exemple (fig. 27).

f. On est en droit de penser que cette phase d'expansion n'est pas sans rapport avec la différenciation d'une forme de l'espèce dans un type de milieu interstitiel nouvellement accessible: le sous-écoulement à larges interstices, aux eaux bien renouvelées, riches en oxygène et en nourriture du Salat et de ses affluents du Couserans. St. virei boui est inféodé à ces biotopes et serait un variant local de St. virei virei né de la reconquête post-glaciaire (fig. 27).

g. Si la réinstallation des Sténaselles dans le sous-écoulement des rivières d'altitude, par migration de l'aval vers l'amont, dans le chenal d'alluvions, ne fait pas de doute, il semble que St. virei hussoni n'ait jamais pu se réinstaller dans certains massifs karstiques désormais trop isolés par le creusement du réseau hydrographique: ce serait le cas pour les massifs urgo-aptiens situés au 
Sud du bloc cristallin et paléozoïque de l'Arize (région de Tarascon-sur-Ariège). Les vastes et multiples grottes ayant subi les glaciations, qui s'y trouvent, sont bien pourvues en eau, mais les Sténaselles n'y ont jamais été mis en évidence. Ce serait également le cas des massifs crétacés dominant Lourdes à l'Ouest.

4. La période historique: En poursuivant l'énumération des phénomènes qui ont pu influer sur la répartition des Sténaselles, nous en arrivons à des événements plus récents. Les uns sont naturels, comme le retour d'un climat à caractère plus boréal avec une baisse des températures moyennes et peut-être des précipitations; les autres sont liés à l'action de l'Homme sur les milieux naturels, action qui n'a fait que s'amplifier depuis l'aube des temps historiques:

a. Les déboisements et les drainages des régions basses restreignant le domaine des eaux interstitielles permanentes au profit des écoulements épigés,

b. Les ponctions massives d'eau souterraine dans les vallées alluviales qui ont fait baisser définitivement le niveau de la nappe phréatique comme dans la vallée de la Garonne, par exemple,

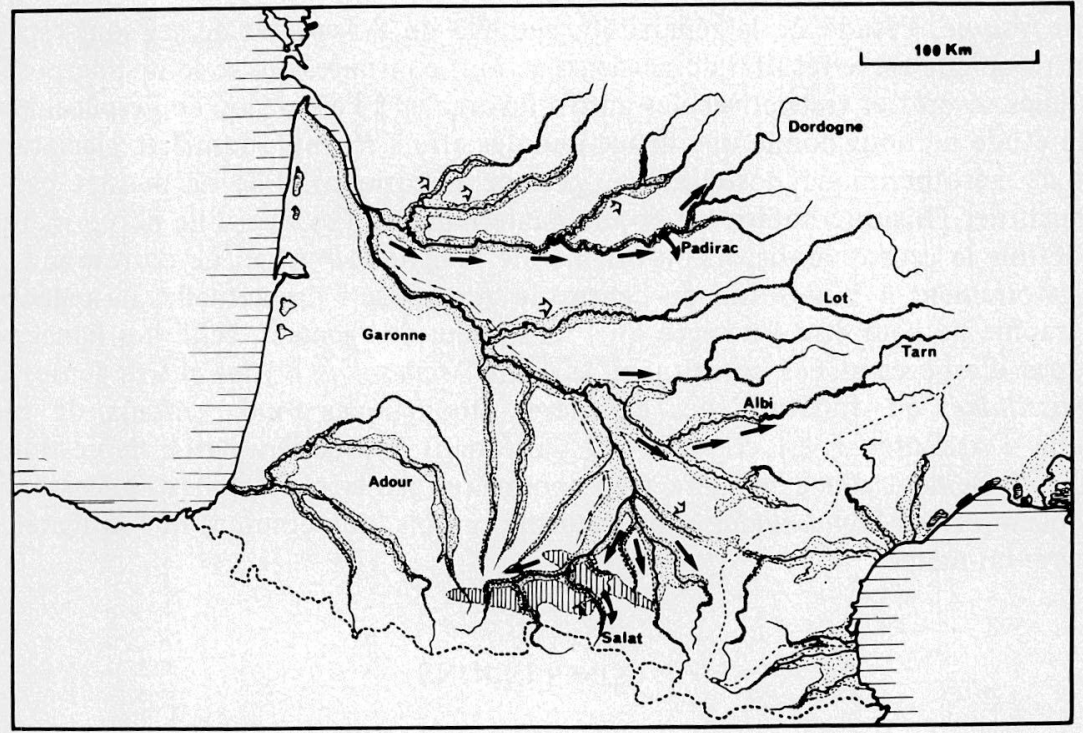

\section{FIGURE 27}

Carte schématique des chenaux alluviaux du réseau hydrographique aquitain. L'aire en hachures verticales signale les massifs karstiques où vit actuellement Stenasellus virei hussoni. Les flèches fines indiquent le probable retrait de St. virei virei vers les nappes alluviales de basse altitude, lors des phases froides quaternaires.

Les flèches grasses signalent le phénomène de recolonisation post-glaciaire des vallées alluviales, par migration vers l'amont: cas de la Dordogne et du Tarn (pour St. virei virei), cas du Salat, qui a donné lieu à la différenciation tardive de $S t$. virei boui (flèche courbe). Les flèches évidées indiquent la recolonisation probable des chenaux alluviaux de certains autres affluents de la Garonne (pratiquement démontrée, pour l'Aveyron, mais non encore, pour le Lot ou les affluents de la Dordogne, par exemple). 
c. Les dragages de graviers pratiqués systématiquement dans le lit 'de nombreux cours d'eau (Garonne, Dordogne) qui détruisent un des biotopes de l'espèce tout en abaissant le niveau de la nappe fluviale, l'ouverture de gravières dans les vallées alluviales, qui dégrade le biotope correspondant, au profit des faunes épigées,

d. Les retenues d'eau sur le haut des cours des rivières, pour l'hydro-électricité par exemple, qui provoquent le dépôt de limons colmatant le milieu hyporhéique. Les installations de lavage de minerai sur les torrents pyrénéens qui conduisent au même résultat,

e. La contamination des eaux karstiques ou interstitielles par des substances nocives minérales, organiques ou hydrocarburées, d'origine agricole ou industrielle.

Cette énumération incomplète tend à montrer l'existence de toute une série de causes qui peuvent être à l'origine de disparitions récentes, voire subactuelles, de l'espèce au niveau de certains cours d'eau du bassin aquitain. Il est vrai que, dans certains cas, les apports de bois macéré dans l'eau de certaines grottes semble avoir eu une influence favorable sur la densité des populations de St. virei hussoni, mais cette constatation est loin de compenser les dégradations causées aux divers milieux interstitiels. Il faut donc globalement envisager au cours des temps historiques une série de facteurs restrictifs ayant porté atteinte à l'extension du Crustacé.

5. En résumé, l'étude de la répartition actuelle de $S t$. virei et de ses sous-espèces montre qu'elle est le résultat de plusieurs actions contraires qui se sont superposées. Les unes sévères et restrictives, les autres favorables à l'extension de l'espèce. Mais, cette étude ne nous donne une image que des effets récents (dernières glaciations, période xérothermique postglaciaire, période historique). Elle ne permet pas de reconstituer l'histoire antérieure et antéquaternaire de l'espèce. Elle ne permet pas de définir le centre de dispersion originel de la lignée virei, qui ne correspond pas obligatoirement à la position du centre de gravité de l'aire actuelle. La paléobiogéographie ne peut être envisagée qu'à un niveau plus général, celui des lignées ou groupes d'espèces alliées constituant le genre Stenasellus ou les autres genres des Stenasellidae, en fonction des caractères éthologiques fondamentaux de cette famille d'Asellotes. C'est ce qui a été tenté dans la première partie de ce travail, malheureusement d'une manière trop sommaire, car la plupart des lignées extraeuropéennes des Stenasellidae sont beaucoup moins bien connues que la lignée de St. virei lui-même.

\section{CONCLUSIONS}

Les prospections intensives réalisées au cours des dernières décennies ont eu pour résultat de multiplier les stations connues de Stenasellus virei. Le nombre des stations classiques de l'espèce n'était que de 15 en 1950, alors qu'il atteint 117 en 1974. Dans le même temps, alors que les biotopes connus primitivement étaient très uniformes: collections d'eau des grottes dénoyées, nous assistons maintenant à une diversification écologique considérable. Il s'avère que l'espèce colonise, dans son aire, à la fois les eaux karstiques et les eaux interstitielles. Les biotopes karstiques se situent non seulement dans la partie supérieure des massifs karstiques (zone dénoyée, zone de percolation ou zone d'infiltration et de ruissellement souterrain, selon les auteurs), mais aussi au niveau des rivières souterraines actives (zone am- 
phibie) et également dans la zone d'imbibition générale, lorsqu'il s'agit de systèmes holokarstiques. Les biotopes interstitiels sont parfois constitués par des nappes éluviales ou colluviales locales (captures au niveau des sources vraies), mais se développent considérablement dans les nappes phréatiques fonctionnelles du réseau hydrographique actuel (Garonne et ses affluents). Cette constatation permet de montrer que l'aire de répartition de l'espèce est beaucoup plus vaste qu'on ne le pensait auparavant, car, au lieu de la réduire à quelques massifs calcaires plus ou moins isolés les uns des autres, il faut l'étendre à l'ensemble des réseaux hydrographiques considérés, y compris leur cours inférieur (bassins de la Garonne, de l'Ebre et des fleuves côtiers adjacents). Il s'ensuit que Stenasellus virei ne doit pas être considéré comme une espèce fondamentalement cavernicole, mais comme un phréatobie dont certaines lignées ont colonisé depuis fort longtemps les eaux karstiques. Dans un même biotope cavernicole, la température de l'eau est relativement constante, mais pour l'ensemble de ces stations, nous trouvons un éventail de températures s'échelonnant de $6^{\circ}$ à $14^{\circ}$ environ. De plus, dans les biotopes hyporhéiques, l'espèce peut être soumise à des variations de température qui oscille, dans certains cas, entre $5^{\circ}$ et plus de $23^{\circ}$. On ne peut donc la considérer comme sténotherme. Leur dissémination géographique considérable est à mettre en rapport avec le caractère fouisseur des Sténaselles. Par ailleurs, il a été montré que Stenasellus virei désigne une espèce polytypique au sein de laquelle 5 sous-espèces ont été reconnues. Ces 5 formes correspondent chacune à un ensemble de populations morphologiquement semblables et possédant une localisation géographique ou écologique similaire:

- St. virei virei est largement disséminé dans les nappes alluviales aquitaines et dans celles de l'Ebre.

- St. virei boui est une forme interstitielle très localisée dans le haut bassin du Salat et de ses affluents.

- St. virei buchneri vit dans les eaux karstiques des massifs urgoniens cantabriques.

- St. virei hussoni est largement répandu dans les eaux des massifs karstiques nord-pyrénéens entre Foix et Bagnères de Bigorre.

- St. virei angelieri est une forme interstitielle des nappes alluviales des fleuves côtiers méditerranéens (Pyrénées Orientales et Catalogne).

Il semble enfin que l'aire de répartition actuelle ne peut être considérée comme originelle. D'ailleurs, dans les conditions climatiques actuelles, l'espece devrait avoir une répartition géographique beaucoup plus vaste. La localisation présente indique qu'une restriction considérable de l'aire s'est produite lors des phases glaciaires quaternaires. Cette restriction a été suivie d'une phase de reconquête des eaux souterraines vers l'amont, qui est surtout nette au niveau des nappes alluviales (Dordogne, Tarn, Salat etc...). Comme cette reconquête était tributaire du réseau hydrographique actuel, elle est restée limitée. Il semble qu'à l'occasion de cet essaimage dans un milieu interstitiel vierge, rendu disponible par le recul des glaciers pyrénéens, l'espèce ait pu différencier une forme locale hyporhéique propre au Salat: Stenasellus virei boui. 


\section{DEUXIEME CHAPITRE}

\section{DONNEES SUR LES POPULATIONS NATURELLES DE STENASELLUS VIREI}

Le texte de ce chapitre a été publié très récemment sous le titre: "Les populations naturelles de Stenasellus virei Dollfus (Crustacé Asellote troglobie)", (Int.J.Speleol., 5, 1, 31-48), cf. Magniez 1973a. Pour la bonne compréhension du mémoire d'ensemble, nous nous contenterons d'en reprendre le sommaire, les conclusions générales et l'illustration (fig. 28, 29).

\section{CONCLUSIONS}

Les récentes prospections et les observations sur le terrain ont permis d'améliorer nos connaissances sur les peuplements de Stenasellus virei dans leurs milieux de vie naturels.

Les seules populations directement observables sont celles qui vivent dans des collections d'eau permanentes de la zone de percolation des massifs karstiques. Dans ce type de biotope, les véritables populations, c'est-à-dire les peuplements durables qui se renouvellent essentiellement par reproduction in situ, sont rares. La plupart des "stations" de cette catégorie ne correspondent, en fait, qu'à de petites accumulations d'individus ayant migré des systèmes aquifères du massif vers les collections d'eau de la grotte où ils sont plus ou moins étroitement prisonniers.

Les populations karstiques des zones amphibie et noyée, les populations interstitielles des nappes alluviales et éluviales sont les plus importantes. Toutefois, elles ne sont pas directement accessibles. On ne peut les connaitre que par des échantillons recueillis par divers artifices: piégeage, filtrage continu des émergences, sondages tubés.

Ces échantillons provenant de biotopes où l'eau se trouve à l'état divisé (milieu perméable en petit, par exemple), présentent toujours une composition en classes de taille normale, c'est-à-dire avec une large prédominance des stades jeunes sur les adultes. Cette composition est conforme à celle qui est connue pour les Asellides épigés.

Dans ces biotopes, l'espèce fait partie d'une biocénose complexe de formes hypogées très variées. Elle doit pouvoir y trouver des proies convenables (Copépodes, Microparasellides, par exemple), mais elle doit y être soumise à l'action des formes prédatrices plus robustes (Amphipodes, Planaires). Les Sténaselles s'y trouvent donc soumis aux conditions d'une concurrence vitale multispécifique normale.

Les populations karstiques (St. virei buchneri et St. virei hussoni) des collections d'eau plus ou moins isolées dans la zone dénoyée des massifs présentent une composition en classes de taille inhabituelle: elles sont formées d'une grande majorité d'adultes auxquels s'ajoute un faible pourcentage de subadultes de taille déjà importante. Les jeunes y sont anormalement rares, aussi efficace que soit la technique de capture. Lorsque aucun prélèvement n'y a été encore fait, ces populations se com- 


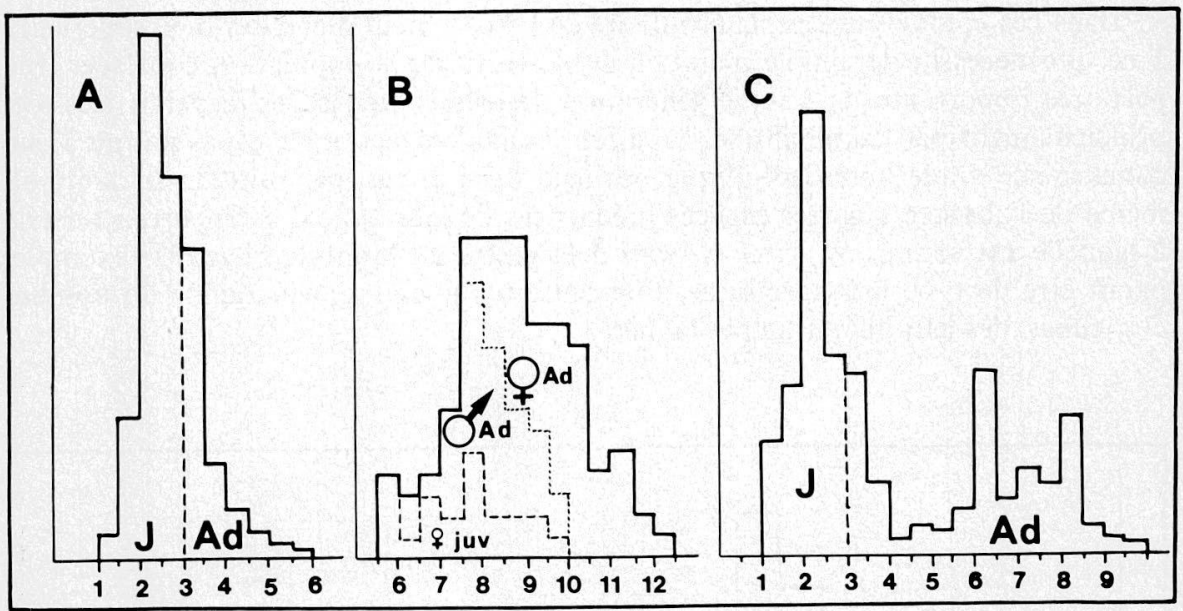

FIGURE 28

A. Composition en classes de taille de $1 / 2 \mathrm{~mm}$, d'une population épigée de Proasellus meridianus (Racovitza), au mois de juin, d'après Steel (1961), modifié. On remarque l'importance considérable du nombre des individus jeunes ( $70 \%$ du total). La maturité sexuelle se produit pour une taille de $3 \mathrm{~mm}$. Toutes les catégories de taille possibles sont représentées, depuis les plus petites (pulli de 1 à $1,5 \mathrm{~mm}$ ).

B. Composition en classes de taille de $1 / 2 \mathrm{~mm}$, d'une population cavernicole de Stenasellus virei hussoni, vivant en eau libre au siphon du Goueil-di-Her (Haute-Garonne). Toutes les catégories de taille comprises entre 1,6 et $5,5 \mathrm{~mm}$ sont absentes. Les seuls individus immatures de la population sont des femelles sans oostégites de taille déjà importante ( $q$ juv., 5,5 à $9,6 \mathrm{~mm}$ ). Selon les données fournies par les élevages, une telle population ne comprendrait aucun individu âgé de moins de cinq ans environ.

C. Composition en classes de taille de $1 / 2 \mathrm{~mm}$, d'une population épigée d'Asellus aquaticus L., au mois de mai, d'après Steel (1961), modifié. Toutes les classes supérieures à $5 \mathrm{~mm}$ représentent des individus nés en fin d'été de l'année précédente et qui sont destinés à disparaître prochainement, par mort naturelle. Cette génération est déjà disparue de l'échantillon de $P$. meridianus de juin, considéré dans la fig. A. La génération de printemps de l'année en cours montre une composition normale, où toutes les classes de taille, depuis les pulli, sont représentées.

Les échelles des abscisses des trois histogrammes représentent les longueurs, en millimètres, des individus. Les ordonnées sont proportionnelles aux fréquences des différentes classes.

portent comme des accumulations stabilisées d'adultes atteignant la plus grande taille possible ( $\uparrow$ de $12 \mathrm{~mm}$ ) et leur âge naturel maximal. Les ponctions répétées d'individus dans ces peuplements sont responsables d'une diminution rapide de la taille moyenne et provoquent un accroissement du pourcentage des immatures présents dans le groupe, c'est-à-dire un relèvement du taux de remplacement dans la population. Cette observation montre qu'il s'agit de populations dont le nombre d'individus est étroitement limité et apporte une preuve de leur confinement plus ou moins parfait dans la collection d'eau. 
Dans ces colonies isolées, la prolificité de l'espèce peut demeurer bien supérieure à ce que nécessite le simple maintien de l'effectif de la population confinée. Une part très importante de chaque génération de jeunes Sténaselles disparait très tôt, principalement par cannibalisme. En effet, les adultes ne semblent pas soumis à une concurrence vitale hétérospécifique normale dans ce cas, par suite de la rareté ou même de l'absence d'autres espèces prédatrices de leur taille. La concurrence vitale à laquelle est soumis St. virei hussoni à la grotte du Mont-de-Chac, par exemple, parait être de type intraspécifique. Elle cause un amenuisement rapide du nombre des jeunes, dès leur libération par la mère.

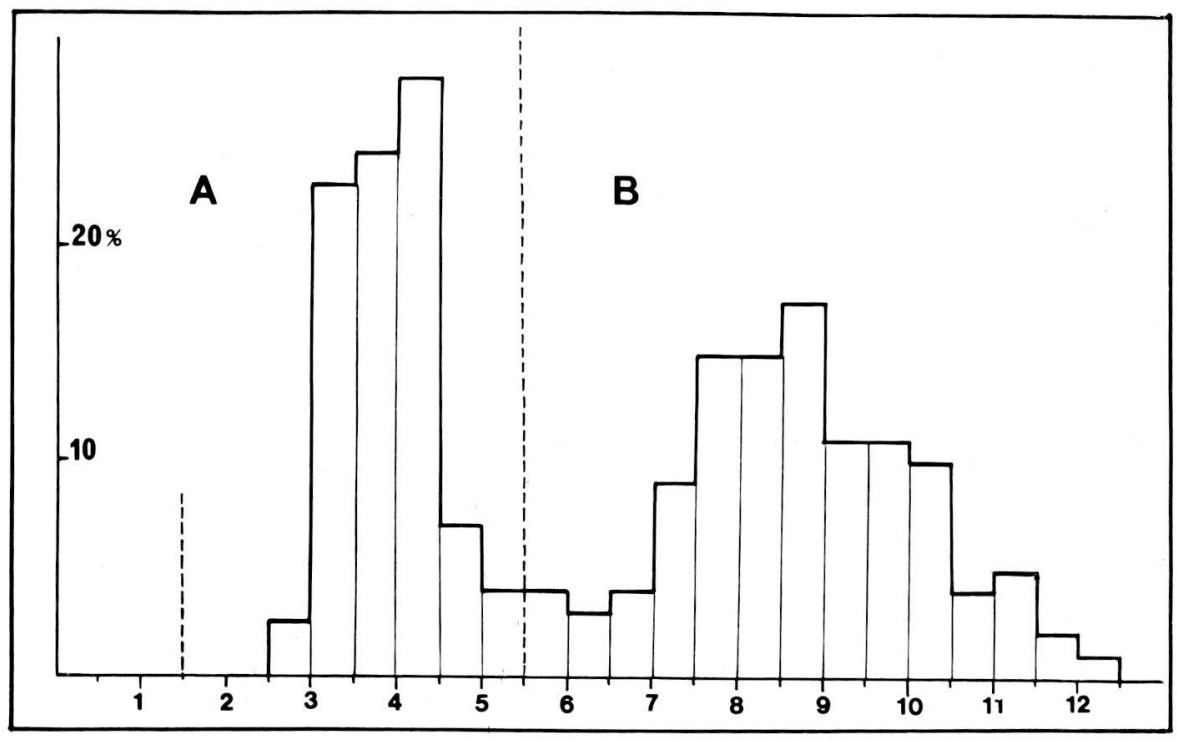

FIGURE 29

Composition en classes de taille de $1 / 2 \mathrm{~mm}$, des prélèvements globaux de Stenasellus virei hussoni, effectués au siphon du Goueil-di-Her (Haute-Garonne).

A. Lot d'individus provenant du milieu interstitiel (sables et graviers du siphon). Prédominance des tailles comprises entre 3 et 4,5 m (stades juvéniles et quelques adultes exceptionnellement précoces). Absence des pulli et très jeunes individus (1,6 à 2,5 mm), sans doute par suite de l'imperfection des méthodes de prospection.

B. La portion de l'histogramme située à droite de la ligne pointillée verticale correspond à la figure $\mathrm{B}$ de la planche 28 , ramenée à la même échelle que 29 A. Elle représente la population des eaux libres du siphon. Les deux populations sont étroitement complémentaires: il s'agit d'une seule population, au sein de laquelle se produit une ségrégation en fonction de la taille des individus.

Le déficit des classes comprises entre 5 et $7 \mathrm{~mm}$ semble uniquement dû à des raisons pratiques: impossibilité des prélèvements dans certaines zones et à certaines profondeurs dans les graviers. 
Au niveau des zones amphibie et noyée des massifs karstiques, le milieu offre des abris très variés aux jeunes Sténaselles (dans l'interstitiel des rivières souterraines, par exemple) et l'on peut observer une ségrégation entre classes de taille qui assure la survie normale des plus petites. Les véritables peuplements karstiques sont donc ceux des zones inférieures du massif et ceux des réseaux de fissures où l'eau se trouve à l'état divisé. Les colonies visibles en grottes ne sont que des peuplements secondaires, écologiquement accessoires.

Les prélèvements ménagés dont sont l'objet ces populations particulières ne risquent donc pas, en principe, de porter atteinte à l'extension de l'espèce.

\section{Observations sur Stenasellus virei dans ses biotopes naturels (Crustacea Isopoda Asellota des eaux souterraines)}

\section{RESUME}

Grâce aux prospections intensives et à de nouvelles méthodes de capture de la faune aquatique souterraine, 117 stations de Stenasellus virei sont maintenant connues.

La description de quelques biotopes typiques montre que l'espèce est installée, tant dans les eaux karstiques que phréatiques, dans les différents milieux correspondant à la classification hydrogéologique des eaux souterraines.

St. virei buchneri et St.v.hussoni sont surtout cavernicoles. St.v.angelieri est disséminé dans les eaux souterraines de Catalogne. St.v.boui est localisé dans le sous-écoulement du bassin du Salat. St.v.virei colonise largement les nappes alluviales des bassins de la Garonne et de l'Ebre.

La dispersion de St. virei dans le domaine alluvial explique le mode d'expansion de l'espèce et par conséquent, l'existence de la population du Gouffre de Padirac, apparemment isolée en milieu karstique.

La répartition actuelle des cinq sous-espèces s'explique par des restrictions importantes de l'aire aux temps glaciaires, suivies d'expansions locales aux temps postglaciaires (nappes des affluents de la Garonne). La reconquête postglaciaire de la nappe du Salat par l'espèce serait responsable de la plus récente subspéciation (St.v.boui).

Les populations endémiques des réseaux karstiques fossiles semblent avoir une composition anormale. Elles sont formées surtout de grands adultes, les jeunes étant rares. Elles diffèrent des populations phréatiques, dont la composition en classes de taille est normale, avec un pourcentage normal de jeunes.

Ces différences entre populations karstiques et interstitielles seraient dues au fait que, dans les grotes, St. virei est souvent isolé de sa biocénose phréatique originelle et que la concurrence intraspécifique entre classes de taille y a remplacé la concurrence vitale hétérospécifique normale.

\section{BIBLIOGRAPHIE}

Cet article constitue la seconde partie d'un travail plus important qui sera présenté comme thèse d'Etat de Sciences Naturelles. Les références bibliographiques complètes seront annexées au mémoire principal.

Référence de la première partie:

MAGNIEZ, G. 1974. Données faunistiques et écologiques sur les Stenasellidae (Crustacea Isopoda Asellota des eaux souterraines). Int.J.Speleol., 6, 1,pp.1-80. 